DOE-HTGR-90322, Rev. 0

ORNL/TM-12238, Rev. 0
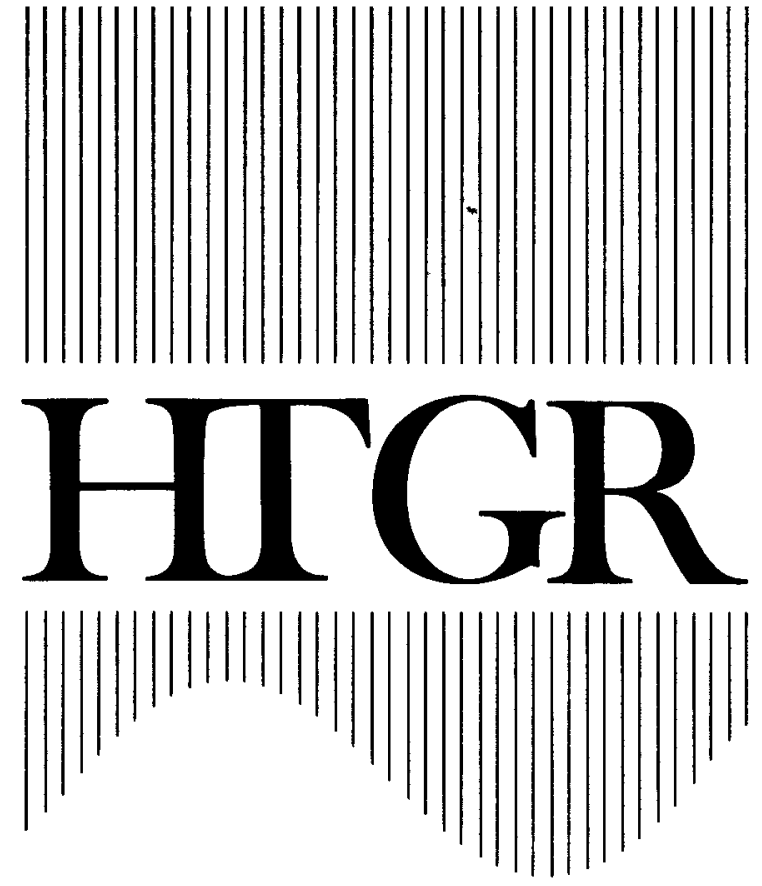

\title{
HRB-21 Irradiation Phase Test Report
}

\begin{abstract}
APPLIED TECHNOLOGY
Any further distribution by any holder of this document or data therein to third parties representing foreign interests, foreign governments, foreign companies, and foreign subsidiaries or foreign divisions of U.S. companies shall be approved by the Associate Deputy Assistant Secretary for Reactor Systems, Development and Technology, U.S. Department of Energy. Further, foreign party release may require DOE approval pursuant to Federal Regulation 10CFR Part 810, and/or may be subject to Section 127 of the Atomic Energy Act.
\end{abstract}

\section{AUTHORS/CONTRACTORS}

PECEIVED

FEB 261993

\section{Oak Ridge National Laboratory}

G. L. Bell

G. L. Copeland

J. T. Parks

L. C. Emerson

Oak Ridge National Laboratory

Oak Ridge, Tennessee 37831-6285

managed by

MARTIN MARIETTA ENERGY SYSTEMS, INC.

for the

UNITED STATES DEPARTMENT OF ENERGY

January 1993

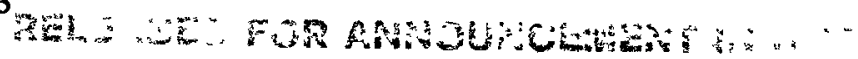

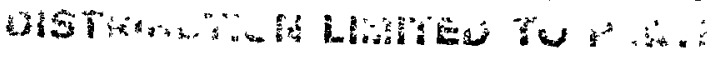

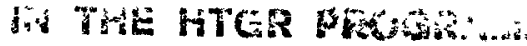

OTHEDS REQUEST FAUA HTE 


\section{DISCLAIMER}

This report was prepared as an account of work sponsored by an agency of the United States Government. Neither the United States Government nor any agency Thereof, nor any of their employees, makes any warranty, express or implied, or assumes any legal liability or responsibility for the accuracy, completeness, or usefulness of any information, apparatus, product, or process disclosed, or represents that its use would not infringe privately owned rights. Reference herein to any specific commercial product, process, or service by trade name, trademark, manufacturer, or otherwise does not necessarily constitute or imply its endorsement, recommendation, or favoring by the United States Government or any agency thereof. The views and opinions of authors expressed herein do not necessarily state or reflect those of the United States Government or any agency thereof. 


\section{DISCLAIMER}

Portions of this document may be illegible in electronic image products. Images are produced from the best available original document. 
This report has been reproduced directly from the best available copy.

Avallable to DOE and DOE contractors from the Office of Scientific and Technical Information, P.O. Box 62, Oak Ridge, TN 37831; prices available from (615) 576-8401, FTS 626-8401.

This report was prepared as an account of work sponsored by an agency of the United States Government. Neither the United States Government nor any agency thereof, nor any of their employees, makes any warranty, express or implied, or assumes any legal liability or responsibility for the accuracy, completeness, or usefulness of any information, apparatus, product, or process disclosed, or represents that its use would not infringe privately owned rights. Reference herein to any specific commercial product, process, or service by trade name, trademark, manufacturer, or otherwise, does not necessarily constitute or imply its endorsement, recommendation, or favoring by the United States Government or any agency thereof. The views and opinions of authors expressed herein do not necessarily state or reflect those of the United States Government or any agency thereof. 
DOE-HTGR-90322, Rev. 0

ORNL/TM-12238, Rev. 0

Metals and Ceramics Division

HRB-21 IRRADIATION PHASE TEST REPORT

G. L. Bell, G. L. Copeland, J. T. Parks, and L. C. Emerson

\section{APPLIED TECHNOLOGY}

Any further distribution by any holder of this document or data therein to third parties representing foreign interests, foreign governments, foreign companies, and foreign subsidiaries or foreign divisions of U.S. companies shall be approved by the Associate Deputy Assistant Secretary for Reactor Systems, Development and Technology, U.S. Department of Energy. Further, foreign party release may require DOE approval pursuant to Federal Regulation 10 CFR Part 810, and/or may be subject to Section 127 of the Atomic Energy Act.

Date Published: January 1993

NOTICE This document contains information of a preliminary nature.
It is subject to revision or correction and therefore does not ropresent a
final report.
Prepared for the
U.S. Department of Energy
Office of Advanced Reactor Programs
AF 20 50 10 0
Prepared by the
OAK RIDGE NATIONAL LABORATORY
Oak Ridge, Tennessee
managed by
for the


.

- 
ISSUE/RELEASE SUMMARY

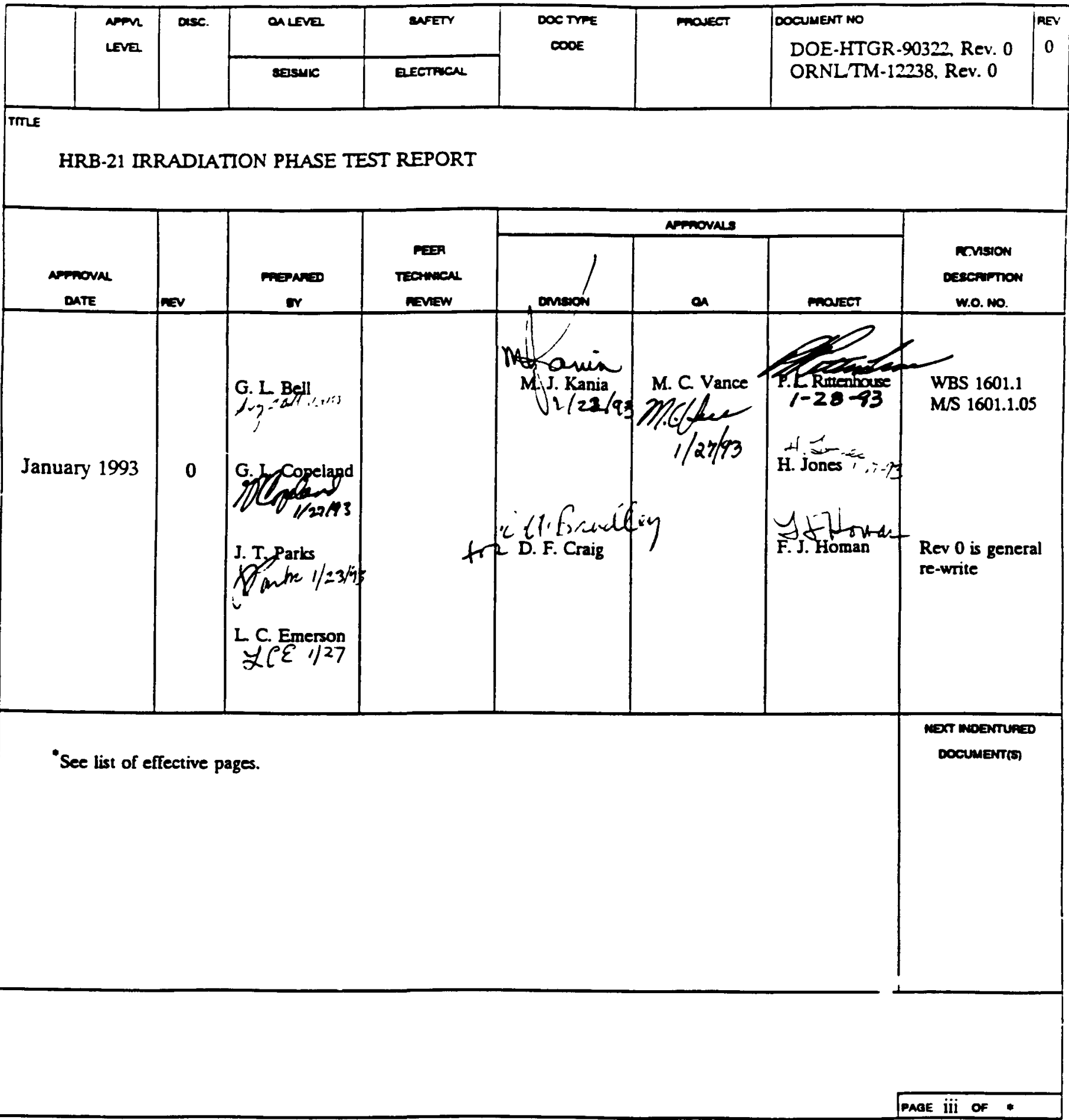




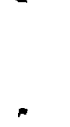




\section{HTGR PROGRAM PROCEDURE}

TITLE:

FORMAT REQUTREMENTSFOR PROJECT DOCUMENTATION

DOCUMENT NUMBER: HP-10302

REVISION: 0

LIST OF EFFECTIVE PAGES

PAGE NUMBER

\begin{tabular}{|c|}
\hline REV. \\
\\
0 \\
0 \\
0 \\
0 \\
0 \\
0 \\
0 \\
0 \\
0 \\
0 \\
0 \\
0 \\
0 \\
0
\end{tabular}

Cover

i through xvii

$1-1$

2-1 through $2-3$

3-1 through 3-8

4-1 through 4-2

5-1 through 5-10

6-1 through 6-13

7-1 through 7-5

8-1 through 8-20

$9-1$

10-1

11-1 through 11-2

A-1 through A-20

A-1 through A-20

更


CONTENTS

$\underline{\text { PAGE }}$

LIST OF APPENDICES . . . . . . . . . . . . . . . . . . . . . . . . . ix

LIST OF FIGURES . . . . . . . . . . . . . . . . . . . . . . . . . . . $x i$

LIST OF TABLES . . . . . . . . . . . . . . . . . . . . . . . . . . . xiii

ABBREVIATIONS AND ACRONYMS . . . . . . . . . . . . . . . . . . . . . $\mathrm{xV}$

ABSTRACT . . . . . . . . . . . . . . . . . . . . . . xvii

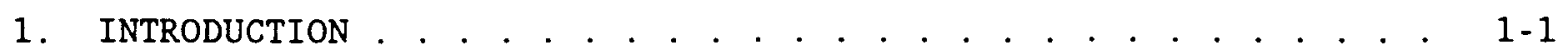

1.1 BACKGROUND . . . . . . . . . . . . . . . . . . . . . 1-1

2. CAPSULE OPERATION IN THE HFIR . . . . . . . . . . . . . . . . . 2-1

3. CALCULATION OF VOLUME-AVERAGED FUEL COMPACT TEMPERATURE . . . . 3-1

3.1 MEASURED AND CALCULATED INPUT PARAMETERS . . . . . . . . . 3-6

3.2 PARAMETERS CALCULATED FROM DESIGN EQUATIONS . . . . . . . . 3-8

4. CALCULATION OF THE LOCAL MAXIMUM FUEL TEMPERATURE . . . . . . . 4-1

5. RESUltS OF TEMPERATURE CALCULATIONS . . . . . . . . . . . . . . 5-1

6. REACTOR OPERATION . . . . . . . . . . . . . . . . . . 6-1

7. DISCUSSION OF CAPSULE OPERATION . . . . . . . . . . . . . . . . 7-1

8. DISCUSSION OF FUEL PERFORMANCE . . . . . . . . . . . . . . . . . 8-1

8.1 SWEEP GAS RADIATION LEVEL MONITORING . . . . . . . . . . . 8-1

$8.2 \mathrm{R} / \mathrm{B}$ RATIOS .. . . . . . . . . . . . . . . . . . . . . 8-7

9. CONCLUSIONS .......................... . . . . . . . .

10. ACKNOWLEDGMENTS . . . . . . . . . . . . . . . . . . . . . . . . 10-1

11. LIST OF REFERENCES ... . . . . . . . . . . . . . . . . . . . . 11-1 
7-3 Capsule average fuel temperature with points of interest labeled for discussion. The cycle numbers are listed just above the abscissa................ 7-3

8-1(a) Photograph of strip-chart recording of ionization chamber response during beginning of second irradiation cycle capsule HRB-21. The sweep gas He concentration was changed from 100 to about $61 \%$ between $10: 04$ and 10:29, 7/26/91.

8-1(b) Ionization chamber response during beginning of second irradiation cycle - capsule HRB-21. In this drawing, the effect of ammeter scale changes seen in 8-1(a) has been compensated for . . . . . . . . . . . . . . . . . . . .

8-2 This photograph of a "classic" example of particle failure pulse is from a strip chart recording the output current from the ionization chamber during the second irradiation cycle - capsule HRB-21 - on pure helium. On $8 / 3 / 91$ at $08: 15 \mathrm{hr}$ the test was $8.42 \mathrm{~d}$ into cycle 299. Elapsed time $=43.583 \mathrm{~d}$. Full-power days $=28.947$. . . . . . . . . 8-4

8-3 Photograph of strip-chart recording of ionization chamber response during the second irradiation cycle - capsule HRB-21. The sweep gas He concentration was about 658 helium. On 8/8/91 at 01:53 hr the test was $13.155 \mathrm{~d}$ into cycle 299 . Elapsed time $=48.318 \mathrm{~d}$. Full-power days $=33.681$. . . . 8-5

8-4 Cumulative count of ionization chamber pulses (failed particles) and ${ }^{85} \mathrm{~m} \mathrm{Kr} \mathrm{R} / \mathrm{B}$ for $\mathrm{HRB}-21$ capsule . . . . . . . . 8-6

8-5 R/B values for $\mathrm{Xe}-133$ and $\mathrm{Xe}-138$ and the capsule average fuel temperature as a function of time from the start of the irradiation . . . . . . . . . . . . . . . . . 8-18

8-6 $\mathrm{R} / \mathrm{B}$ values for ${ }^{85 \mathrm{~m}} \mathrm{Kr}$ and ${ }^{88} \mathrm{Kr}$ and the capsule average fuel temperature as a function of time from the start of the irradiation . . . . . . . . . . . . . . . . 8-19 


\section{LIST OF TABLES}

PAGE

2-1 HRB-21 irradiation dates, with time elapsed since first HFIR full-power exposure, cycle time at full power and total time at full power ................... 2-1

7-1 Analyses of He and Ne gas cylinders from HFIR cycle 299 startup compared to pre-test values . . . . . . . . . . . . 7-4

8-1 Measured release rates for krypton and xenon isotopes for the HRB-21 capsule. . . . . . . . . . . . . . . . . . . . . . 8-8

8-2 R/B values for selected isotopes for the HRB-21 capsule . . 8-13 


\author{
.
}

-

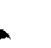

. 
ABBREVIATIONS AND ACRONYMS

DOE

U.S. Department of Energy

EFPD

Effective Ful1-Power Days

EOC

End-of-Cycle (outage)

FIMA

Fissions Per Initial Metal Atom

HFIR

High Flux Isotope Reactor

$\mathrm{HRB}-21$

Test Identification

IFEL

Irradiated Fuels Examination Laboratory

LEU

Low-Enriched Uranium

MHTGR

Modular High-Temperature Gas-Cooled Reactor

$\mathrm{RB}$

Removable Beryllium

$\mathrm{R} / \mathrm{B}$

Release Rate-to-Birth Rate Ratio

TC

Thermocouple

$3-D$

Three-Dimensional

RERC

Reactor Experiment Review Committee 


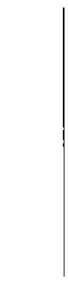

. 
G. L. Bell, G. L. Copeland, J. T. Parks, and L. C. Emerson

\begin{abstract}
Irradiation capsule HRB-21 is a test capsule containing samples of candidate low-enriched-uranium (LEU) fuel for the Modular High-Temperature Gas-Cooled Reactor (MHTGR). Its function is to provide fuel performance data at normal MHTGR operating temperatures in an accelerated irradiation environment. ${ }^{1}$ The accelerated irradiation test was performed in the High Flux Isotope Reactor (HFIR) removable beryllium (RB) position, RB-3B. The irradiation period began with cycle 298 on June 20, 1991, and concluded at the end of cycle 302 on November 21, 1991, for a total of 105 equivalent full-power days. This report presents the data collected during the irradiation test. Included are test thermocouple and gas flow data, the inferred test fuel temperatures, measured gaseous fission product activity in the purge gas, and associated release rate-to-birth rate $(R / B)$ results. Also included are key reactor parameters monitored as part of the test data validation process.
\end{abstract}

${ }^{*}$ Research sponsored by the Office of Advanced Reactor Programs, Division of HTGRs, U.S. Department of Energy, under contract DE-AC05-840R21400 with Martin Marietta Energy Systems, Inc. 


\section{SECTION 1}

INTRODUCTION

\subsection{BACKGROUND}

The HRB-21 capsule was installed on June 15, 1991, in the High Flux Isotope Reactor (HFIR) RB-3B position, during the end-of-cycle (EOC) 297 outage. The test was originally scheduled to be irradiated for six cycles, but due to loss of ability to maintain test temperatures within the allowable limit (coupled with a higher-than-expected fission gas release rate), the irradiation was terminated after the fifth cycle, cycle 302 , which ended on November 21, 1991. The total irradiation time at power was 104.7 effective full-power days (EFPDs).

The reactor was operated at a nominal power of $85 \mathrm{MW}(t)$ throughout the irradiation period, except at the beginning of cycle 302. As will be shown in the data, the reactor power was temporarily reduced to about $80 \mathrm{MW}(t)$ for about $30 \mathrm{~h}$ at the beginning of cycle 302 to resolve a thermocouple alarm setpoint problem on the HRB-21 test. This report presents test thermocouple and gas flow data, inferred average fuel compact temperatures, measured gaseous fission product release rates, and associated release-rate to birthrate $(R / B)$ calculations. Key reactor parameters are also presented as a means of characterizing reactor operation. 
SECTION 2

CAPSULE OPERATION IN THE HFIR

The capsule was operated in the HFIR in accordance with the operating guideline, which included a staged ascent to reactor power to minimize particle failures due to rapid increases in the power generated per particle. ${ }^{2}$ Table 2-1 presents the dates bounding the HRB-21 irradiation. The startup time is taken to be the time at which the reactor reaches fullpower operation $[85 \mathrm{MW}(t)]$. Reactor shutdown is attained by rapidly inserting the control shims (reactor scram). The sweep gas at startup was $100 z$ helium for all cycles. The sweep gas between cycles was $100 z$ helium.

Table 2-1.

HRB-21 IRRADIATION DATES, WITH TIME ELAPSED SINCE FIRST HFIR FULL-POWER EXPOSURE, CYCLE TIME AT FULL POWER AND TOTAL TIME AT FULL POWER.

\begin{tabular}{cccccc}
\hline $\begin{array}{c}\text { HFIR } \\
\text { cycle }\end{array}$ & $\begin{array}{c}\text { Cycle } \\
\text { start/end }\end{array}$ & $\begin{array}{c}\text { Cumulative } \\
\text { calendar time } \\
(\text { d) }\end{array}$ & $\begin{array}{c}\text { Cycle length } \\
\text { (d) }\end{array}$ & $\begin{array}{c}\text { Cumulative } \\
\text { time at } \\
\text { power } \\
\text { (d) }\end{array}$ \\
\hline 298 & $6 / 20 / 91$ & $18: 15$ & 0 & 20.526 & 20.526 \\
& $7 / 11 / 91$ & $06: 53$ & 20.526 & & \\
299 & $7 / 25 / 91$ & $22: 10$ & 35.163 & 20.448 & 40.974 \\
& $8 / 15 / 91$ & $08: 55$ & 55.611 & & \\
300 & $8 / 28 / 91$ & $11: 48$ & 68.731 & 20.247 & \\
& $9 / 17 / 91$ & $17: 44$ & 88.978 & & \\
301 & $9 / 27 / 91$ & $21: 18$ & 99.127 & 21.845 & \\
& $10 / 19 / 91$ & $17: 35$ & 120.972 & & 104.663 \\
302 & $10 / 30 / 91$ & $12: 00$ & 131.781 & 21.596 & \\
& $11 / 21 / 91$ & $02: 18$ & 153.377 & & \\
\hline
\end{tabular}

The HRB-21 capsule was operated to meet the goal of controlling the volume-averaged fuel temperature at $975^{\circ} \mathrm{C}$ without exceeding a local maximum fuel temperature of $1250^{\circ} \mathrm{C}$. Capsule temperatures were adjusted as required by changing the composition of the sweep gas flowing in the annular regions between the fuel compacts and the graphite fuel holders and between the graphite fuel holders and the primary containment. Helium and neon were the 
sweep gases utilized to control the temperature. Greater fractions of helium, which has the higher thermal conductivity by a factor of three, decrease thermal resistance in the gap resulting in lower capsule temperatures.

The burnup and fluence goals for the test ${ }^{1}$ were to achieve a fast fluence ( $E \geq 29 \mathrm{fJ}$ ) of $\leq 5 \times 10^{25}$ neutrons $/ \mathrm{m}^{2}$ and a peak fissile burnup of $\leq 268$ fissions per initial metal atom (FIMA). As shown in Fig. 2-1, shortening the irradiation time to five cycles rather than six achieved fluence and burnup levels of 70 and 878 of the desired peaks based on the best predictions currently available. ${ }^{3,4}$ The increasing temperatures, which caused the test to be shortened, may have been partly due to increased fertile material fissions because of the much longer average time between cycles than had been anticipated during the thermal design. The postirradiation thermal neutron fluence and burnup analyses will provide pertinent data for these important parameters. 
ORNL-DWG 92-12005

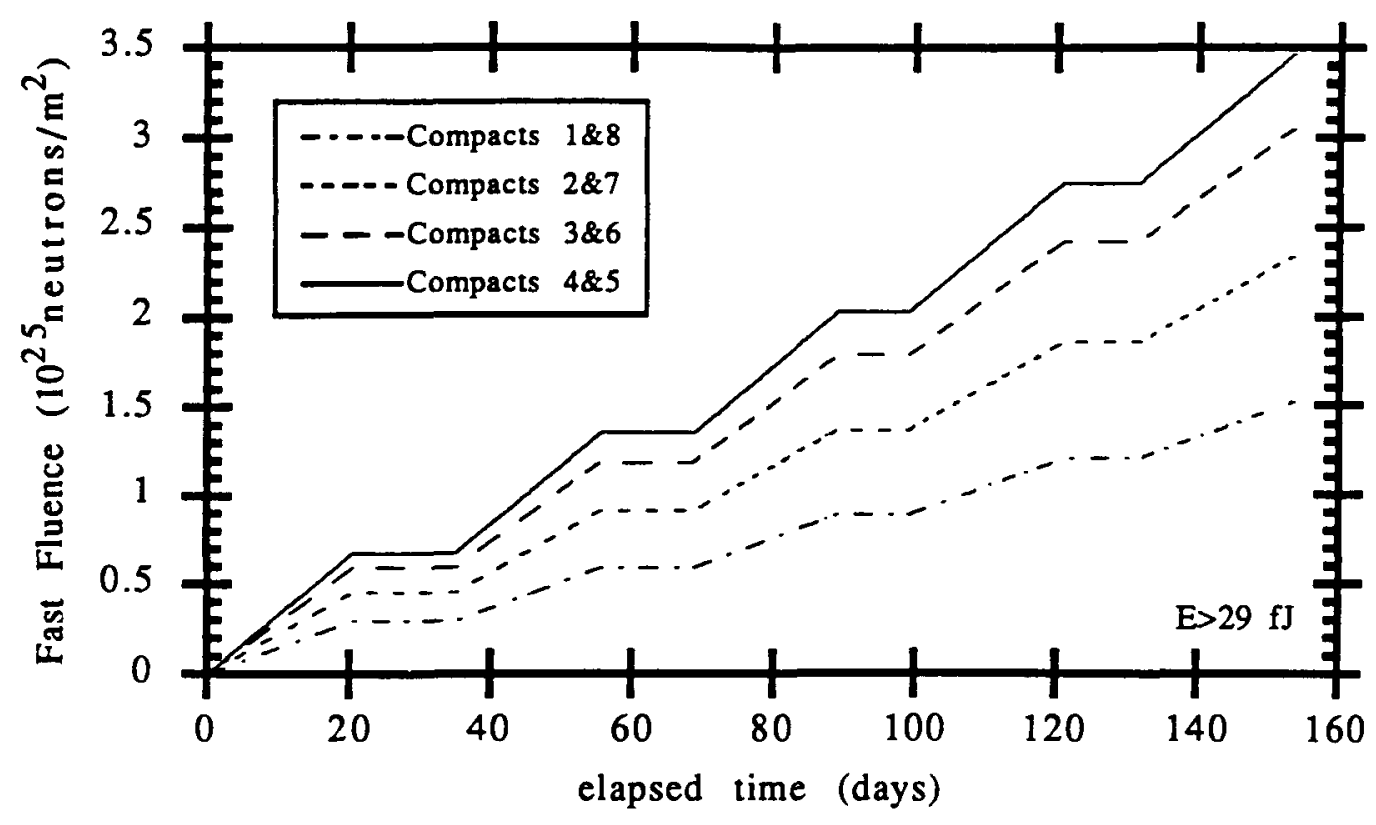

ORNL-DWG 92-12006

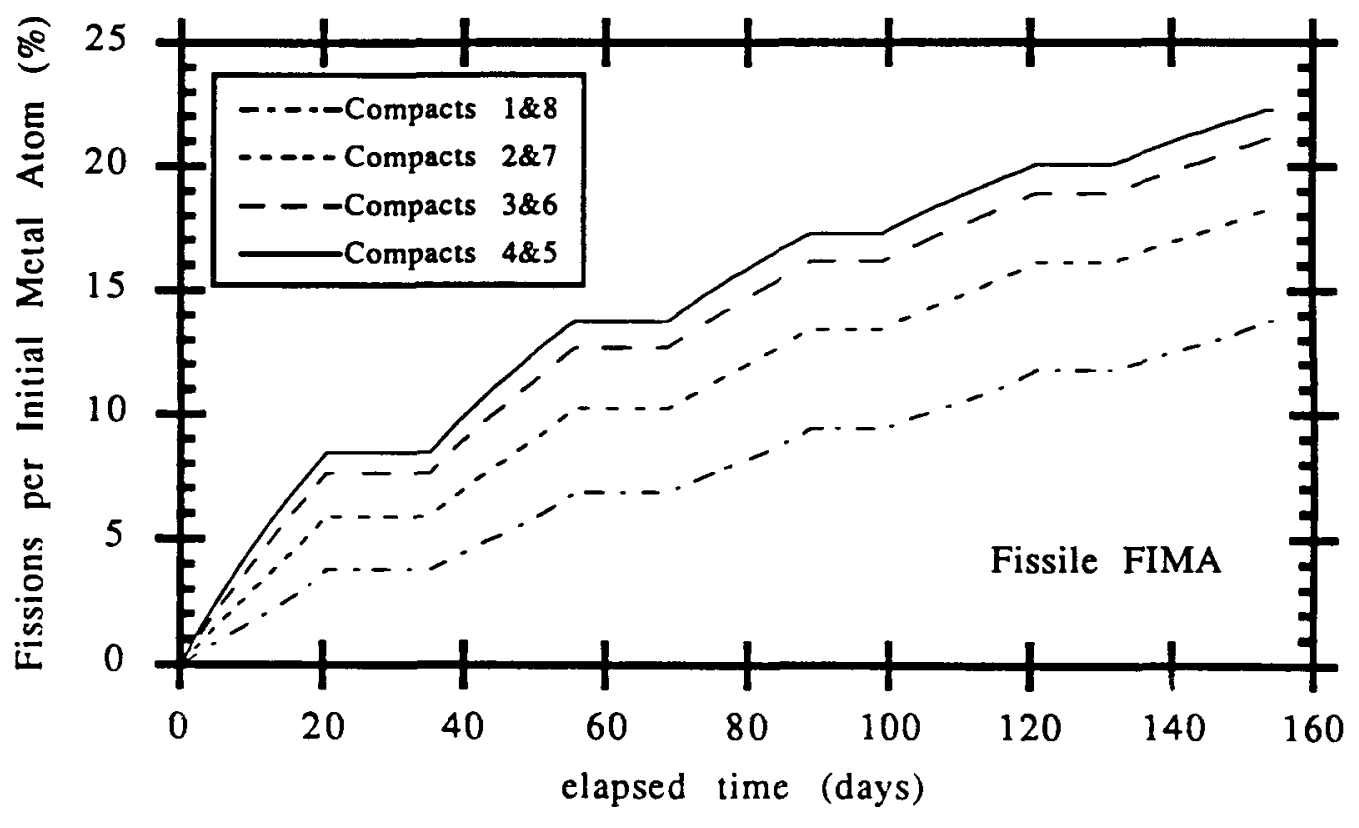

Figure 2-1.

CAPSULE HRB-21 FUEL BURNUP AND FAST FLUENCE. 
SECTION 3

CALCULATION OF VOLUME-AVERAGED FUEL COMPACT TEMPERATURE

The thermocouples were located at the axial midplane in each graphite body at the locations shown in Fig. 3-1 (three out of four of the positions in each body are occupied since 24 thermocouples are available). The axial arrangement of the thermocouples in the fuel regions is shown in Fig. 3-2. Since there were no thermocouples in contact with the fuel compacts, the fuel compact temperatures were calculated based on the temperatures measured by the thermocouples located in the graphite bodies. It is important to note that the fuel temperatures quoted herein are best estimates extracted from thermocouple measurements of the graphite fuel holder temperature. The calculated volumetric fuel temperature is a function of several variables, including the thermocouple (TC) temperatures, the thermal conductivity of the fuel compact, the thermal conductivity of the graphite, the gas gap between the fuel and the graphite, the gas gap between the graphite and the primary containment wall, and the helium-filled gap between the primary and secondary containments.

In the course of the irradiation, the properties of the fuel and graphite change as a function of fast fluence and temperature. The variation of the thermal conductivity of the graphite and fuel compacts, and the gas gaps as a function of fast fluence and temperature, were included as part of the thermal analysis to calculate the best possible estimate of the volume-averaged fuel temperature and the maximum local fuel temperature. The agreement between the model and physical reality is, of course, dependent on the "goodness" of the model, the accuracy of the design equations used to calculate physical parameters such as gas gaps and thermal conductivities, and the accuracy of the neutronics description of the irradiation facility. The quality of the calculation itself is assured via verification of the computer codes by proper review and documentation, and validation of the model by benchmarking against properly qualified empirical data.

The three-dimensional (3-D) numerical model (Fig. 3-3) of a $60^{\circ}$ section of the capsule was generated for thermal analysis by the HEATING 7.0 computer code. ${ }^{5}$ In this model, each geometric region was assigned a thermal conductivity (constant or temperature dependent), a power generation rate 

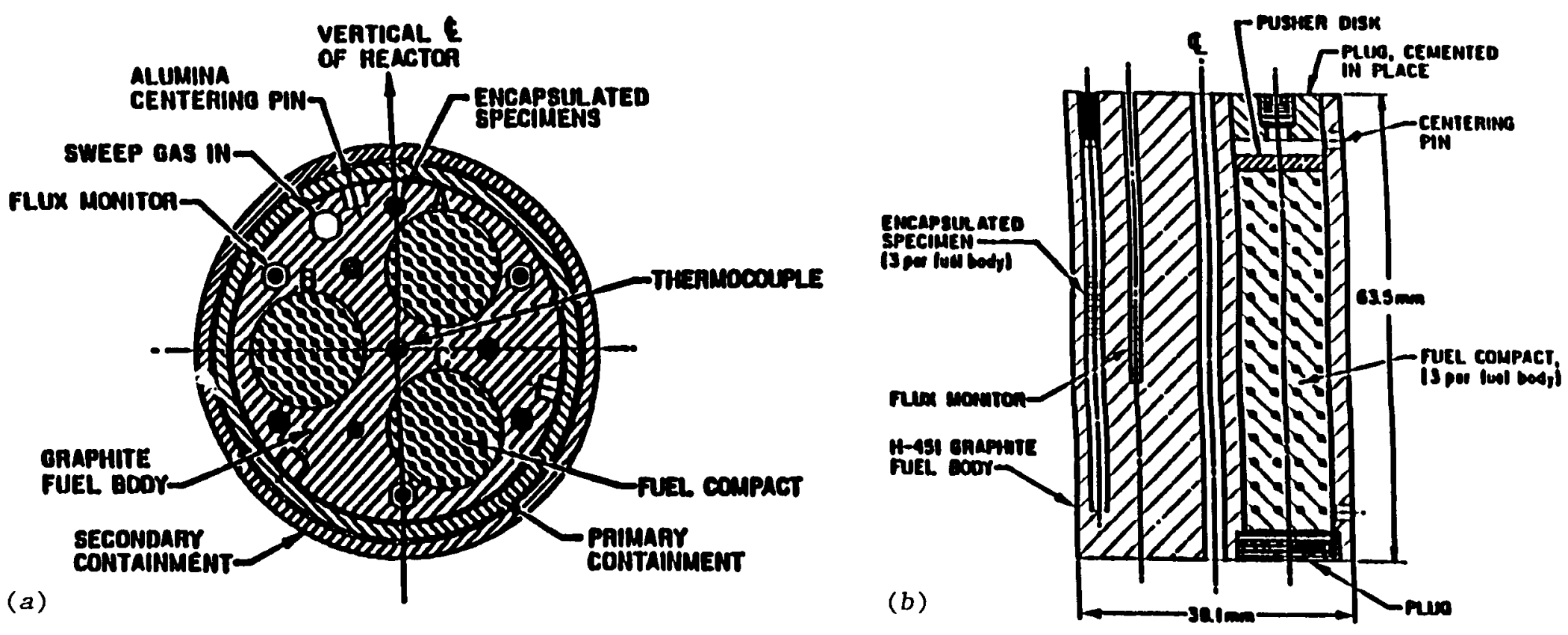

Figure 3-1.

SCHEMATIC CROSS SECTIONS OF CAPSULE HRB-21 SHOWING ARRANGEMENT OF FUEL COMPACTS, ENCAPSULATED PIGGYBACK SPECIMENS, FLUX MONITORS, AND THERMOCOUPLES: (a) HORIZONTAL AND (b) VERTICAL . 
ORNL-DWG 87-4717 ETD

THERMOCOUPLE

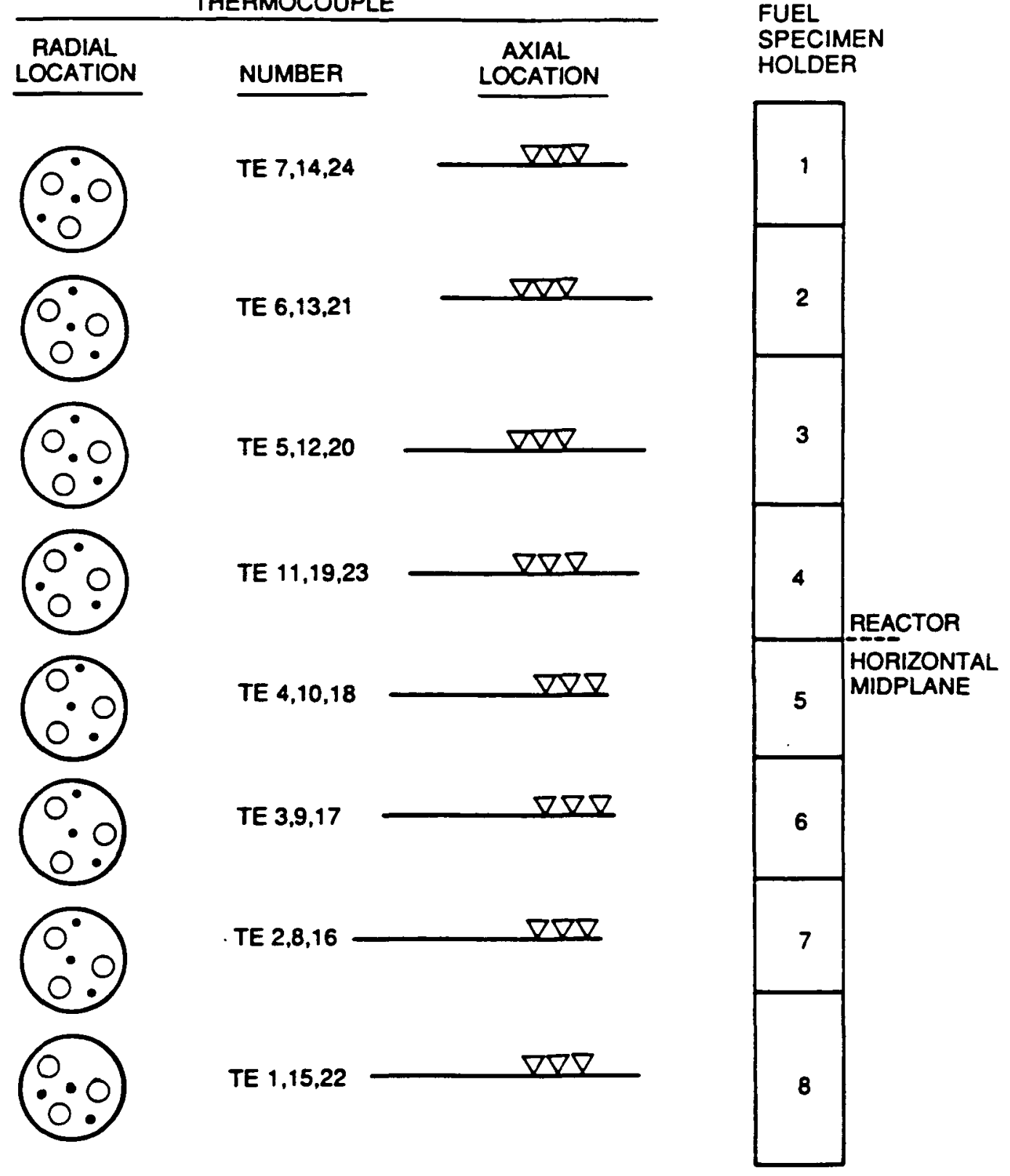

Figure 3-2.

THERMOCOUPLE ARRANGEMENT IN IRRADIATION CAPSULE HRB-21. 
ORNL-DWG 92A-683C

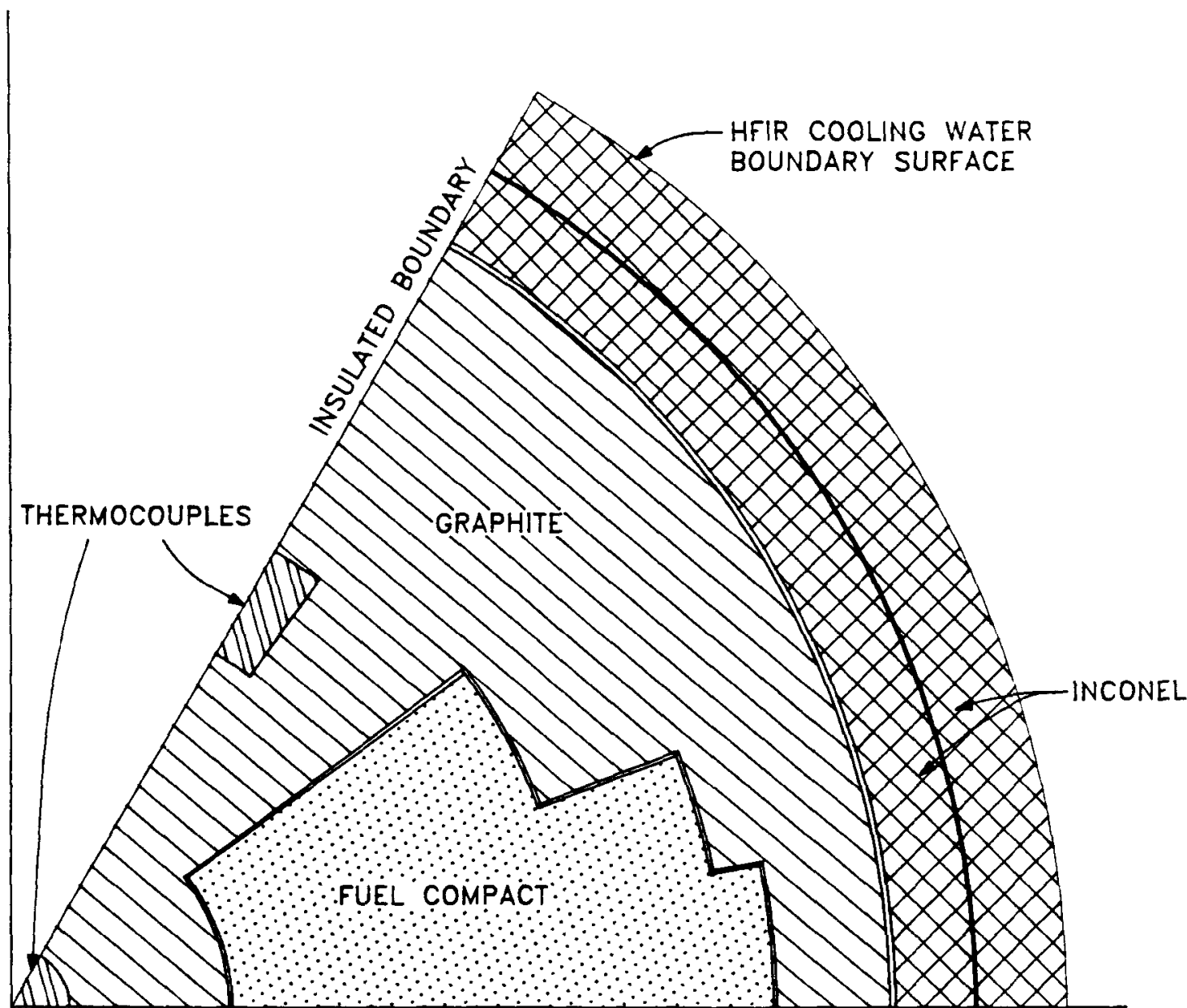

INSULATED BOUNDARY

Figure 3-3.

CROSS-SECTION MOCK-UP OF IRRADIATION CAPSULE HRB-21 FOR

THERMAL DESIGN CALCULATIONAL PURPOSES: HORIZONTAL

CROSS SECTION, R- $\Theta$ VIEW. 
(power density), and specific boundary conditions (radiative emissivity, surface heat flux, etc.) to form a mathematical model of the heat transport problem posed by the capsule. In this model, the thermocouples were included as regions with a nuclear heating rate determined by the average density of the thermocouple array tube. The piggyback samples and the inlet gas passages were assumed to be filled with 4451 graphite. The gap between the fuel and the graphite was assumed to be filled with the sweep gas. It was assumed that the fuel compact was perfectly centered in the hole, and that the graphite fuel body was perfectly centered within the containment tube. Results of the HEATING 7.0 execution (nodal temperature map) were post-processed to provide:

1. $\langle\mathrm{T}\rangle=$ volume-averaged fuel temperature,

2. $\mathrm{TC}=$ average thermocouple temperature,

3. radial temperature profiles through the compact horizontal midplanes, and

4. axial profiles through the compacts which pass through the maximum temperature node.

To facilitate day-to-day control of the fuel temperature, a program was developed to map measured thermocouple temperatures into calculated average fuel temperatures. Due to the large amounts of time required to execute the HEATING 7.0 model of the HRB-21 capsule, a program was written to quantify the dependence of $\langle\mathrm{T}\rangle$ on the various input parameters.

To develop parametric dependences, a series of HEATING 7.0 runs were executed in which the input parameters were scanned over the range of their expected values. The parameters of interest are:

$P_{v}=$ heat-generation rate of the compact $\left(\mathrm{W} / \mathrm{cm}^{3}\right)$ from fission and nuclear heating (gamma heat),

$\mathrm{K}_{\mathrm{B}}=$ thermal conductivity of $\mathrm{H}-451$ graphite $(\mathrm{W} / \mathrm{cm} \cdot \mathrm{K})$,

$K_{f}=$ thermal conductivity of the fuel compact $(\mathrm{W} / \mathrm{cm} \cdot \mathrm{K})$,

$f_{\text {_g }}=$ radial gas gap between the fuel compact and the graphite $(\mathrm{cm})$, g_inc = radial gas gap between the graphite and the primary wall $(\mathrm{cm})$, and

sthe = percentage of helium in the helium/neon sweep gas. 
A standard HEATING input model was prepared from the design model. A

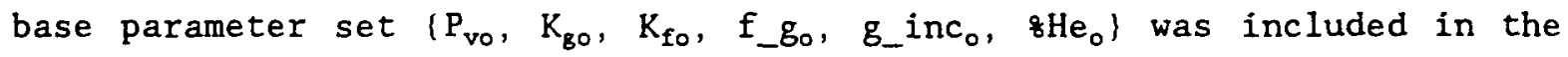
standard input case. A set of computer runs was then carried out where one parameter was varied over its expected range, while all other parameters were held constant. Scaling equations derived from these parametric scans were incorporated into the program Txave.f (where $x$ denotes the set of three compacts in a given axial location) to generate an estimate of $\langle\mathrm{T}\rangle$ when the program is provided with inputs TC, reactor thermal power, and time. $K_{B}, K_{f}$, $f_{-} g$, and $g_{-}$inc are calculated by subroutines using design equations. ${ }^{6-8}$ The flow chart shown in Fig. 3-4 outlines the logic path. A program listing is provided in Appendix A. The methodology used in the development of this program can be examined in ref. 8. A summary and explanations of the inputs required for Txave.f to generate the nominal $<\mathrm{T}>$ are shown below.

\subsection{MEASURED AND CALCULATED INPUT PARAMETERS}

1. TCob = average of the outboard thermocouple readings from a given holder at time $t$. For fuel holder 4, TCob is the average of the temperatures indicated by thermocouples 11,19 , and 23 .

2. $T C C l=$ the centerline thermocouple reading from a given holder at time $t$. For fuel holder $5, T C c l$ is the temperature indicated by thermocouple 4.

3. $t=$ time elapsed since first exposure to HFIR full-power operation (used to calculate fast fluence).

4. HFIR thermal power output at time $t$ (used to calculate fast fluence). The fast flux is calculated from design equations at the axial location of the horizontal midplane of the fuel compact. ${ }^{3}$ The flux equations were developed for $100-\mathrm{MW}(t)$ HFIR operation. The flux used in the calculation of the fluence is the 100-MW( $t$ ) flux multiplied by the current thermal power level/100 MW( $t)$. The time is measured from the beginning of the irradiation where $t_{0}=$ time when the test first experienced HFIR $85 \mathrm{MW}(t)$ operation. 

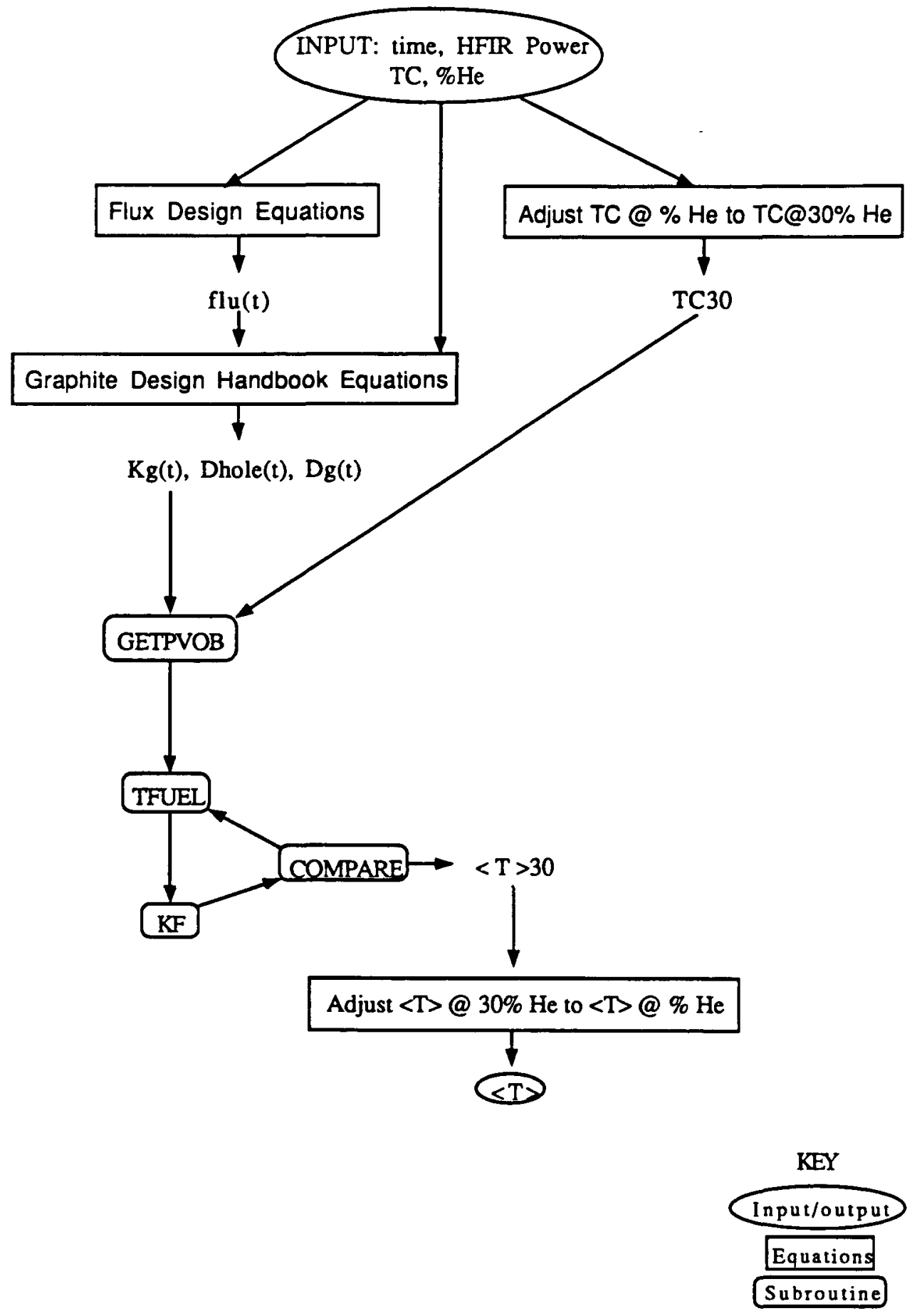

Figure 3-4.

LOGIC PATH OF COMPUTER PROGRAM USED TO ESTIMATE THE VOLUME - AVERAGED FUEL COMPACT TEMPERATURE FROM MEASURED THERMOCOUPLE TEMPERATURES . 


\subsection{PARAMETERS CALCULATED FROM DESIGN EQUATIONS}

These parameters are used in the calculation of the volumetric fuel temperature and are calculated as functions of temperature and fast fluence.

1. $\mathrm{K}_{\mathrm{g}}$, the diameter of the graphite fuel holder, and the diameter of the fuel hole in the holder are calculated from design equations found in the HTGR Graphite Design Handbook. 6 They are functions of the graphite fuel body temperature (TC) and the fast fluence.

2. $K_{f}$ and the diameter of the fuel compact are calculated from design equations found in the Fuel Design Data Manual (Issue F, 1987) supplied by General Atomics.' They are functions of fuel temperature and fast fluence.

3. f_g is calculated from the diameter of the fuel hole and the diameter of the fuel compact and is thus a function of fluence and temperature.

4. g_inc is calculated from the diameter of the primary containment wall and the diameter of the graphite fuel holder. The primary containment diameter is assumed to be held constant at $300^{\circ} \mathrm{C}$. This needs to be corrected for the fission power density changing as a function of time. The diameter of the graphite in the zone of interest is calculated starting from the $25^{\circ} \mathrm{C}$ fabrication diameter and is a function of TCob and fast fluence.

All of these parameters are functions of temperature and fluence and are implicitly time dependent. The only time these parameters are constant is when the reactor power level is below $0.2 \mathrm{MW}(t)$. For those times, the fuel temperature is assumed to be at the average TC temperature. 
SECTION 4

CALCULATION OF THE LOCAL MAXIMUM FUEL TEMPERATURE

The maximum fuel temperature, $T \max$, is calculated using the linear least-squares fit shown in Fig. 4-1. This scatter plot includes results from all model executions used in the derivation of the scaling cquations discussed above. Note that the ratio $T \max /\langle T\rangle$ is, in general, a function of $K_{f}$ and $P_{v}$. In this treatment, the $K_{f}$ and $P_{v}$ parametric scan results are included in the family of points in Fig. 4-1 and are thus included in the least-squares linear fit. Scatter plots for all cases executed for which $T \max \geq 1200^{\circ} \mathrm{C}$ show $\left.\mathrm{Tmax} \leq 1.17<\mathrm{T}\right\rangle$. Figure $4-2$ is an example of a scatter plot for fuel zone 4. Since the power and fuel loadings in the experiment are symmetrical about the axial centerline, the test consists of four fuel zones for calculational purposes. Zone 1 consists of fuel holders 1 and 8 , zone 2 is fuel holders 2 and 7 , zone 3 is fuel holders 3 and 6 , and zone 4 is holders 4 and 5 .

ORNL-DWG 92-12009

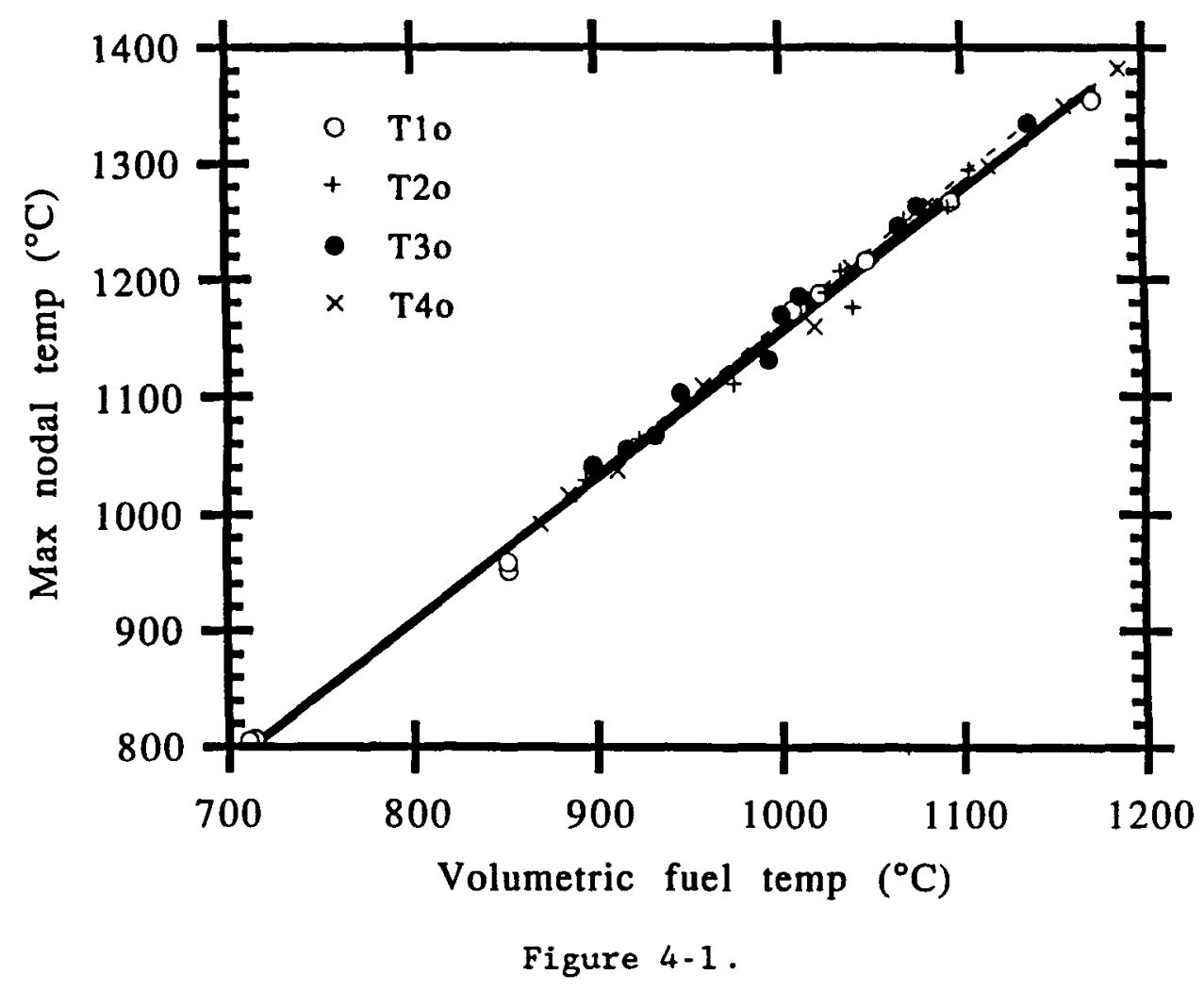

MAXIMUM LOCAL FUEL TEMPERATURE AS A FUNCTION OF THE VOLUMETRIC FUEL TEMPERATURE . 


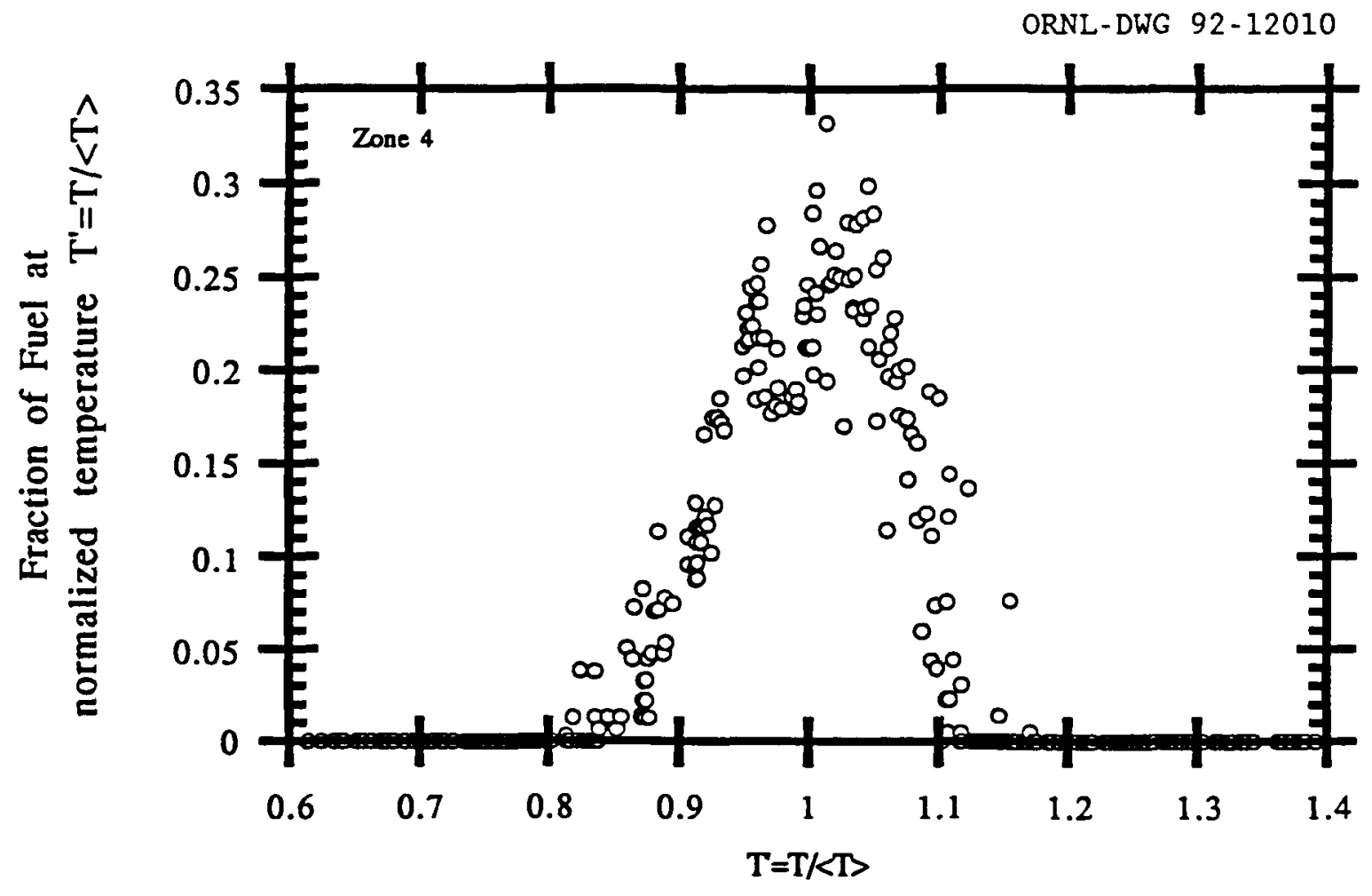

Figure 4-2.

FRACTION OF FUEL AT NORMALIZED TEMPERATURE FOR CASES IN WHICH $T \max \geq 1200^{\circ} \mathrm{C}$ FOR FUEL ZONE 4 . 
Using the technique for calculating the volume average fuel compact temperature described above, the time evolution of the fuel temperature and the measured thermocouple temperatures are shown in Fig. 5-1. Figure 5-2 shows the average fuel temperature and local maximum fuel temperature for each zone. Typical capsule temperatures during reactor shutdowns were about $45^{\circ} \mathrm{C}$. Note that these volume-averaged fuel temperatures are preliminary. Once the postirradiation dimensional measurements are complete and the flux monitors are analyzed, the data will be incorporated into a revised calculation of the volumetric average fuel temperature.

Two of the 24 thermocouples failed during the test. Thermocouple TC-101, a centerline thermocouple in region 8, failed after $102 \mathrm{~d}$ of service. Thermocouple TC-105, a centerline thermocouple in region 5, failed after $142 \mathrm{~d}$ of service. At random intervals, isolated thermocouple data were flagged by the data acquisition software as bad data, but the total amount of bad data accumulated was negligible. At no time did loss of thermocouple data threaten the continuity of the experiment. 
ORNL-DWG 92-12011
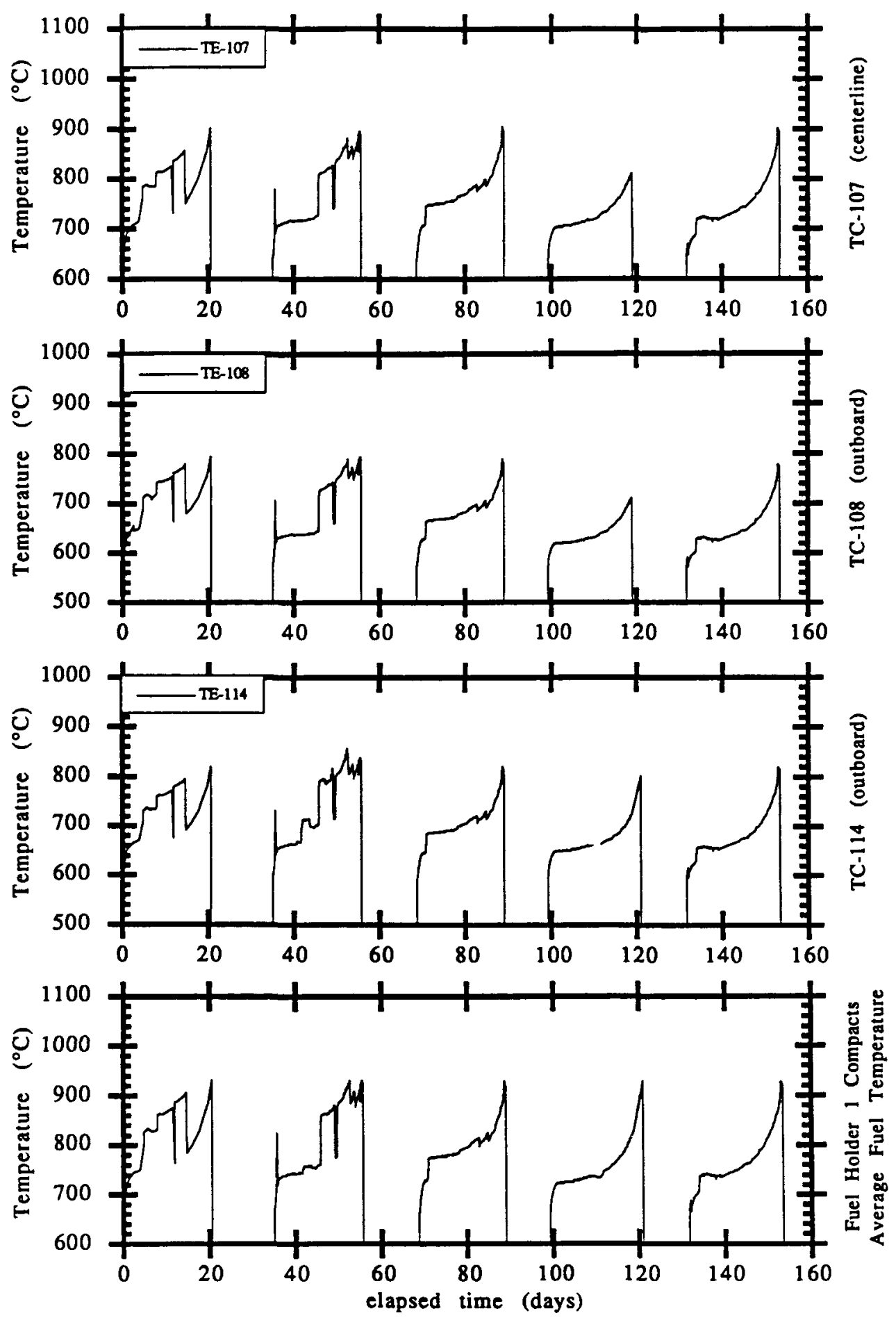

Figure 5-1.

MEASURED THERMOCOUPLE TEMPERATURES AND CALCULATED VOLUMETRIC FUEL TEMPERATURES FOR EACH FUEL HOLDER . 
ORNL-DWG $92-12012$
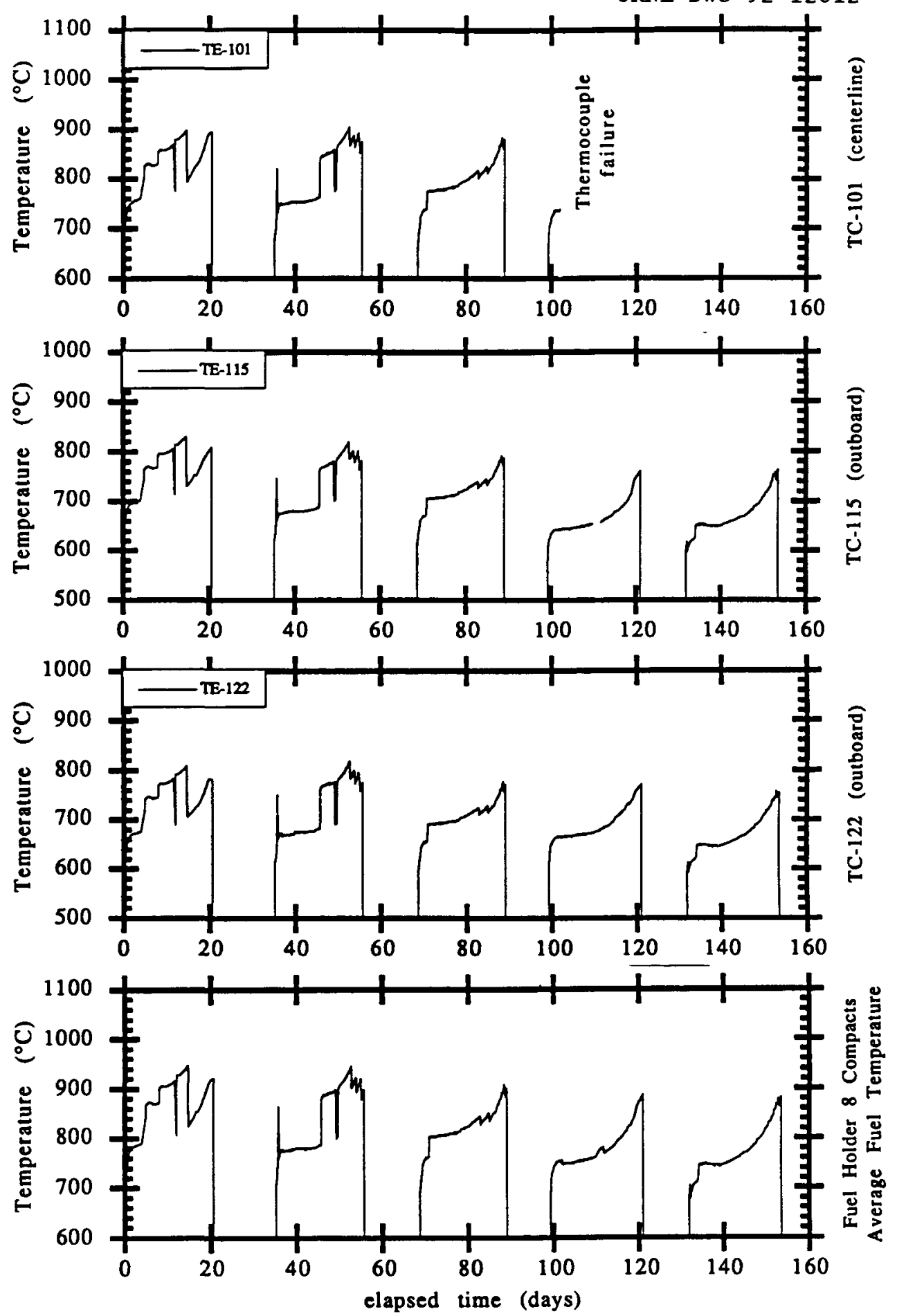

Figure 5-1. CONTINUED. 
ORNL-DWG 92-12013
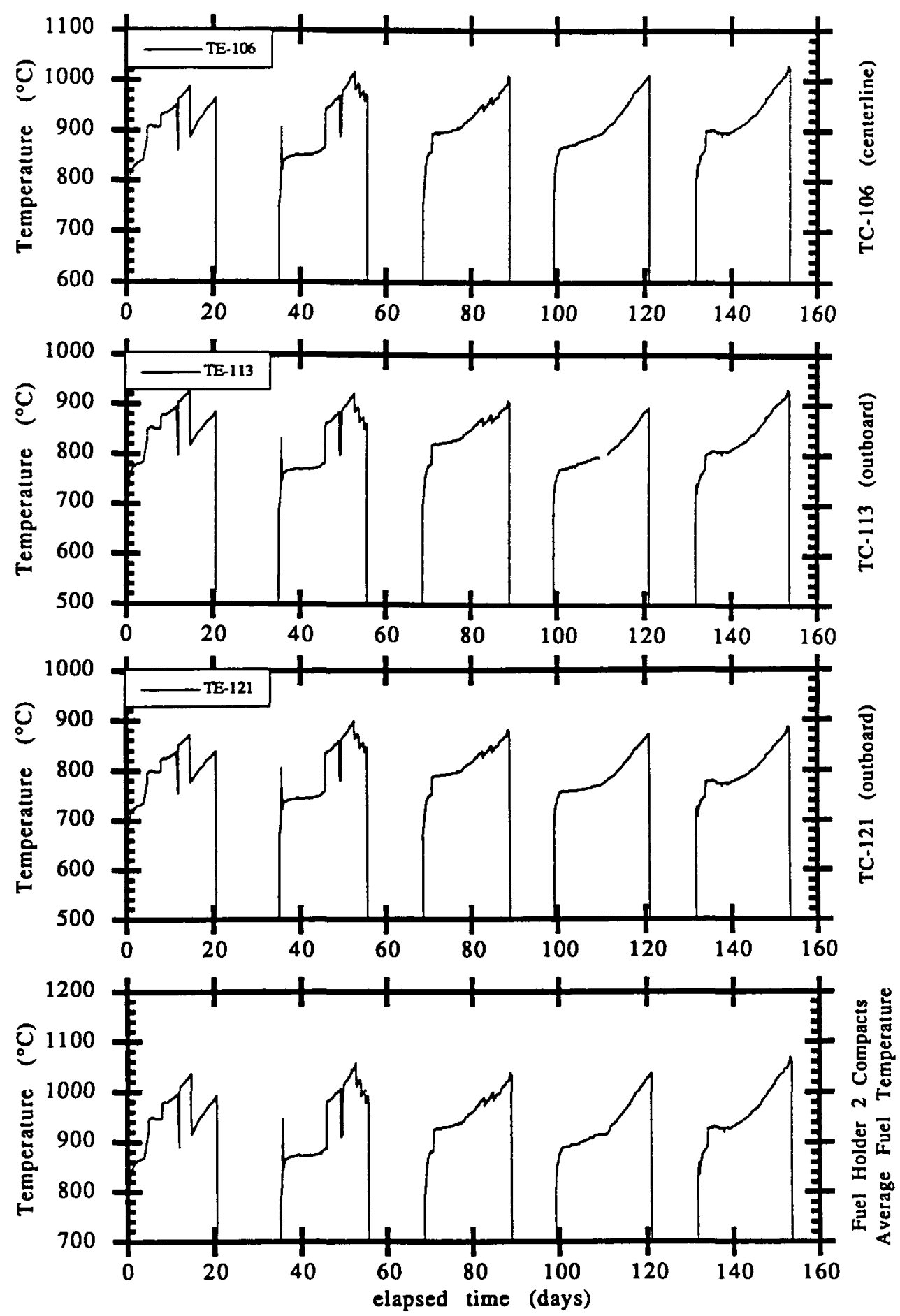

Figure 5-1. CONTINUED. 
ORNL-DWG $92-12014$
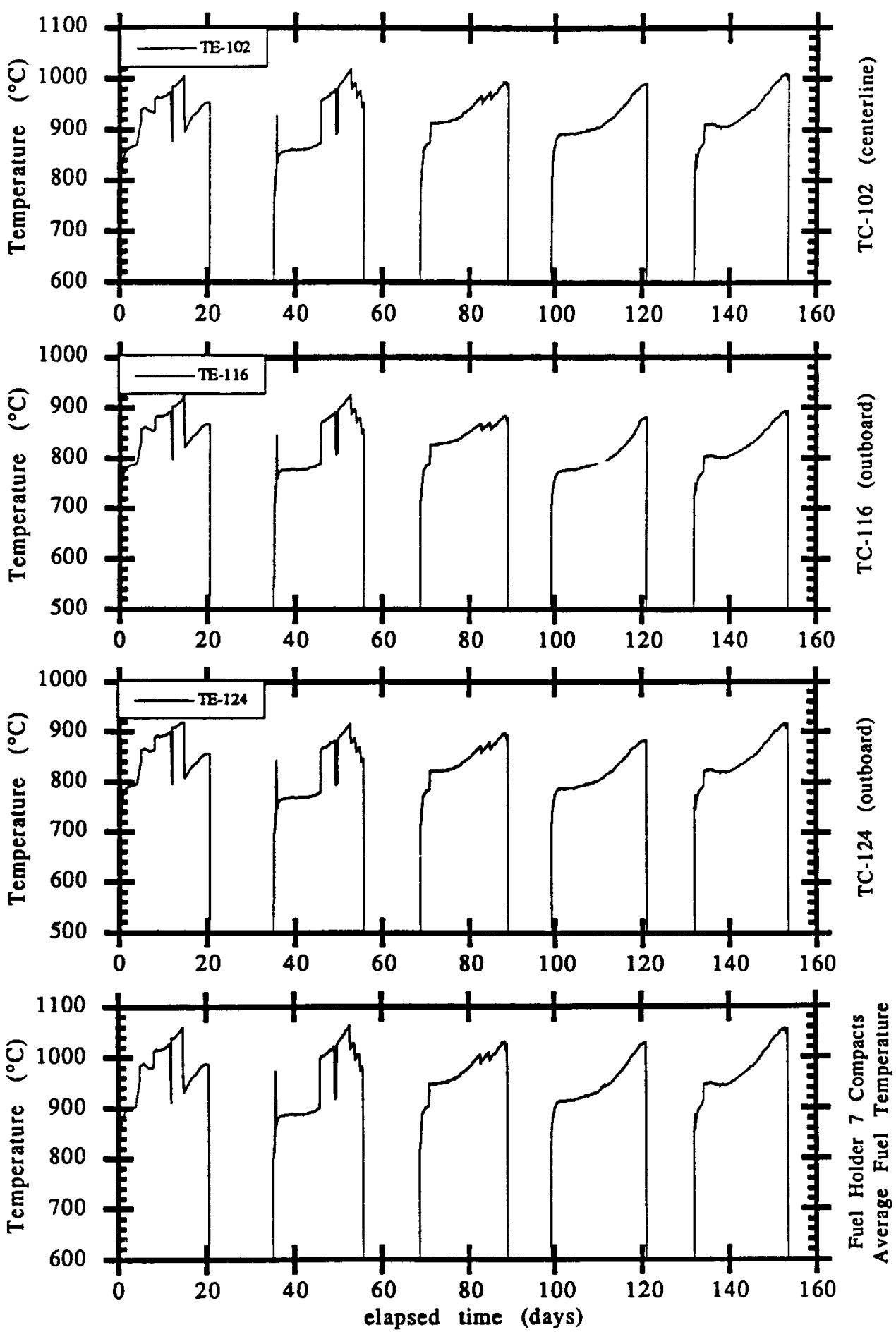

Figure 5-1. CONTINUED. 

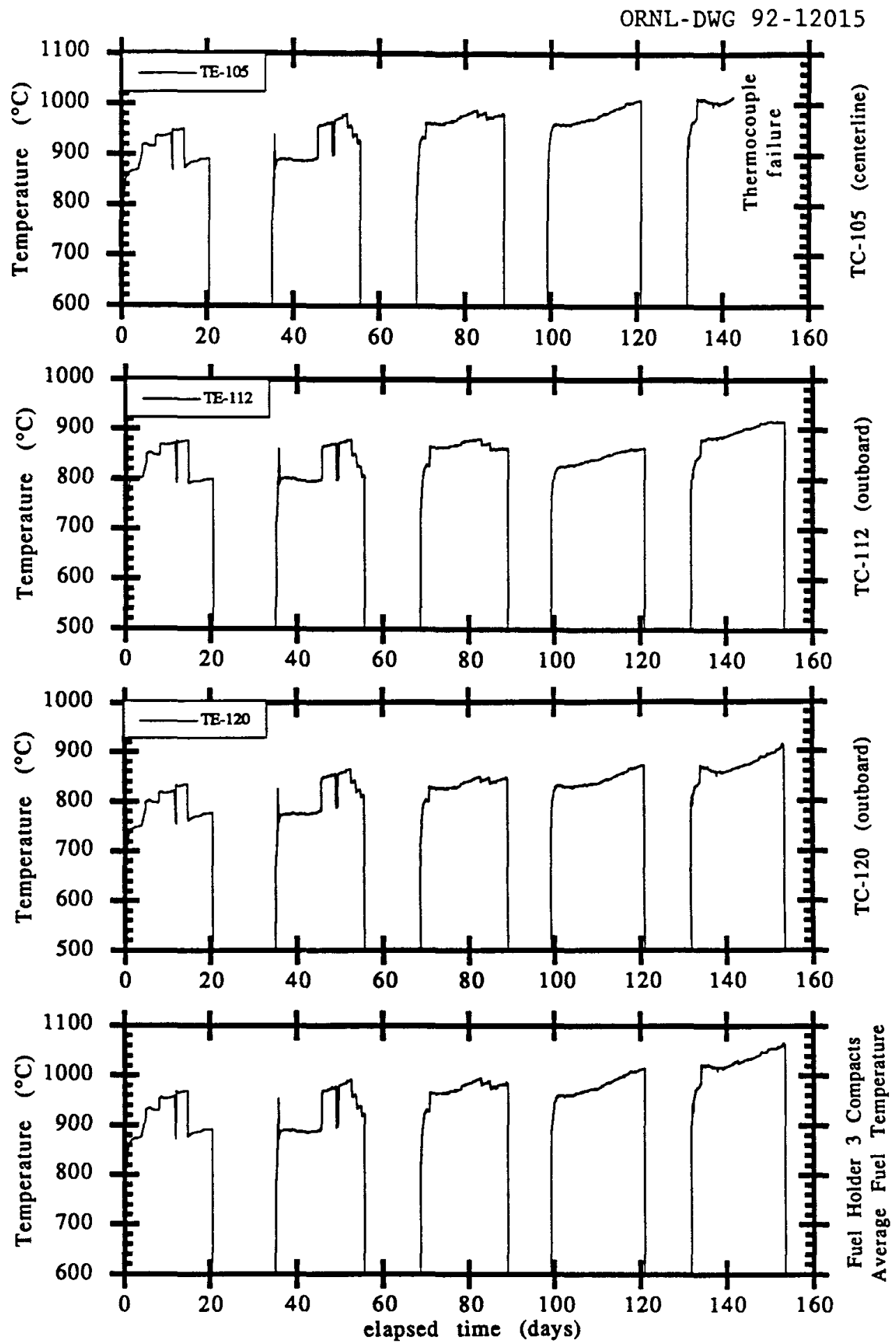

Figure 5-1. CONTINUED. 
ORNL-DWG 92-12016
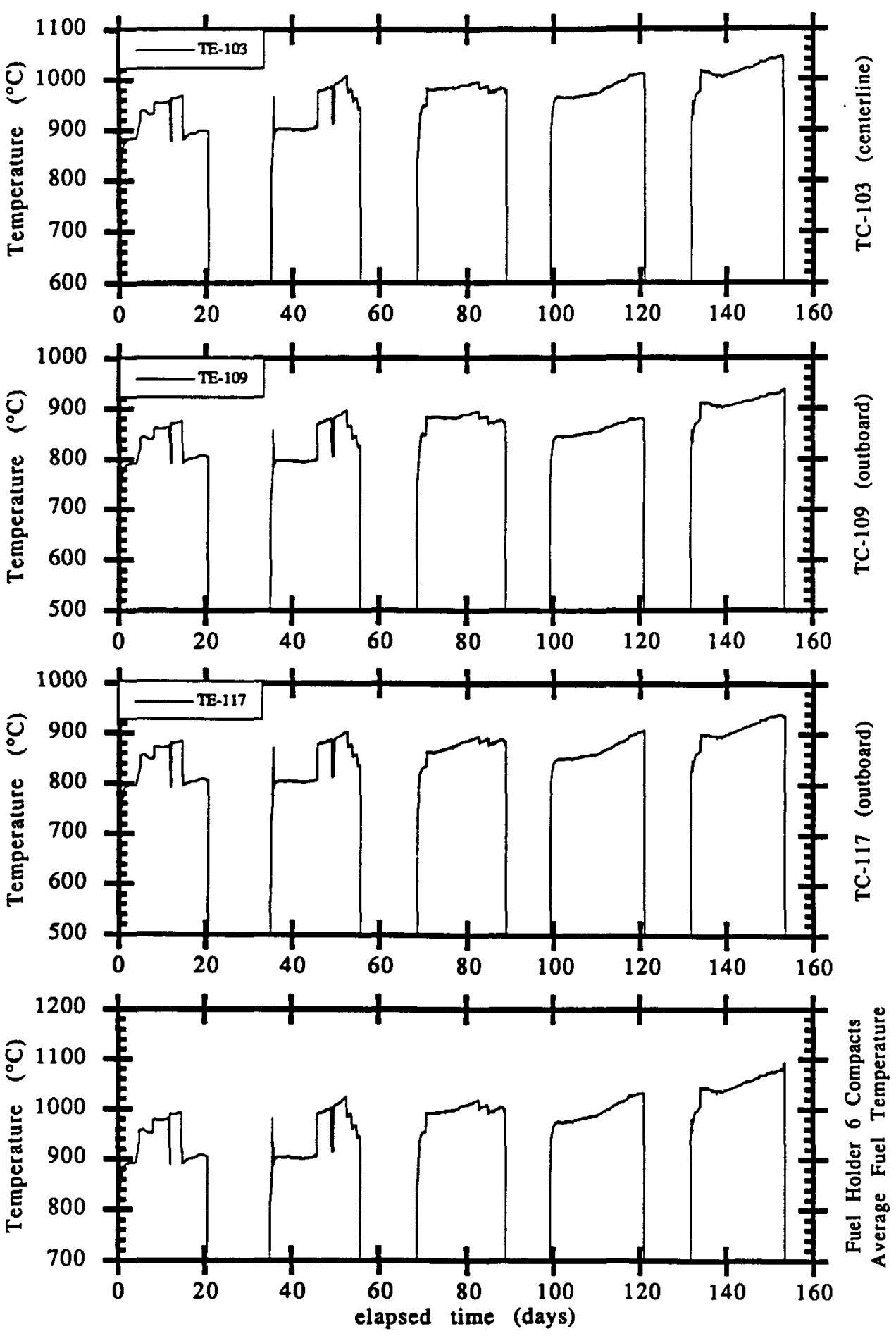

Figure 5-1. CONTINUED. 

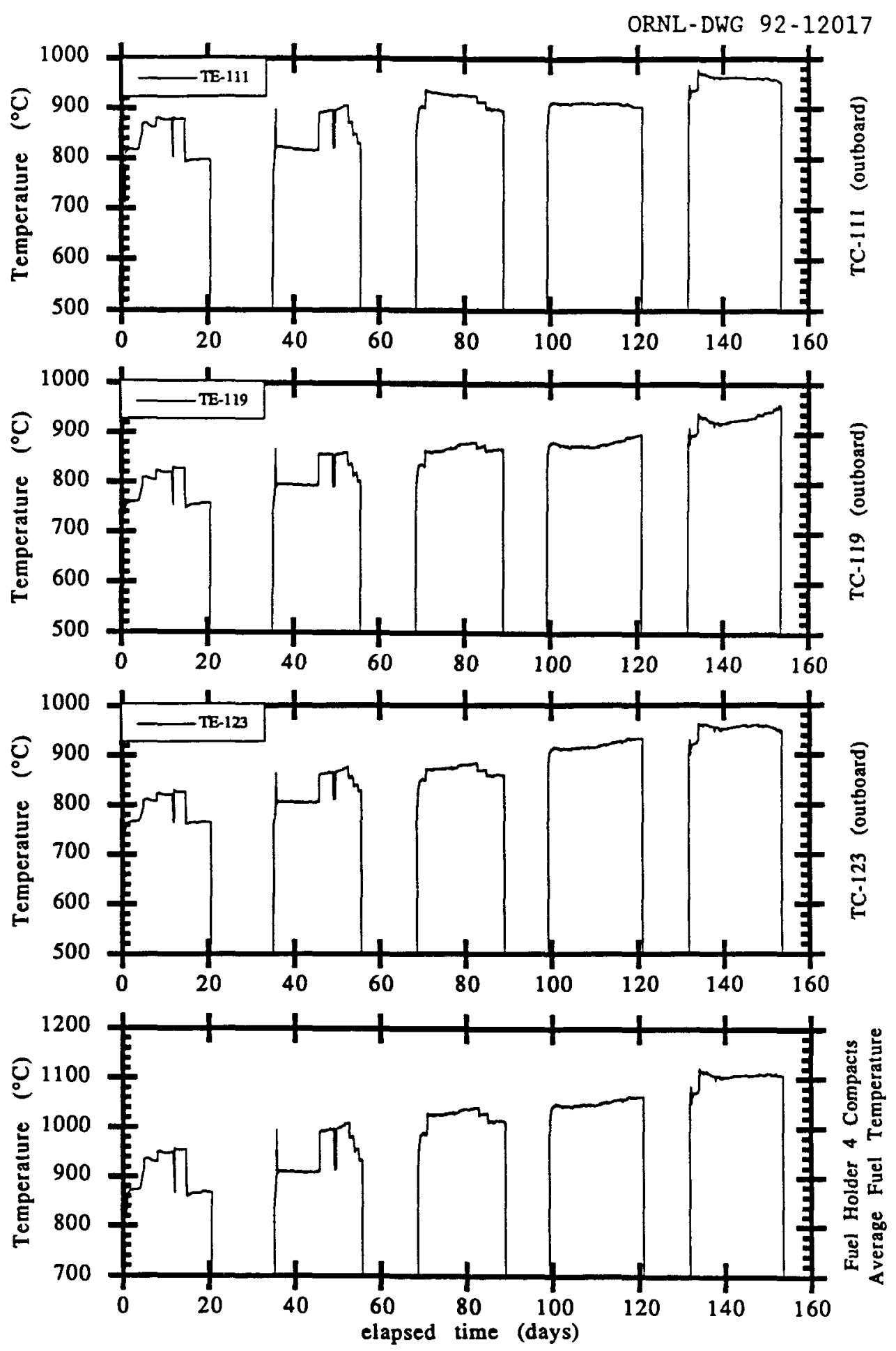

Figure 5-1. CONTINUED. 
ORNL-DWG 92-12018
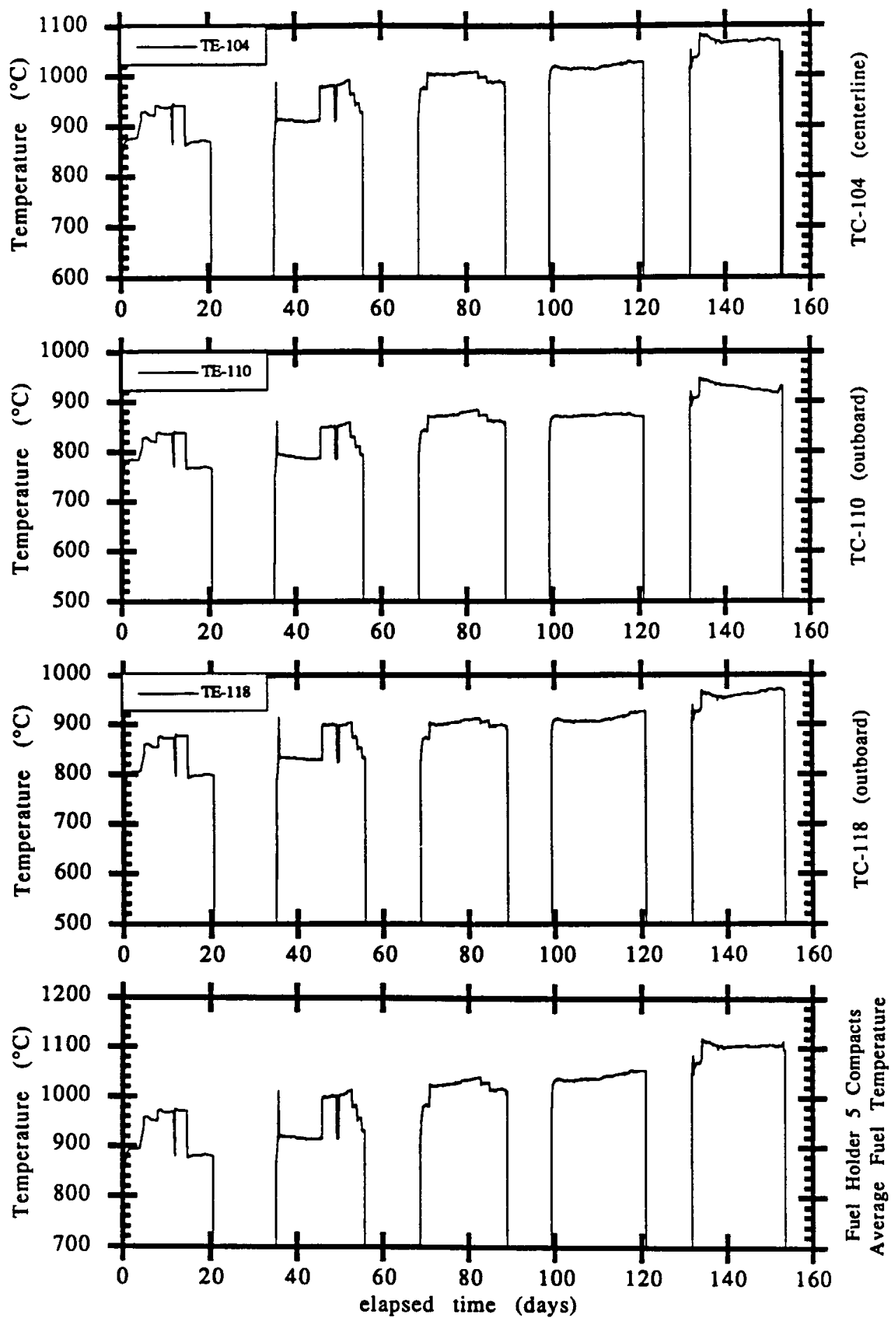

Figure 5-1. CONTINUED. 
ORNL-DWG $92-12019$
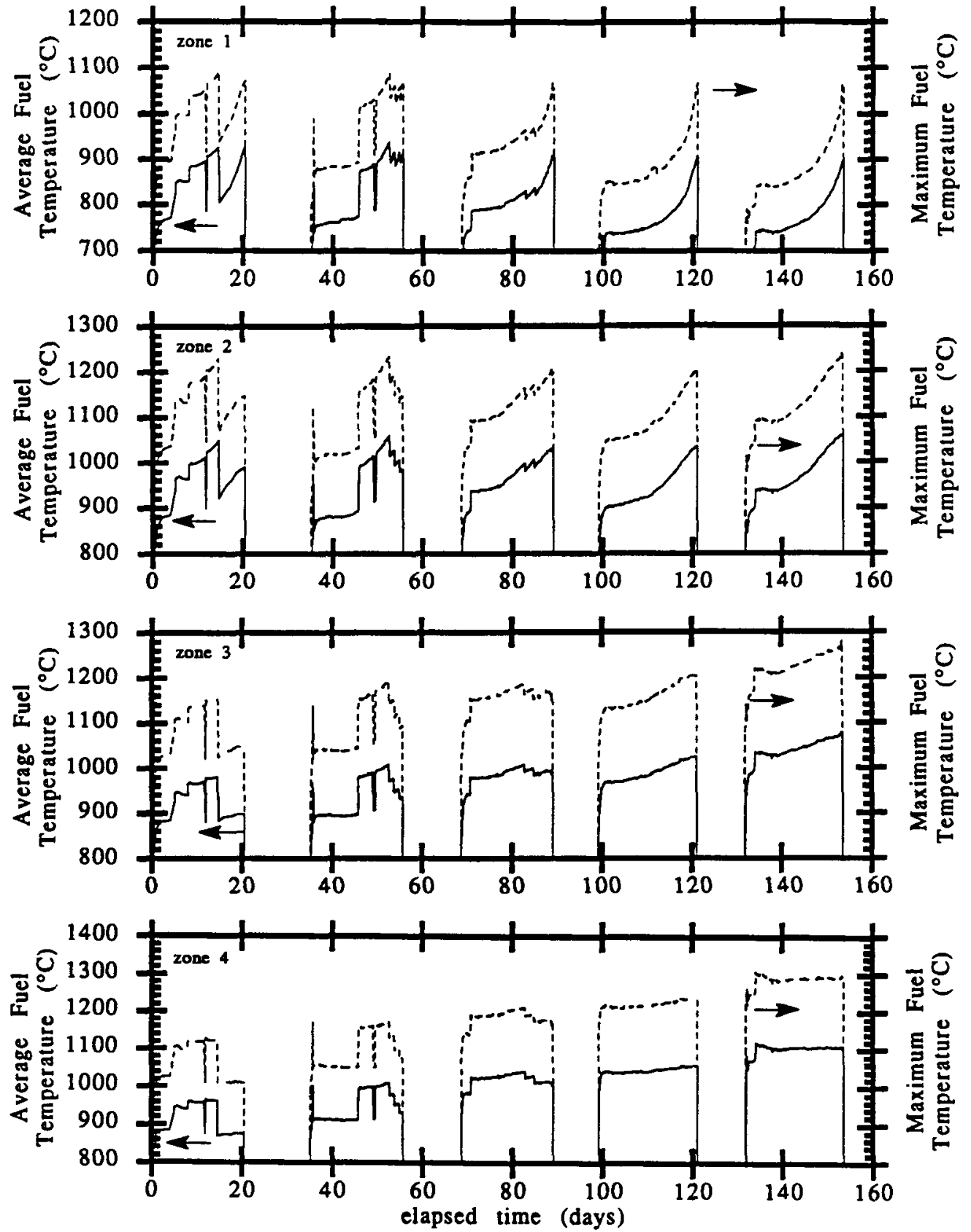

Figure 5-2.

AVERAGE FUEL COMPACT TEMPERATURE AND THE LOCAL MAXIMUM FUEL TEMPERATURE FOR EACH OF THE FOUR FUEL-LOADING ZONES AS A FUNCTION OF ELAPSED TIME. 
SECTION 6

REACTOR OPERATION

Figures 6-1 through 6-4 provide reactor plant data for HFIR cycles 299 through 302. Shown are the reactor vessel primary inlet and outlet cooling water temperature and the primary cooling water flow rate (Fig. 6-1), the inlet primary water pressure and pressure drop between the primary inlet and outlet (Fig. 6-2), the position of the control plates (Fig. 6-3), and a neutron flux chamber signal (Fig. 6-4). The data for cycle 298 were not available on magnetic media, and these data were reconstructed from hard copy for experimental data validation. Thus, the cycle 298 data are constructed from discrete points at 1 -h intervals rather than continuous data as is the case for the remaining cycles. The correlation between control rod withdrawal and temperature of the capsule ends (Fig. 5-1, regions 1 and 8) is readily observed. Detailed review of these reactor data has validated the thermocouple data from the test. The plotted data exhibit no unusual or inexplicable characteristics. 
ORNL-DWG $92-12020$

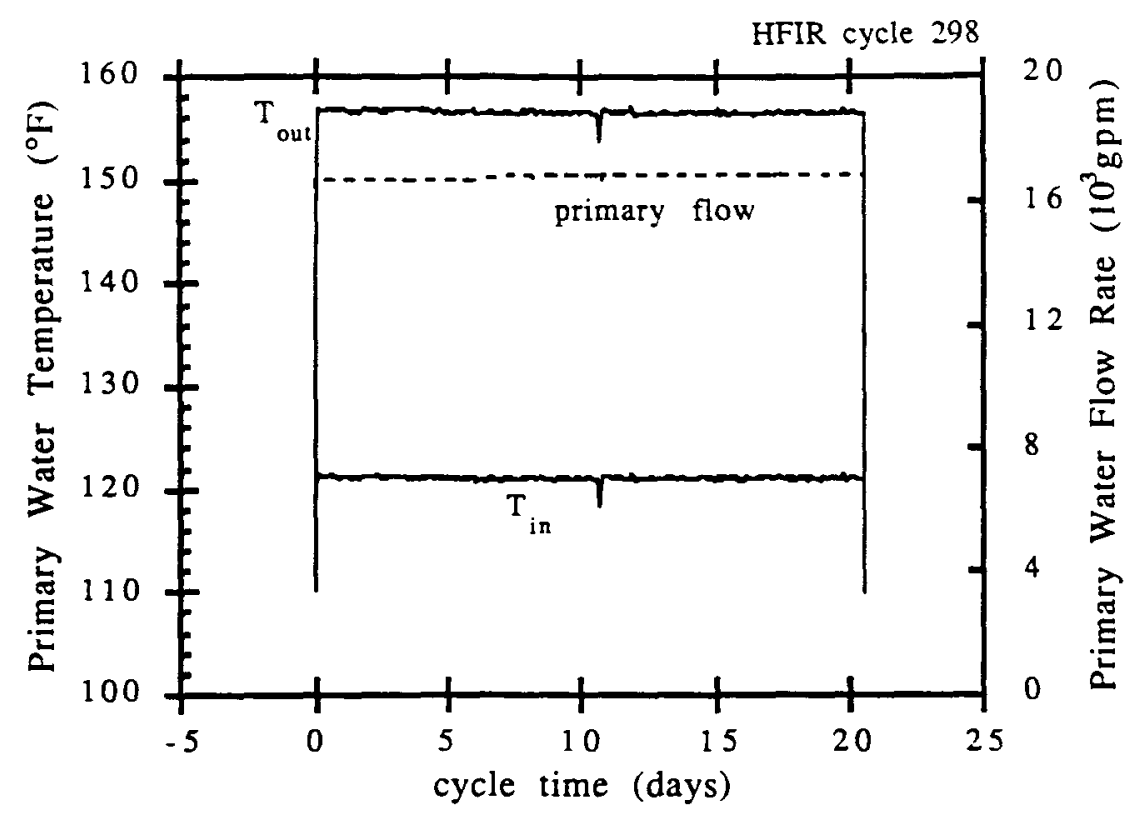

ORNL-DWG $92-12021$

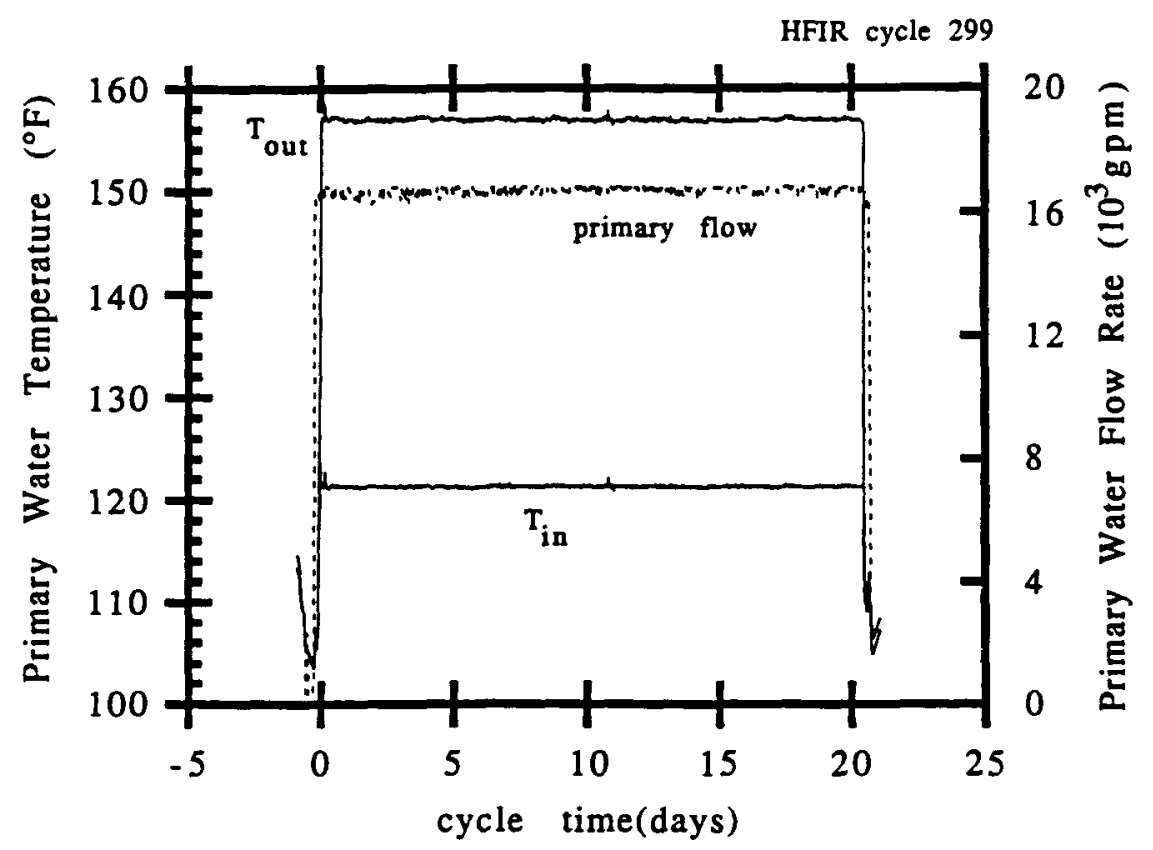

Figure 6-1.

INLET AND OUTLET PRIMARY CIRCUIT COOLING WATER TEMPERATURES AND PRIMARY WATER FLOW

RATE FOR CYCLES 298 THROUGH 302 . 
ORNL-DWG 92-12022

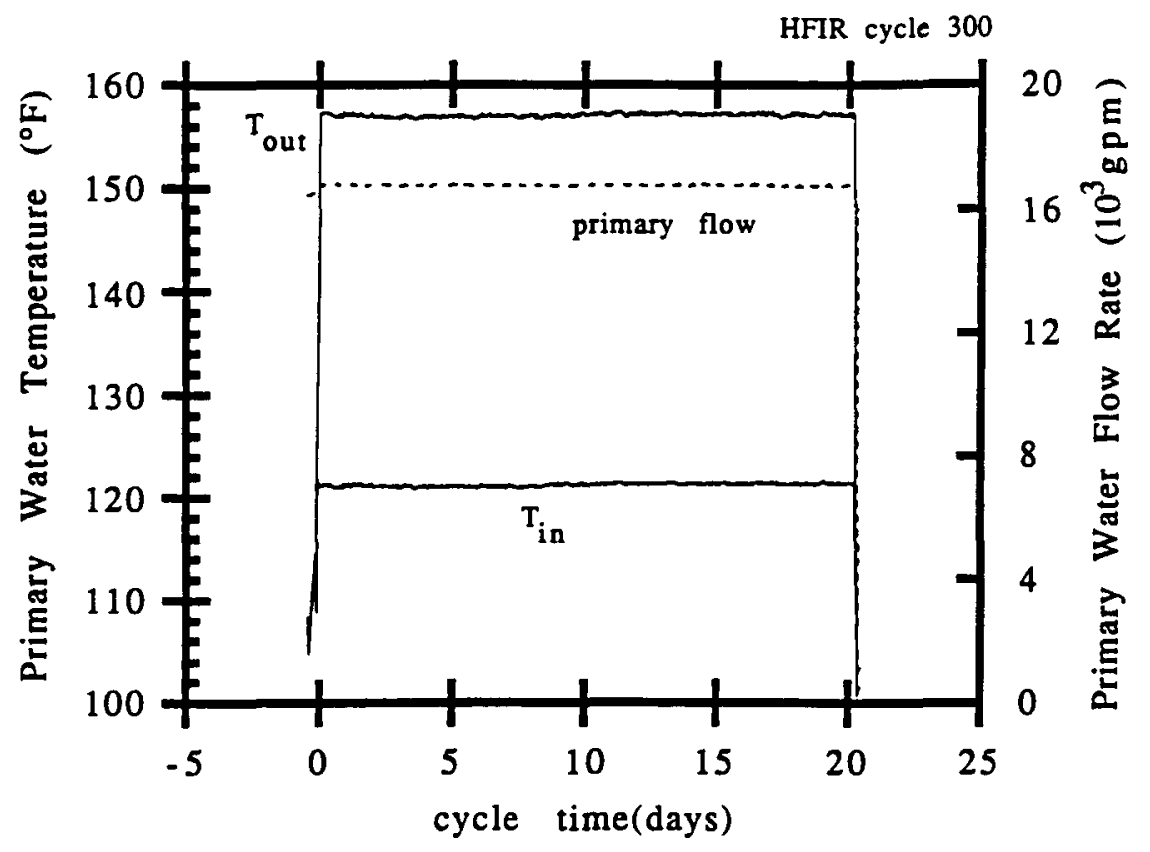

ORNL-DWG 92-12023

HFIR cycle 301

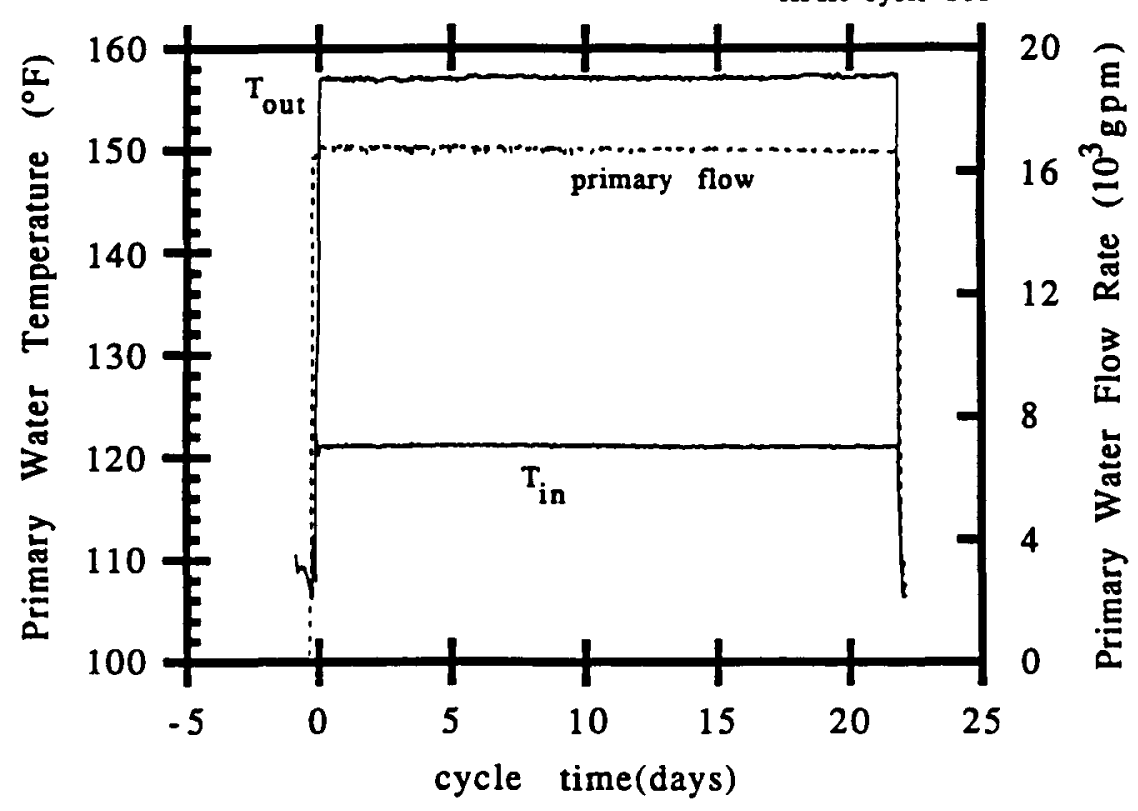

Figure 6-1. CONTINUED. 
ORNL-DWG $92-12024$

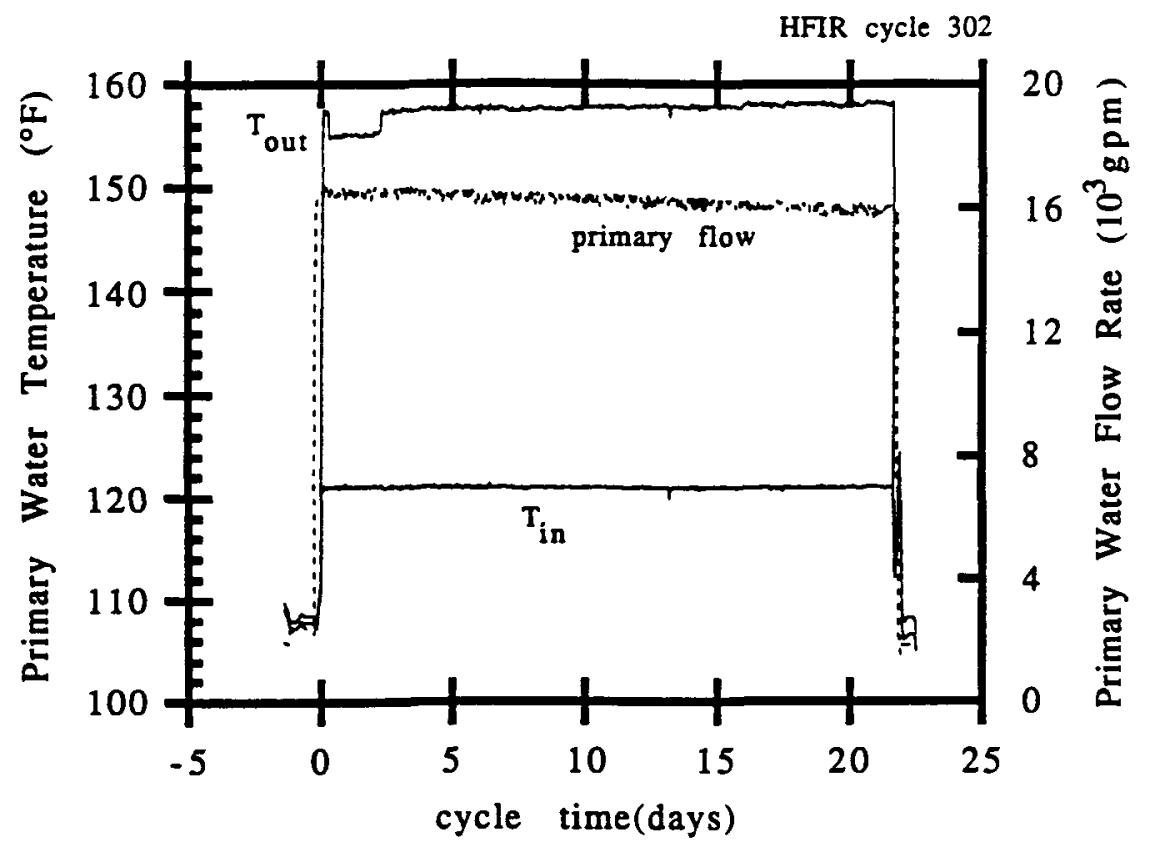

Figure 6-1. CONTINUED. 
ORNL-DWG $92-12025$

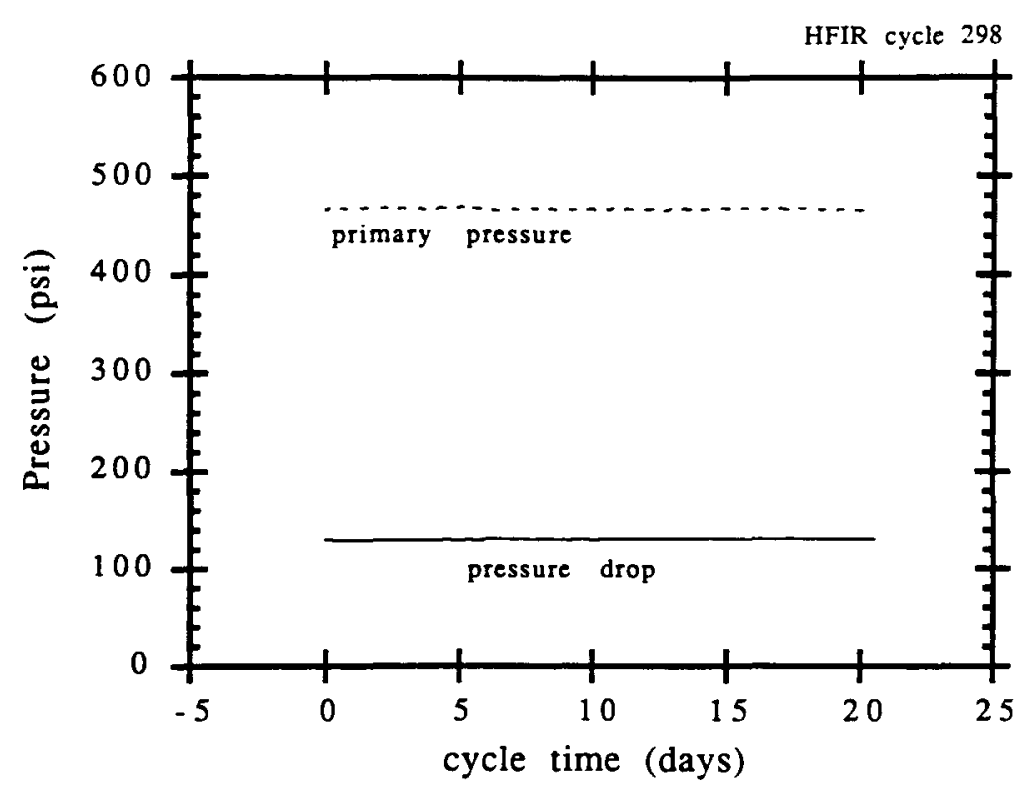

ORNL-DWG 92-12026

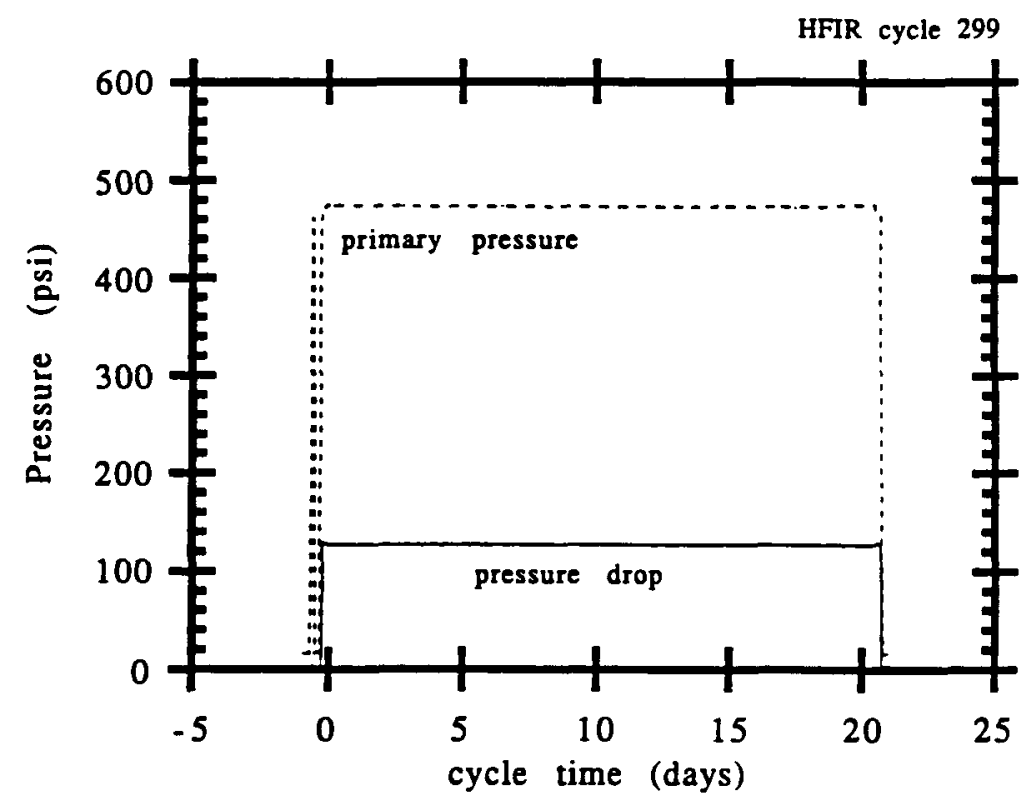

Figure 6-2.

PRIMARY INLET PRESSURE AND THE PRESSURE DROP BETWEEN THE PRIMARY INLET AND OUTLET FOR CYCLES 298 THROUGH 302. 

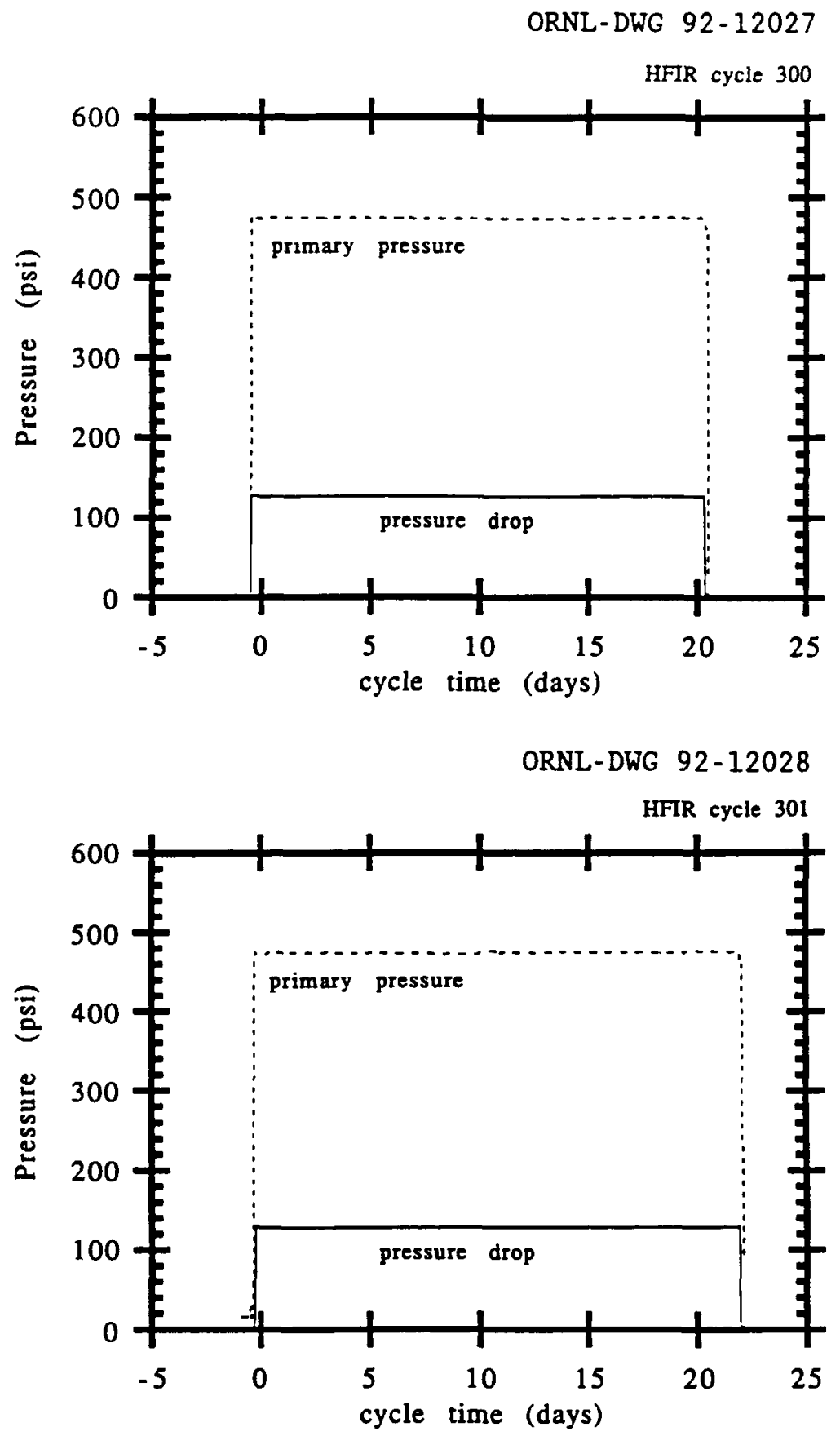

Figure 6-2. CONTINUED. 
ORNL-DWG 92-12029

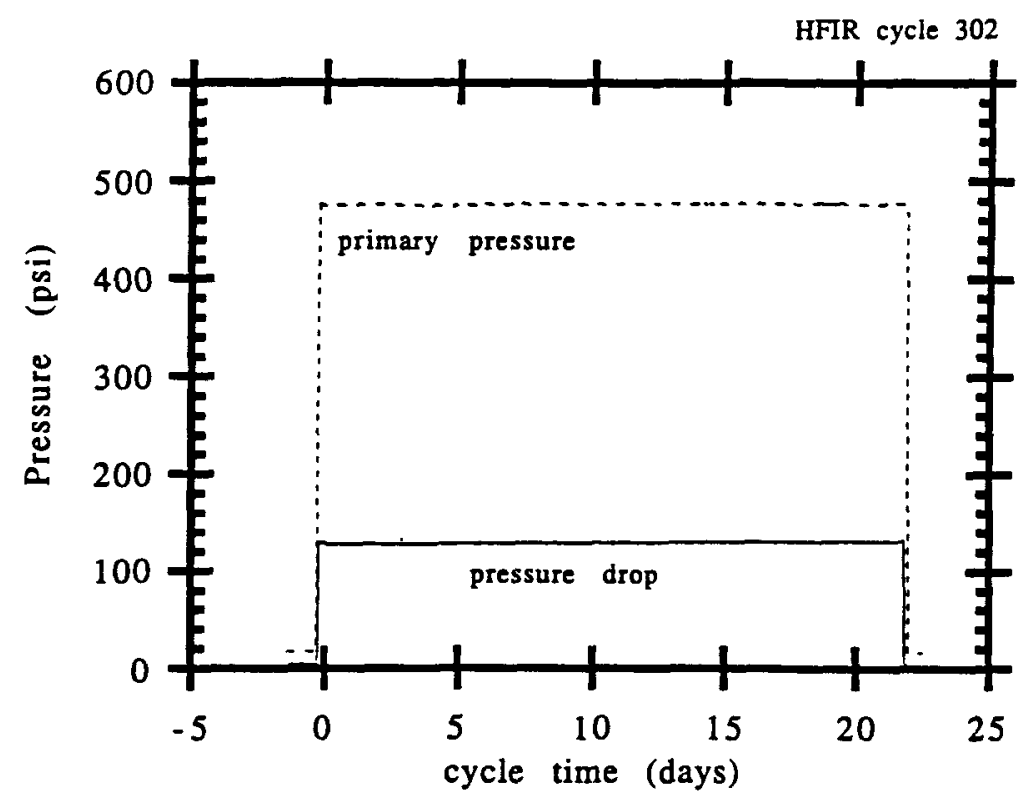

Figure 6-2. CONTINUED. 
ORNL-DWG $92-12030$

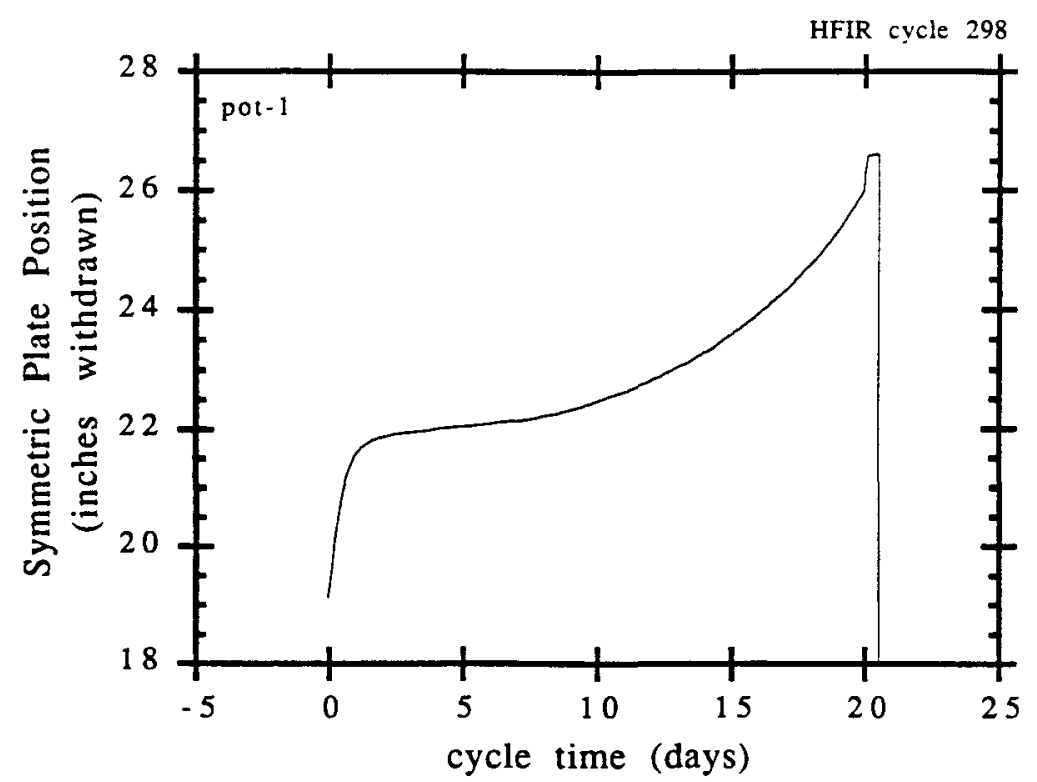

ORNL-DWG 92-12031

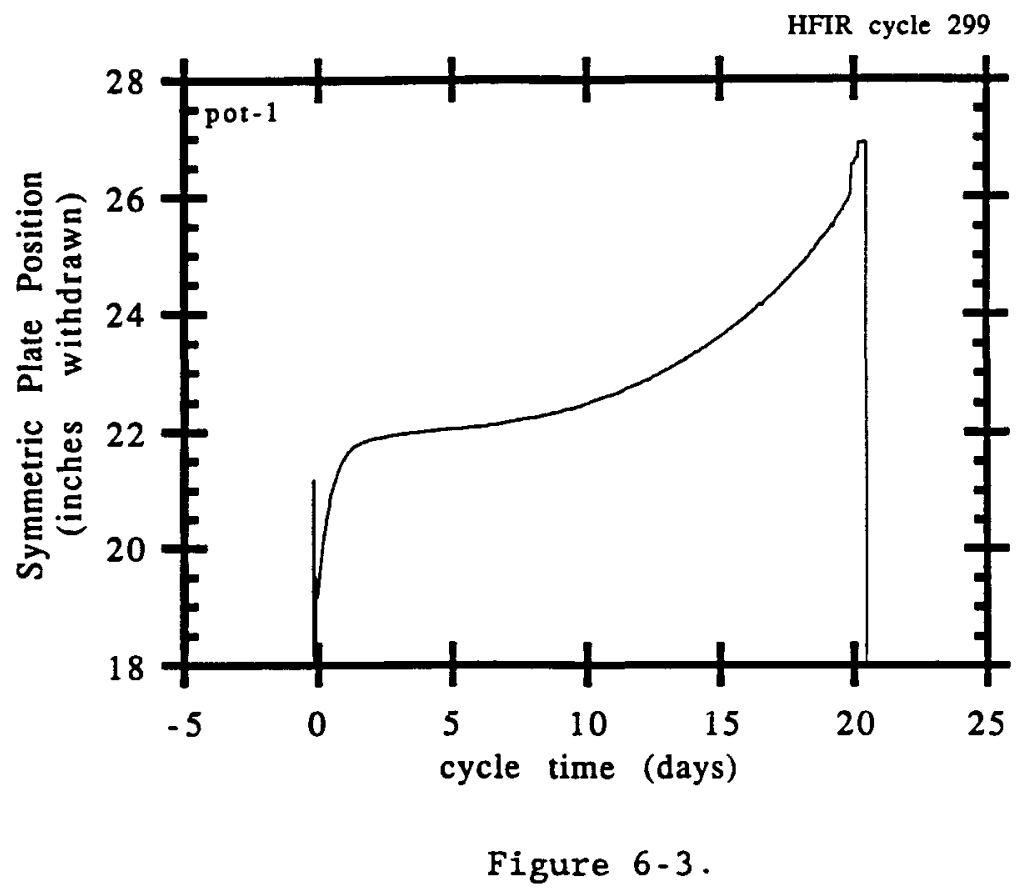

POSITION OF THE CONTROL PLATES SHOWN AS INCHES WITHDRAWN FOR CYCLES 298

THROUGH 302 . 
ORNL-DWG $92-12032$

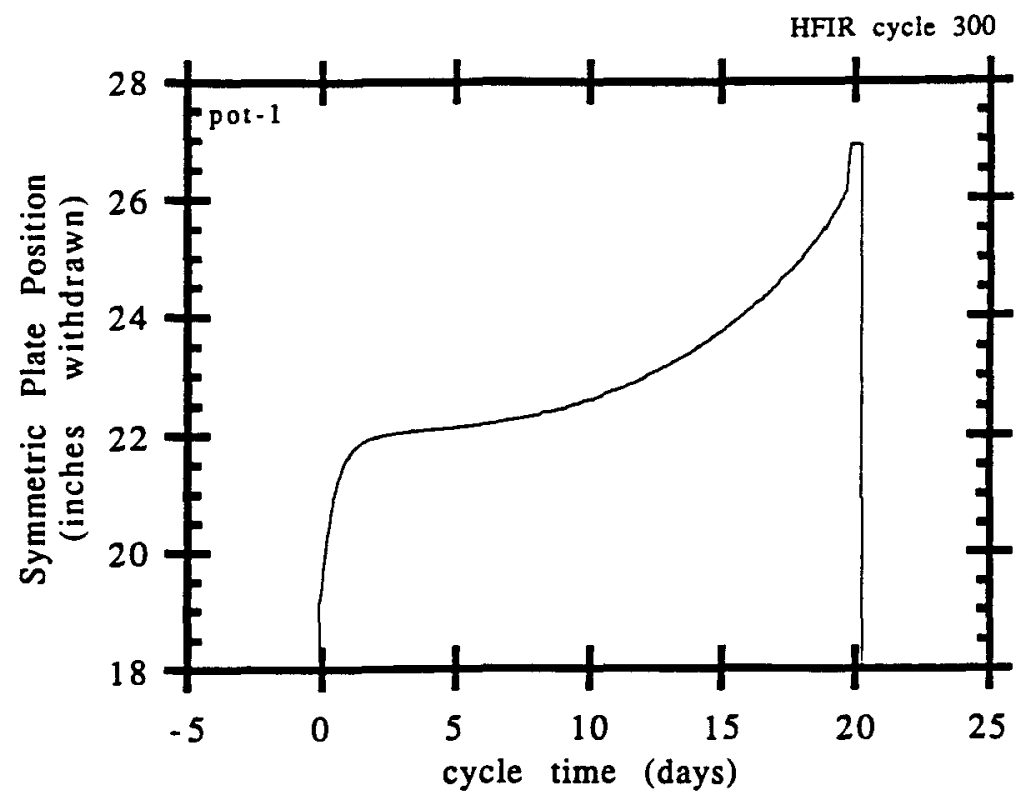

ORNL-DWG 92-12033

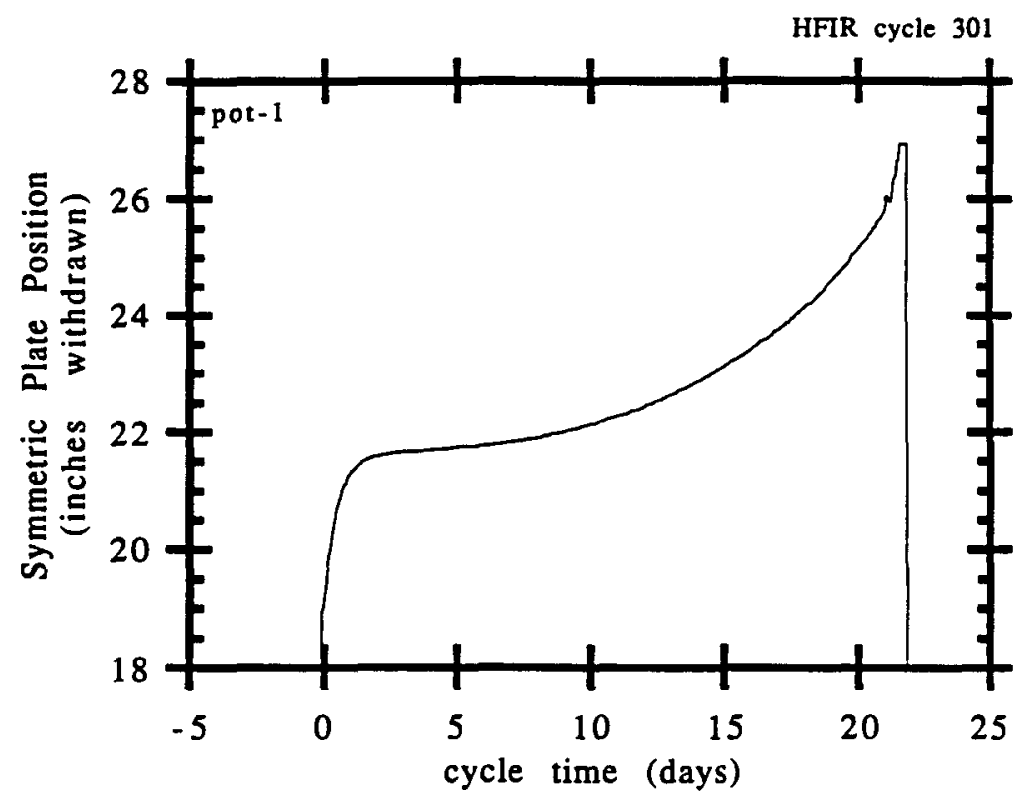

Figure 6-3. CONTINUED. 


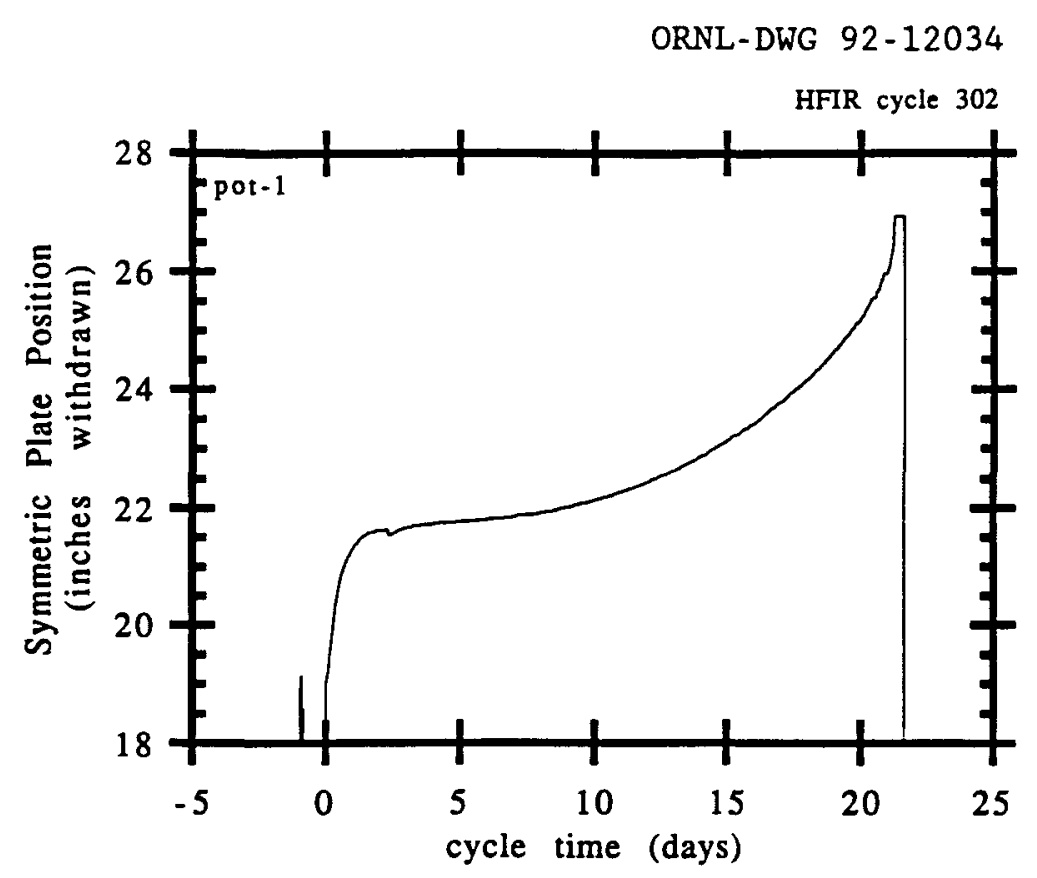

Figure 6-3. CONTINUED. 
ORNL-DWG 92-12035

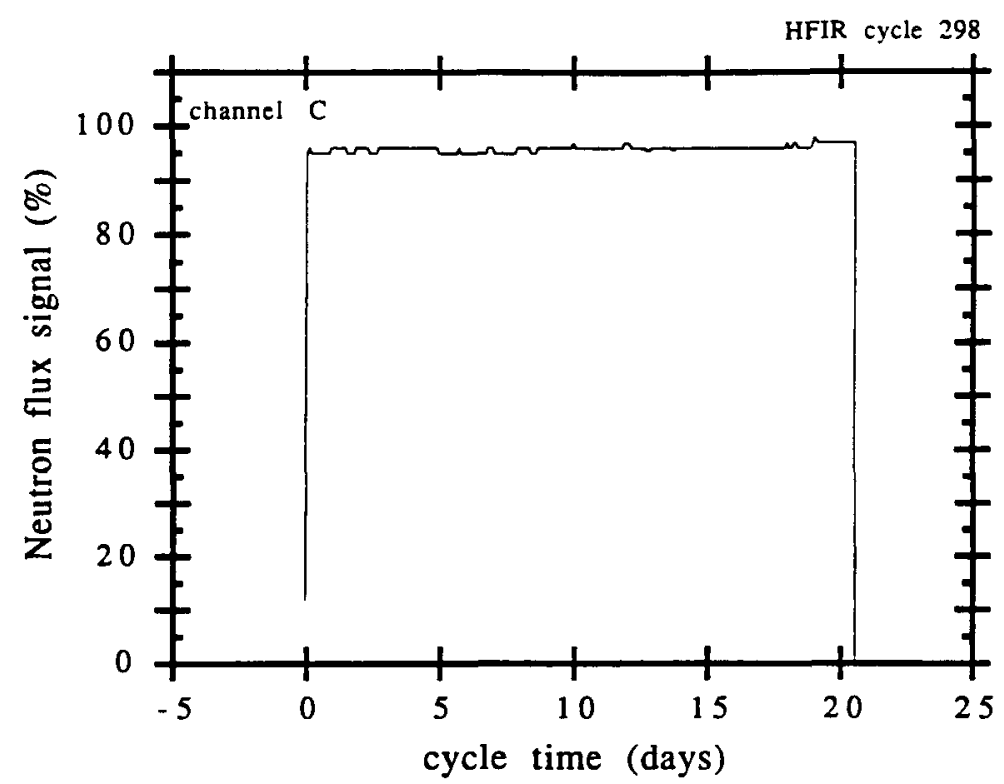

ORNL-DWG 92-15997

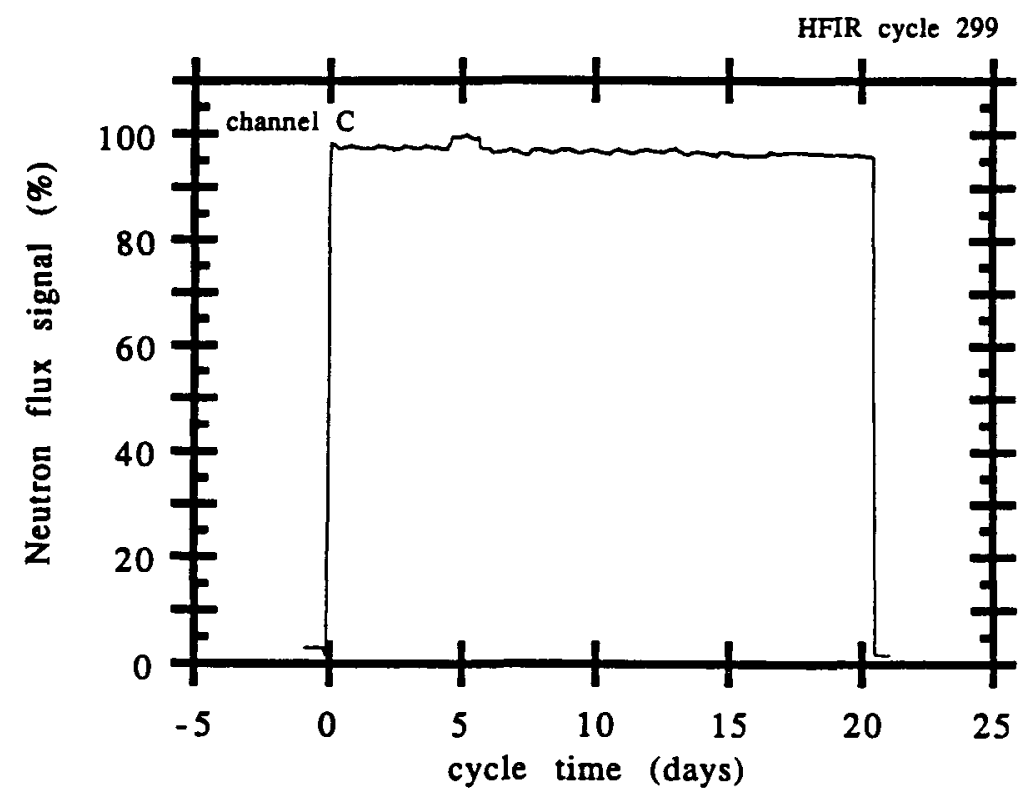

Figure 6-4.

NEUTRON FLUX CHAMBER SIGNAL FOR

CYCLES 298 THROUGH 302. 
ORNL-DWG 92-15998
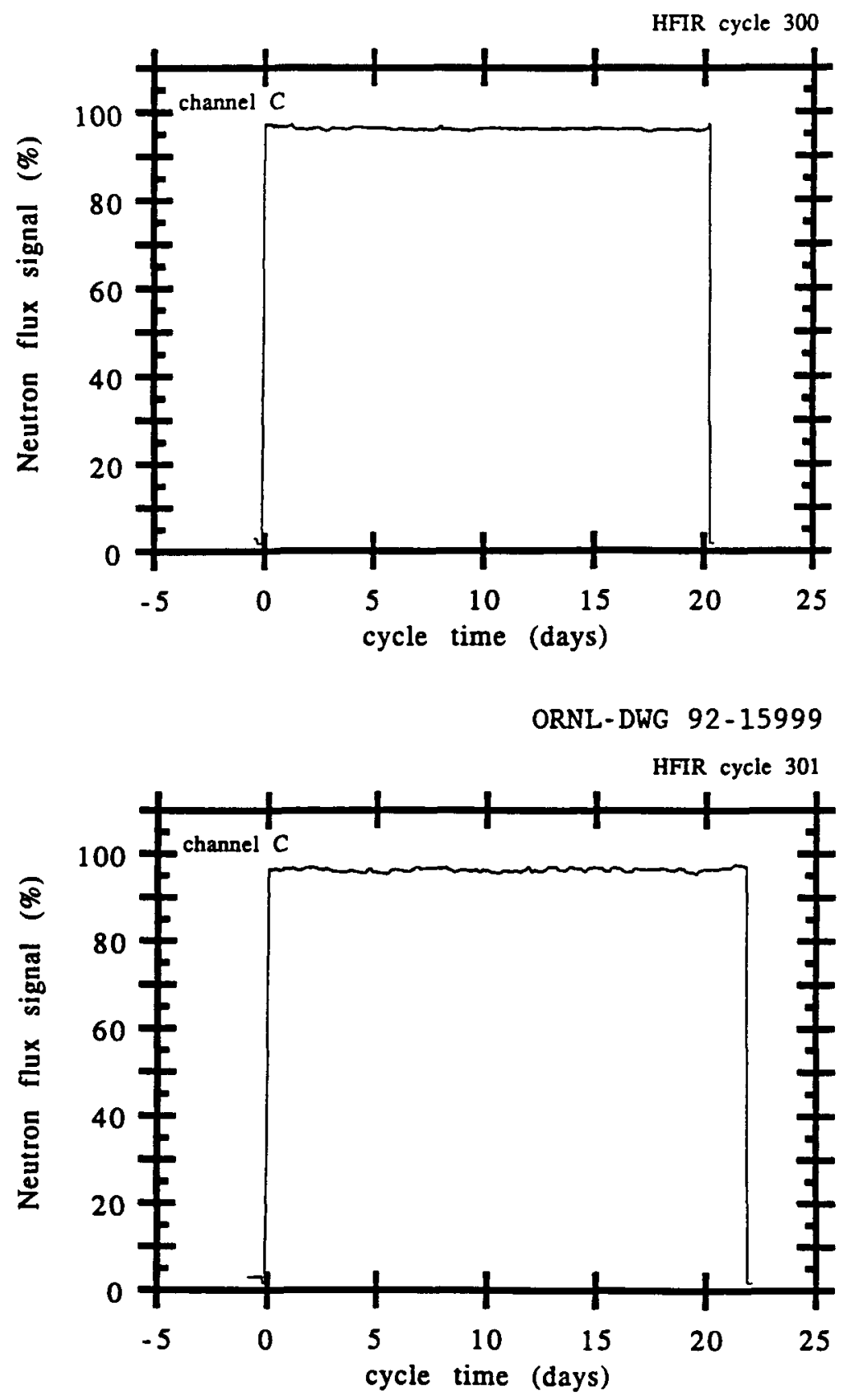

Figure 6-4. CONTINUED. 
ORNL-DWG 92-16000

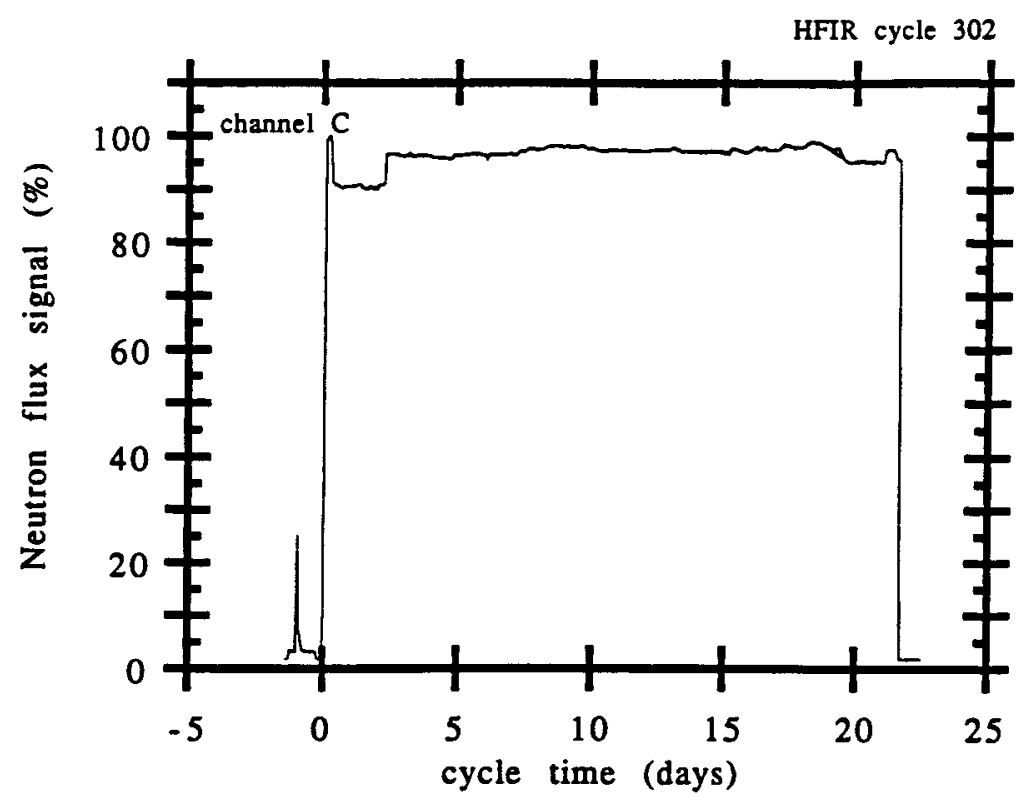

Figure 6-4. CONTINUED. 


\section{DISCUSSION OF CAPSULE OPERATION}

Figure 7-1 presents an overview of the capsule operation showing the capsule average volumetric fuel temperature and the sweep gas composition as a function of elapsed time. Figure 7-2 provides the indicated helium and neon flow rates. Figure 7-3 again illustrates the temperature chronology and is labeled to point out some events of interest. The capsule was first brought to operating temperature on June 21, 1991, by the addition of neon to the sweep gas. The sharp down spikes at points (A) in Fig. 7-3 were induced by a change in the sweep gas to 1008 He. The periodic operation for a short time at 1008 He provides valuable data under well characterized sweep

ORNL-DWG $92-16001$

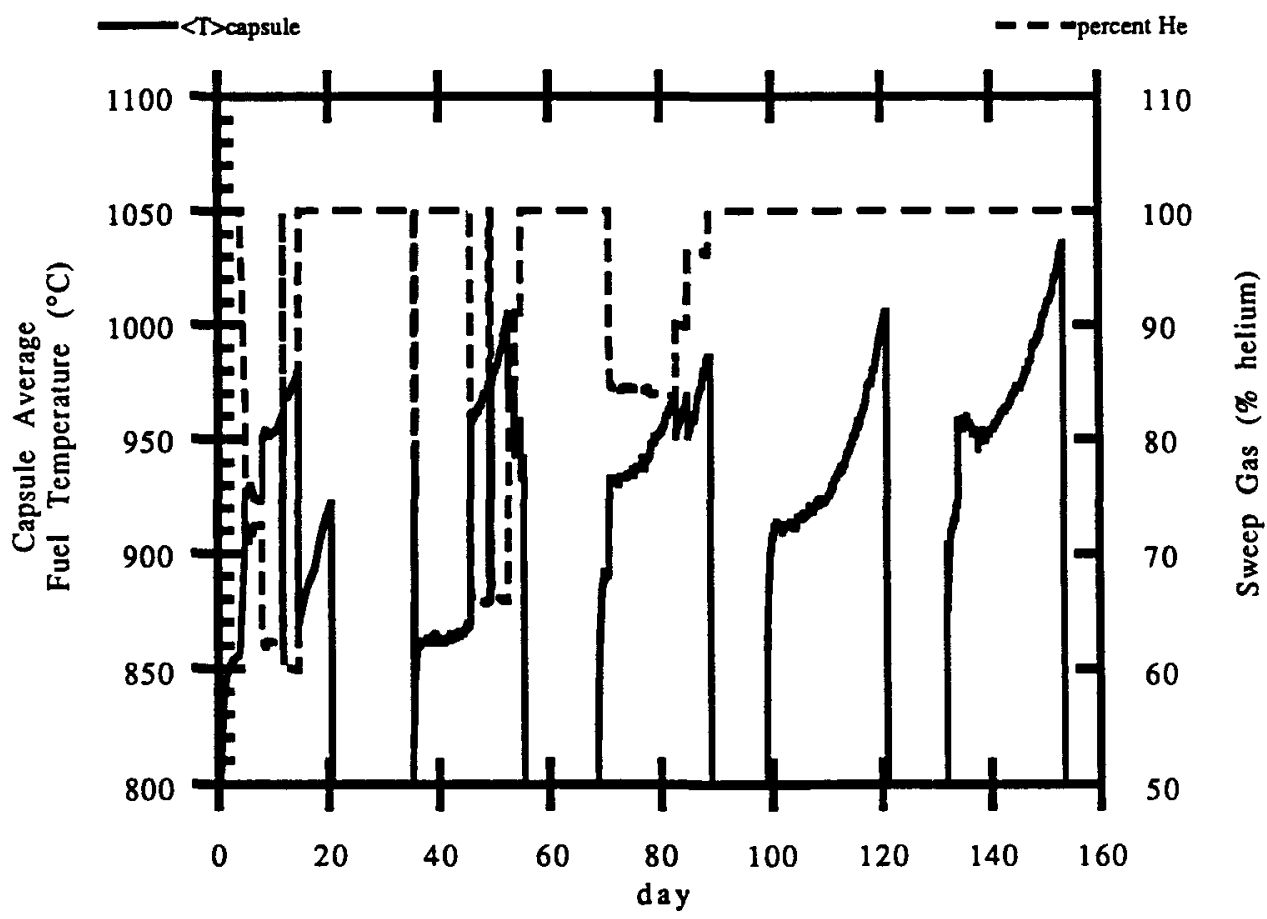

Figure 7-1.

OVERVIEW OF THE CAPSULE OPERATION SHOWING THE TIME EVOLUTION OF THE CAPSULE AVERAGE FUEL TEMPERATURE AND THE PERCENT HELIUM IN THE CAPSULE SWEEP GAS. 

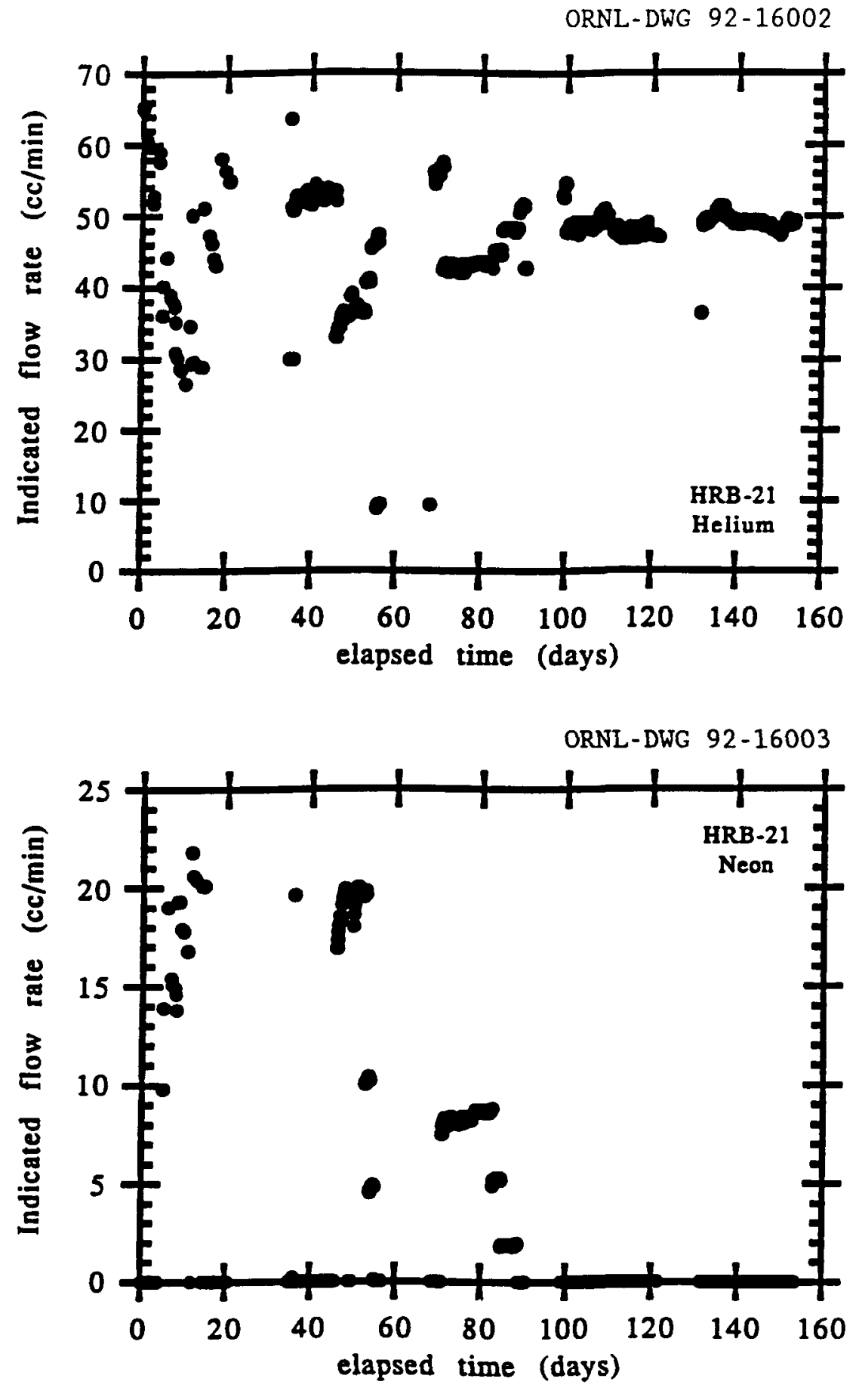

Figure 7-2.

INDICATED HELIUM AND NEON FLOW RATES AS A FUNCTION OF ELAPSED TIME. 
ORNL-DWG $92-16004$

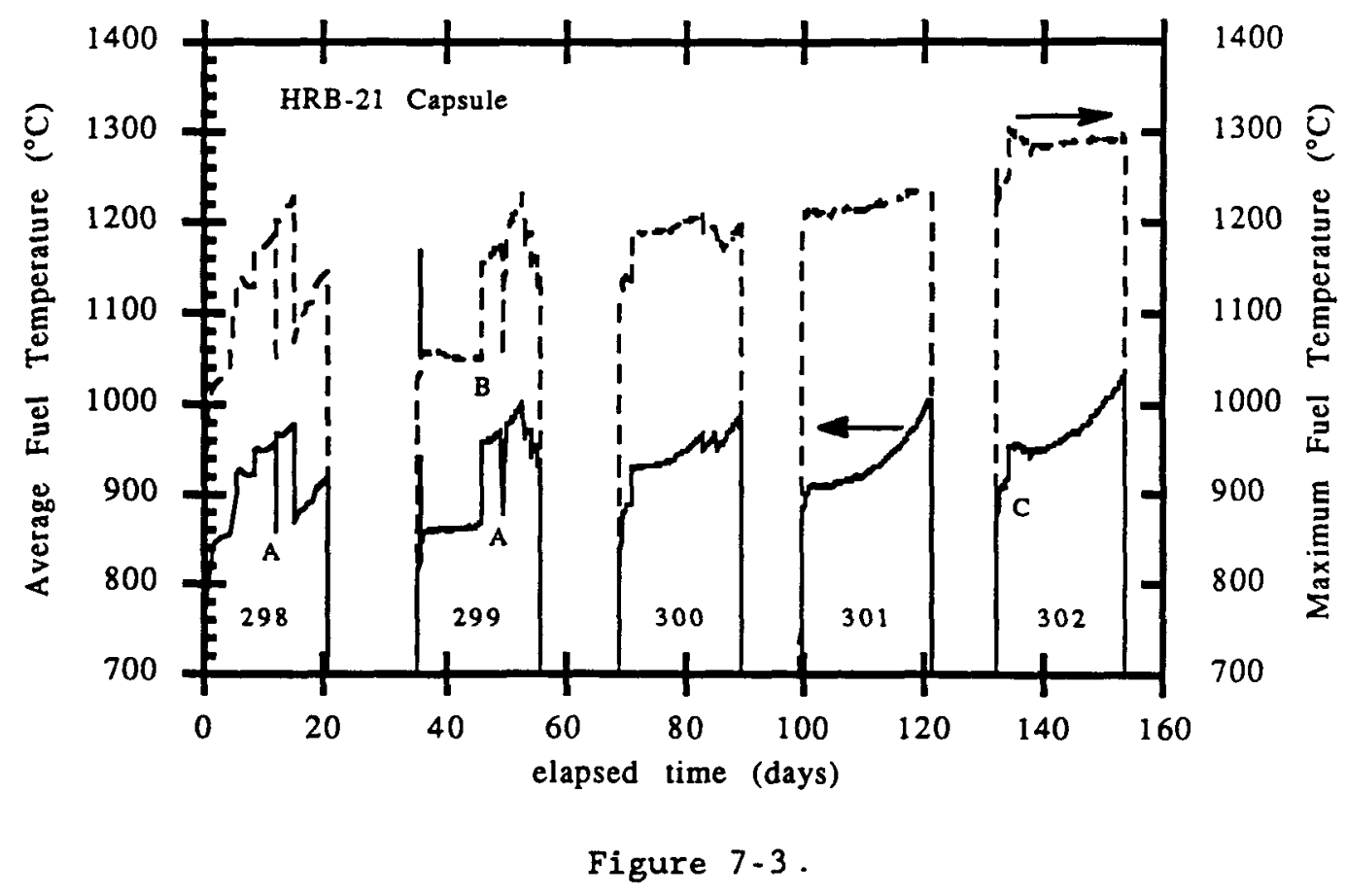

CAPSULE AVERAGE FUEL TEMPERATURE WITH POINTS OF INTEREST LABELED FOR DISCUSSION. THE CYCLE NUMBERS ARE LISTED JUST ABOVE THE ABSCISSA.

gas conditions and contributes to reducing uncertainties in the thermal analysis. Near the end of the first cycle, the sweep gas was changed to 1008 helium because there was some uncertainty in the rate of the anticipated temperature increase near the ends of the capsule as the control plate withdrawal rate increases. No pulses in the activity of the sweep gas were observed during the first cycle of operation.

At the beginning of the second cycle (299), after the test was brought up to operating temperature by an increase in the neon concentration (about $12 \mathrm{~h}$ after the reactor reached full power), the ionization chamber recorded sharp pulses in sweep gas activity characteristic of particle failure (see discussion below). Since no particle failures were expected at this time in this fuel, a programmatic decision was made to lower the capsule temperature while the experimental facility was examined to ensure that experimental anomalies were not causing the unexpected radioactivity pulses. The capsule temperature was reduced by changing the sweep gas back to $1008 \mathrm{He}$ (14:05 h, 
July 26, 1991). At this point, all systems that could contribute to experimental anomalies were checked. The experimental facility was found to be functioning correctly (temperature monitoring, sweep gas integrity, He and Ne purity, etc.). The gas cylinders in use at this time were removed from the manifold and analyzed. The results are in Table 7-1 as "re-analysis," which shows both gases to be of high purity. The vendor analyses received

Table 7-1.

ANALYSES OF He AND Ne GAS CYLINDERS FROM HFIR CYCLE 299 STARTUP COMPARED TO PRE-TEST VALUES .

\begin{tabular}{cccccc}
\hline & \multicolumn{2}{c}{ Helium cylinder } & & \multicolumn{2}{c}{ Neon cylinder } \\
\cline { 2 - 3 } \cline { 5 - 6 } Constituent & $\begin{array}{c}\text { Pre-test } \\
(\mathrm{ppm})\end{array}$ & $\begin{array}{c}\text { Re-analysis } \\
\text { (ppm) }\end{array}$ & & $\begin{array}{c}\text { Pre-test } \\
\text { (ppm) }\end{array}$ & $\begin{array}{c}\text { Re-analysis } \\
\text { (ppm) }\end{array}$ \\
\hline $\mathrm{O}_{2}$ & 0.76 & $\leq 1$ & & 1.5 & $\leq 1$ \\
$\mathrm{CO}\left(\mathrm{N}_{2}\right)$ & - & $\leq 5$ & & - & $\leq 10$ \\
$\mathrm{CO}_{2}$ & - & $\leq 1$ & $\leq 1$ & $\leq 1$ \\
$\mathrm{H}_{2} \mathrm{O}$ & 0.08 & $\leq 10$ & & $\leq 1$ & $\leq 10$ \\
$\mathrm{H}_{2}$ & - & $\leq 1$ & & - & $\leq 1$ \\
$\mathrm{CH}_{4}$ & - & $\leq 1$ & & $\leq 0.5$ & $\leq 1$ \\
\hline
\end{tabular}

with the gases originally are also shown in Table 7-1 as "pre-test." With the concurrence of program management, neon was added to the sweep gas at $13: 20 \mathrm{~h}$ on August 5,1991 , to raise the capsule temperature to the design operating range.

Cycle 300 progressed nominally, with the temperature of the capsule regulated as necessary to maintain the target temperature. During this cycle, it became clear that a point in time would soon be reached where the local maximum fuel temperature could exceed $1250^{\circ} \mathrm{C}$. This unexpected increase in capsule temperature may be due to the breeding in of ${ }^{233} \mathrm{U}$ at a level greater than that anticipated due to the long shutdown periods between operation. In the thermal and neutronic analyses upon which the capsule design is based, the down time between cycles was taken to be $1 \mathrm{~d}$ based on previous HFIR experience. The actual average downtime was about $12.2 \mathrm{~d}$ while the half life of ${ }^{233} \mathrm{~Pa}\left({ }^{233} \mathrm{U}\right.$ precursor) is $27.4 \mathrm{~d}$. Therefore, the ${ }^{233} \mathrm{U}$ 
concentration at the beginning of each cycle was higher than planned for. Postirradiation analysis of the fuel should provide conclusive evidence as to why this temperature increase occurred. It was decided to continue operation of the capsule pending further review.

The sweep gas was 1008 He for cycles 301 and 302. At the beginning of cycle 302, the reactor power was lowered to $80 \mathrm{MW}(t)$ to clear a high-temperature alarm (point C, Fig. 7-3). After the Reactor Experiment Review Committee (RERC) review and authorization from the Department of Energy (DOE) to operate with TC temperatures up to $1100^{\circ} \mathrm{C}, 85-\mathrm{MW}(t)$ operation was resumed. At the end of cycle 302, the HRB-21 capsule was removed from the reactor and placed in the experiment storage facility in the reactor pool. 
SECTION 8

DISCUSSION OF FUEL PERFORMANCE

There are two measures of fuel performance while the experiment is undergoing testing. Both monitor the ability of the fuel to retain its gaseous fission products, and both relate to the presence of radioactive fission products in the sweep gas. The first measure is the monitoring of the radiation level of the sweep gas after it exits the capsule. The second method involves obtaining a grab sample of the sweep gas, determining its fission gas content, and computing an $R / B$ ratio for the specific fission product isotopes in the fuel.

\subsection{SWEEP GAS RADIATION LEVEL MONITORING}

The radiation level of the sweep gas exiting the capsule is continuously monitored by two independent ionization chambers with chart recorders. The failure of a fuel particle in this type fuel test has been shown to yield a sharp, distinctive pulse on the chart recordings. ${ }^{9}$ The behavior of the ionization chamber chart during the addition of neon to raise the temperature at the start of the second cycle is shown in Fig. 8-1. The distinctive shape of the pulses is obscured somewhat by the effects of adding neon and raising the temperature. The general radiation level of the sweep gas increases when neon is added due to the presence of ${ }^{23} \mathrm{Ne}$, which is an activation product of ${ }^{22} \mathrm{Ne}$. More classic examples of particle failure pulses are shown in Fig. 8-2 in which the temperature is stable and the sweep gas is $100 \%$ helium. The pulse is characterized by a very rapid increase in radiation level of only 2 to 3 min duration at half height, followed by a slower return to a level somewhat higher than the original. Figure 8-3 is a characteristic pulse, while the sweep gas is a mixture of helium and neon-the chart line is more erratic when neon is present. The chart pulses representing particle failures continued for the duration of the test. Figure 8-4 shows a plot of the cumulative number of pulses as a function of time superimposed on a plot of the $R / B$ for ${ }^{85 m} \mathrm{Kr}$ (see below). This count is not final since some spikes are not as well defined and subject to some interpretation. This tentative count indicates a total of about 130 particle failures. As a note of caution 
YP16105

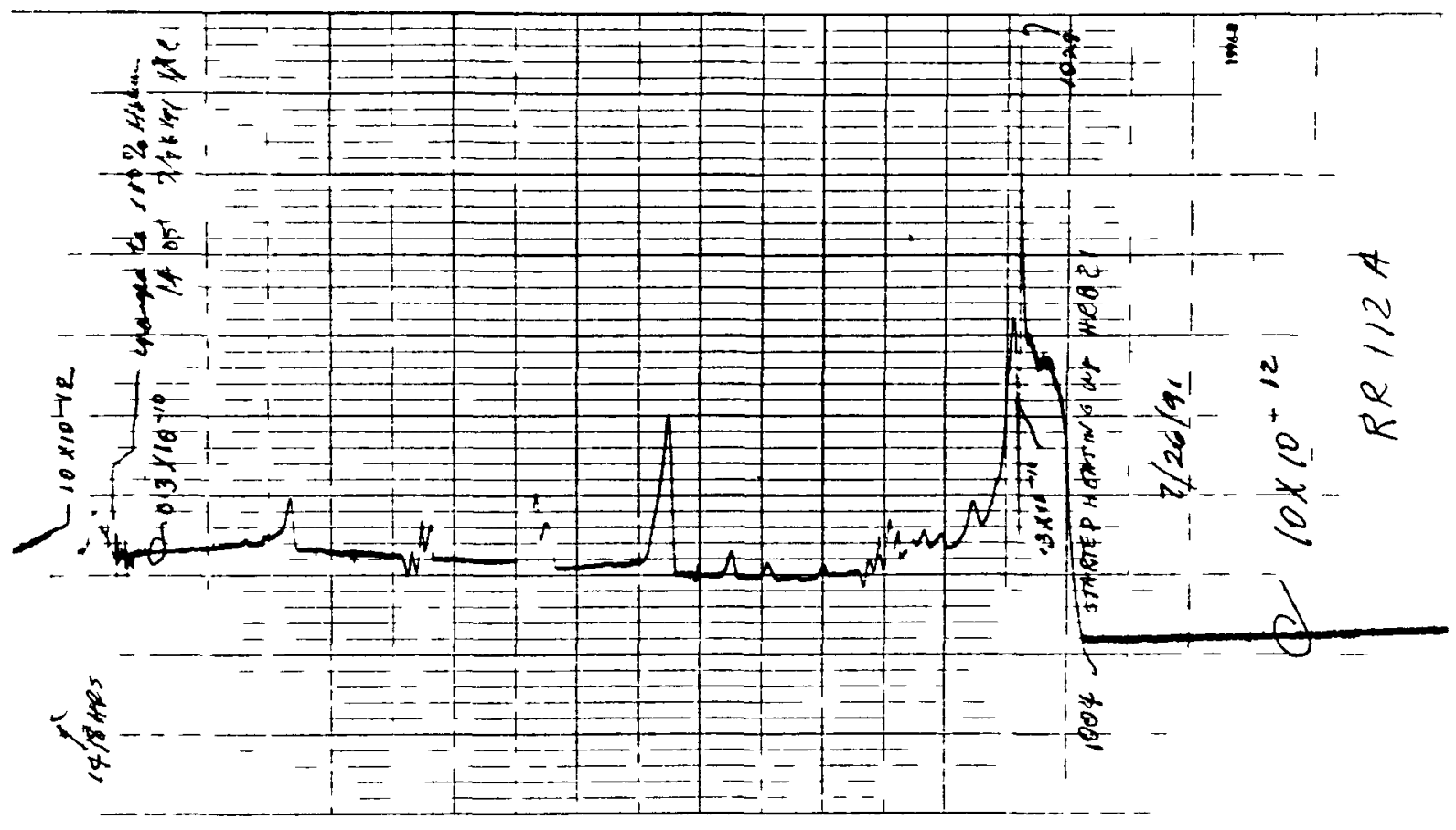

Figure $8-1(a)$.

PHOTOGRAPH OF STRIP-CHART RECORDING OF IONIZATION CHAMBER RESPONSE DURING BEGINNING OF SECOND IRRADIATION CYCLE - CAPSULE HRB-21. THE SWEEP GAS He CONCENTRATION WAS CHANGED FROM 100 TO ABOUT 618 BETWEEN 10:04 AND 10:29, 7/26/91. 


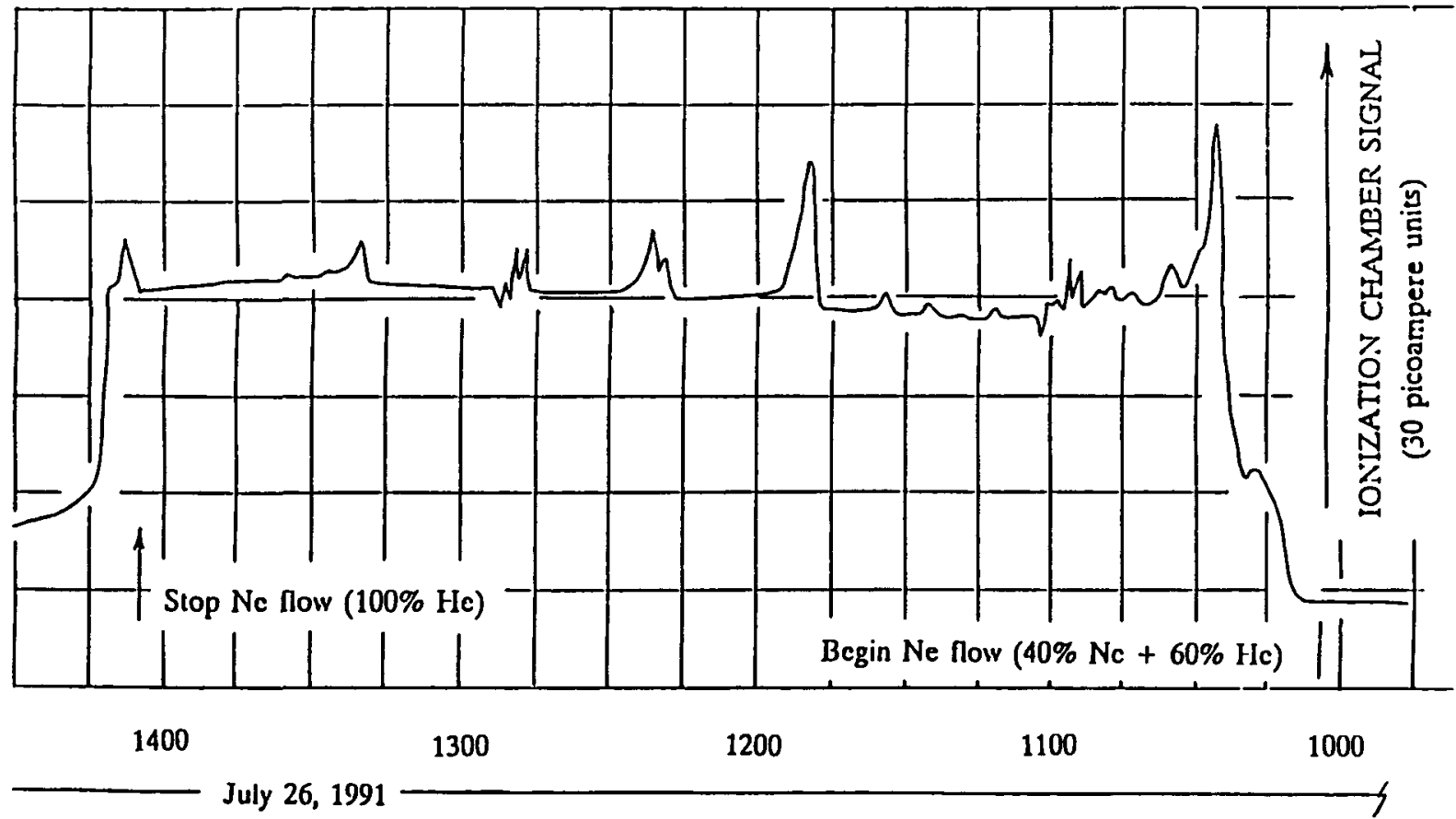

Figure 8-1(b).

IONIZATION CHAMBER RESPONSE DURING BEGINNING OF SECOND IRRADIATION CYCLE - CAPSULE HRB-21. IN THIS DRAWING, THE EFFECT OF AMMETER SCALE CHANGES SEEN IN 8-1(a) HAS BEEN COMPENSATED FOR. 
YP16104

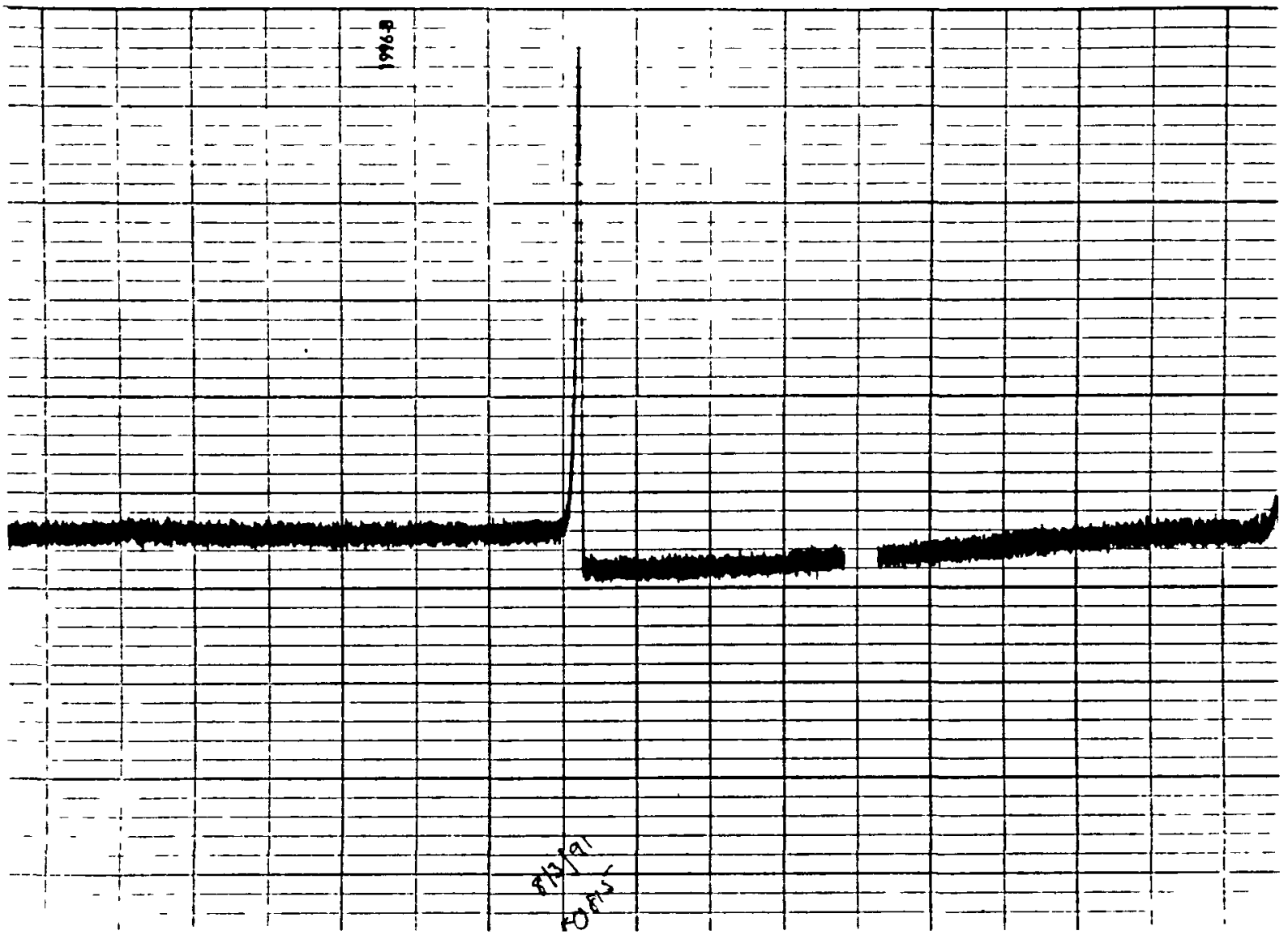

Figure 8-2.

THIS PHOTOGRAPH OF A "CLASSIC" EXAMPLE OF PARTICLE FAILURE PULSE IS FROM A STRIP CHART RECORDING THE OUTPUT CURRENT FROM THE IONIZATION CHAMBER DURING THE SECOND IRRADIATION CYCLE - CAPSULE HRB-21 - ON PURE HELIUM. ON 8/3/91 AT 08:15 hr THE TEST WAS 8.42 d INTO CYCLE 299. ELAPSED TIME = 43.583 d. FULL-POWER DAYS $=28.947$. 
YP16106

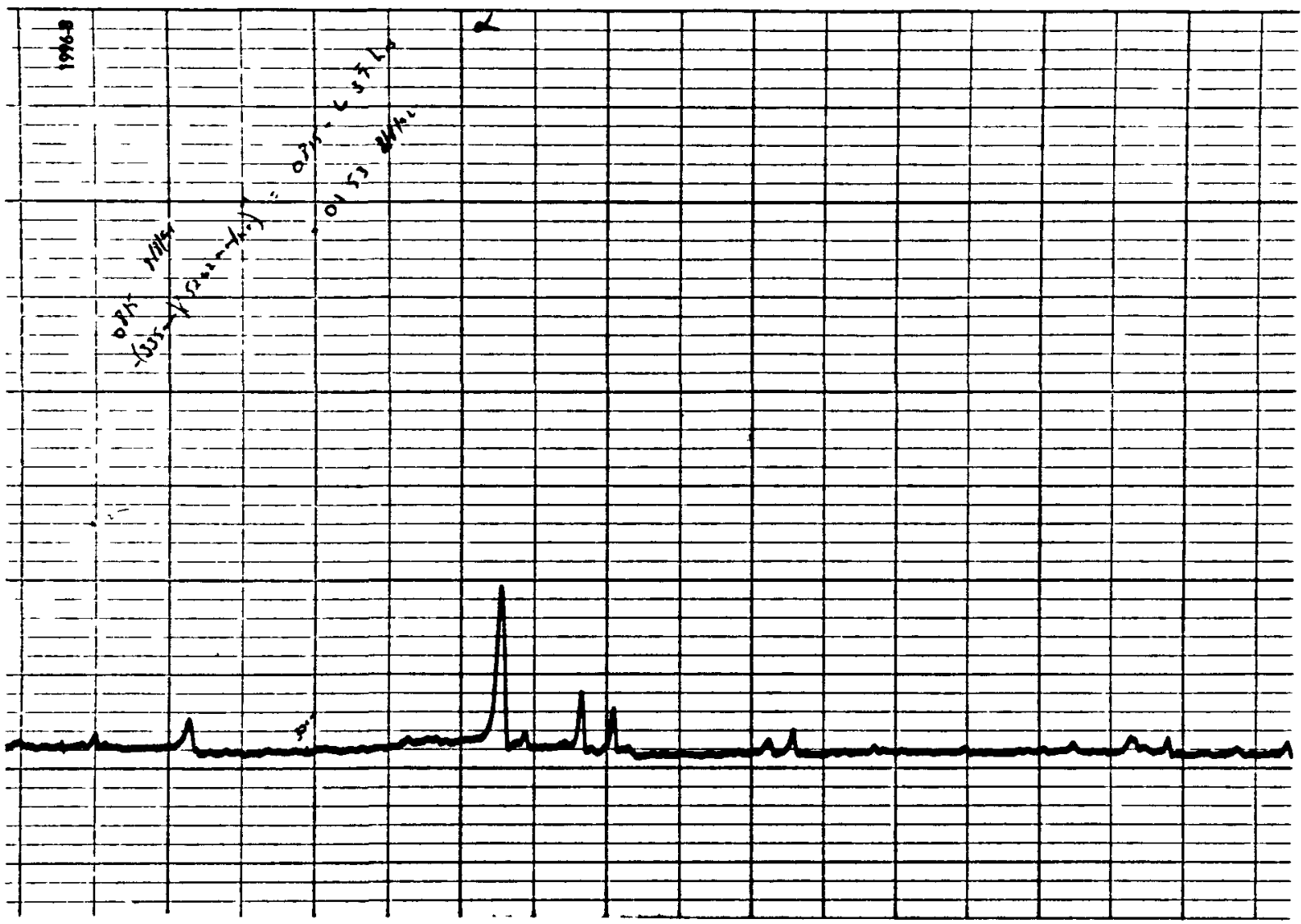

Figure 8-3.

PHOTOGRAPH OF STRIP-CHART RECORDING OF IONIZATION CHAMBER RESPONSE DURING THE SECOND IRRADIATION CYCLE - CAPSULE HRB-21. THE SWEEP GAS He CONCENTRATION WAS ABOUT 658 HELIUM. ON 8/8/91 AT 01:53 hr THE TEST WAS $13.155 \mathrm{~d}$ INTO CYCLE 299. ELAPSED TIME $=48.318 \mathrm{~d}$. FULL-POWER DAYS $=33.681$. 
HRB-21 R/B Values

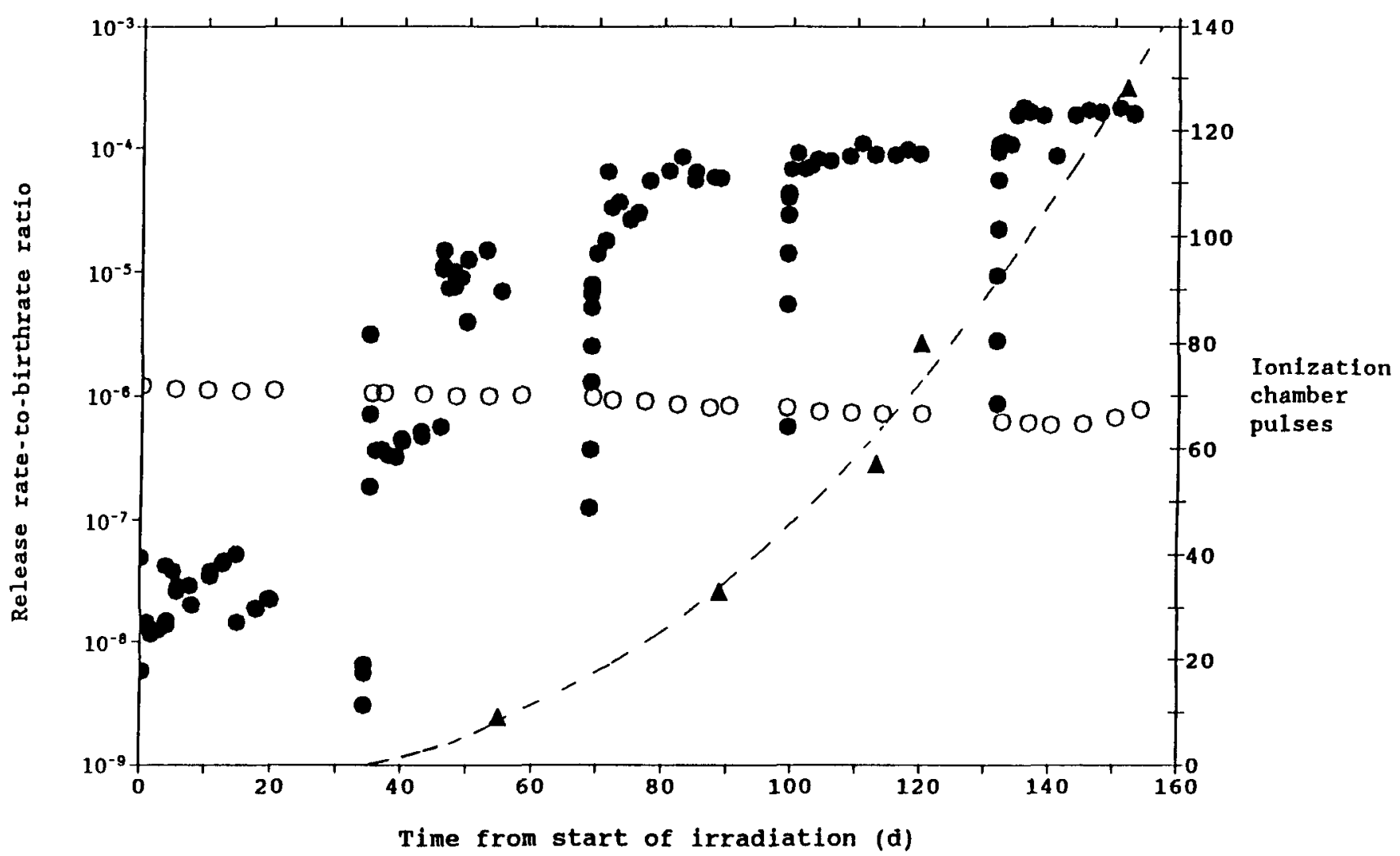

- $\mathrm{Kr}-85 \mathrm{~m}$ (predicted)

$\triangle$ Number of ionization chamber pulses

Figure 8-4.

CUMULATIVE COUNT OF IONIZATION CHAMBER PULSES (FAILED PARTICLES) AND ${ }^{85 m} \mathrm{Kr}$ R/B FOR HRB-21 CAPSULE. 
on interpretation of these results, this test also contained some "piggyback specimens," which included 192 as-fabricated defective (bufferless) particles sealed in $\mathrm{Nb}-1 \mathrm{Zr}$ containers. The failure of these defective particles, combined with the failure of the sealed container, could contribute to the particle failure count. This possibility will be investigated in the postirradiation examination.

\subsection{R/B RATIOS}

Measurements of the fission gas release rates were carried out using the grab sample technique for sampling the sweep gas. ${ }^{10}$ The gas samples were collected in serum bottles at the HFIR. ${ }^{11}$ They were then transported to the Irradiated Fuels Examination Laboratory (IFEL) where they were analyzed for fission gas inventory using a high-efficiency germanium detector gamma spectroscopy system. ${ }^{12}$ Birth rates were calculated using the initial fuel loadings and one group of neutron flux and cross-section data as input to the CACA-2 computer program. ${ }^{4}$ The release rate data for these five cycles are presented in Table 8-1. The calculated $R / B$ ratios for the five irradiation cycles are presented in Table 8-2. R/B plots for Xe-133, Xe-138, $\mathrm{Kr}-85 \mathrm{~m}$, and $\mathrm{Kr}-88$, along with the capsule average fuel temperature, are shown in Figs. $8-5$ and $8-6$.

The reactor startup sequence was modified for this test to minimize particle failures due to rapid increases in power generated per particle. Hold times of 10 to 15 min were instituted at reactor power levels of $10,30,50,70$, and 908 of full power. The sweep gas was sampled for R/B measurements at each of the hold points, and two samples were taken when full power was achieved. Following each startup, two samples per day were taken for the first $5 \mathrm{~d}$ of operation. Then, for the remainder of each cycle, two samples per day were taken $3 \mathrm{~d}$ per week.

The $R / B$ ratios started out very low supporting the low heavy-metal contamination reported for the fuel as well as the low measured preirradiation $^{13}$ values and predictions ${ }^{14}$ for the test. For example, the R/B for one isotope of interest, ${ }^{85} \mathrm{~m} \mathrm{Kr}$;

$$
\begin{array}{ll}
10^{-8} \text { to } 10^{-7} & \text { preirradiation } \\
10^{-7} \text { or } 10^{-6} & \text { predicted (two models) } \\
10^{-8} \text { increasing to } 10^{-4} & \text { during test }
\end{array}
$$


Table 8-1

MEASURED RELEASE RATES FOR KRYPTON AND XENON ISOTOPES FOR THE HRB-21 CAPSULE .

Sweep Gas Concentration (uCi/ml)

Cycle 298

\begin{tabular}{|c|c|c|c|c|c|c|c|c|}
\hline Sample & $\mathrm{Kr}-85 \mathrm{~m}$ & $\mathrm{~K}_{r}-87$ & $k_{r}-88$ & $K r-89$ & $x_{\theta-133}$ & $X_{\theta-135 m}$ & $X_{8}-135$ & $x_{\theta-138}$ \\
\hline НRB21-1 & $0.000 E+00$ & $0.000 E+00$ & $0.000 E+00$ & $0.000 E+00$ & $0.000 E+00$ & $0.000 E+00$ & $0.000 E+00$ & $1.513 E-04$ \\
\hline HRB21-2 & $0.000 E+00$ & $0.000 E+00$ & $0.000 E+00$ & $0.000 E+00$ & $0.000 E+00$ & $0.000 E+00$ & $0.000 E+00$ & 2.867E-04 \\
\hline HRB21-3 & $0.000 E+00$ & $0.000 E+00$ & $0.000 E+00$ & $0.000 E+00$ & $0.000 E+00$ & $0.000 E+00$ & $0.000 E+00$ & 8.366E-04 \\
\hline HRB21-4 & $0.000 E+00$ & $0.000 E+00$ & $1.487 E-04$ & $0.000 E+00$ & $0.000 E+00$ & $0.000 E+00$ & $0.000 E+00$ & $1.343 E-03$ \\
\hline HRB21-5 & 5.875E-04 & 3.591E-04 & 1.663E-04 & $0.000 E+00$ & $0.000 E+00$ & $0.000 E+00$ & $0.000 E+00$ & $1.858 E-03$ \\
\hline HAB21-6 & $0.000 E+00$ & $1.804 E-05$ & $0.000 E+00$ & $0.000 E+00$ & $0.000 E+00$ & $0.000 E+00$ & $0.000 E+00$ & $0.000 E+00$ \\
\hline HAB21-7 & 6.810E-05 & 5.368E-04 & $3.743 E-04$ & $0.000 E+00$ & $0.000 E+00$ & $0.000 E+00$ & $0.000 E+00$ & $1.806 E-03$ \\
\hline HRB21-8 & $1.880 \mathrm{E}-04$ & $7.654 E-04$ & 7.613E-04 & $0.000 E+00$ & $0.000 E+00$ & $3.041 E-04$ & $0.000 E+00$ & $2.864 E-03$ \\
\hline HRB21-9 & $1.721 E-04$ & 9.037E-04 & $7.270 E-04$ & $0.000 E+00$ & $0.000 E+00$ & $3.812 E-04$ & $1.039 E-04$ & $1.740 \mathrm{E}-03$ \\
\hline HAB21-10 & $1.467 E-04$ & $7.712 E-04$ & $7.638 E-04$ & $0.000 E+00$ & $0.000 E+00$ & 5.487E-04 & 8.503E-05 & $2.079 E-03$ \\
\hline HAB21-11 & 1.632E-04 & 8.617E-04 & 5.592E-04 & $0.000 E+00$ & $0.000 E+00$ & 2.923E-04 & $7.054 E-05$ & $1.969 E-03$ \\
\hline HAB21-12 & 1.795E-04 & $9.546 \mathrm{E}-04$ & $6.668 E-04$ & $0.000 E+00$ & $0.000 E+00$ & 1.547E-04 & 8.327E-05 & 1.50 \\
\hline HRB21-13 & 1.827E-04 & $9.014 E-04$ & $8.139 E-04$ & $0.000 E+00$ & $E+00$ & 72E-04 & $E-05$ & -03 \\
\hline HRB21-14 & 1.84 & 8.424E-04 & 6.506E-04 & $0.000 E+00$ & $0.000 E+00$ & $2.116 E-04$ & 1.211E-04 & 1.857E-03 \\
\hline HRB21-15 & $1.730 E-04$ & 8.093E-04 & 7.664E-04 & $0.000 E+00$ & $0.000 E+00$ & 3.467E-04 & $6.080 E-05$ & 58E-03 \\
\hline HRB21-16 & $6.032 E-04$ & 1.919E-03 & $1.970 E-03$ & $0.000 E+00$ & 4.662E-05 & $0.000 E+00$ & 9.609E-05 & 3.373E-03 \\
\hline HRB21-17 & $5.428 \mathrm{E}-04$ & $1.868 E-03$ & $1.889 E-03$ & $0.000 E+00$ & 5.626E-05 & 5.378E-04 & 7.024E-05 & $2.796 \mathrm{E}-03$ \\
\hline HRB21-18 & -04 & $1.564 E-03$ & 1.247E-03 & $0.000 E+00$ & $1.749 E-05$ & $3.924 \mathrm{E}-04$ & $5.083 E-05$ & 9E-03 \\
\hline HRB21-19 & 3.185E-04 & $1.568 E-03$ & $1.205 E-03$ & $0.000 E+00$ & 2.776E-05 & 5.706E-04 & $7.362 E-05$ & $2.568 E-03$ \\
\hline HAB21-20 & -04 & $1.074 E-03$ & 1.192E-03 & $0.000 E+00$ & $3.312 E-05$ & $O E+00$ & -05 & $D O E+00$ \\
\hline HRB21-21 & 3.729E-04 & $1.453 E-03$ & 1.367E-03 & $0.000 E+00$ & $3.944 E-05$ & 7.471E-04 & 7.970E-05 & 2.887E-03 \\
\hline HRB21-22 & 2.645E-04 & 1.315E-03 & 1.007E-03 & $0.000 E+00$ & 2.725E-05 & 2.534E-04 & $1.058 E-04$ & $1.737 E-03$ \\
\hline HAB21-23 & -04 & $E-03$ & $1.929 E-03$ & $0.000 E+00$ & 4.708E-05 & $3 E-04$ & 1.18 & $=-03$ \\
\hline HAB21-24 & $5.919 E-04$ & 2.485E-03 & 2.165E-03 & $0.000 E+00$ & 4.542E-05 & 6.729E-04 & 1.153E-04 & $3.509 E-03$ \\
\hline HRB21-25 & 5.777E-04 & 2.374E-03 & 2.228E-03 & $0.000 E+00$ & 4.107E-05 & $7.229 E-04$ & $1.216 \mathrm{E}-04$ & $2.593 E-03$ \\
\hline HAB21-26 & 6.111E-04 & 2.422E-03 & 2.210E-03 & $0.000 E+00$ & 5.821E-05 & 4.436E-04 & 1.277E-04 & $2.794 E-03$ \\
\hline HAB21-27 & 7.053E-04 & $3.155 E-03$ & 2.815E-03 & $0.000 E+00$ & $7.385 E-05$ & 6.366E-04 & $1.642 \mathrm{E}-04$ & $3.742 E-03$ \\
\hline HAB21-28 & 1.847E-04 & 8.397E-04 & $4.679 E-04$ & $0.000 E+00$ & 1.817E-05 & 7.019E-04 & 1.249E-04 & $2.032 E-04$ \\
\hline HAB21-29 & $3.011 E-04$ & $1.572 E-03$ & $1.409 E-03$ & $3.110 E-03$ & 2.765E-05 & 5.044E-04 & 1.147E-04 & 2.048E-03 \\
\hline HАB21-30 & 3.222E-04 & $1.235 E-03$ & $1.090 E-03$ & $0.000 E+00$ & 2.615E-05 & 4.243E-04 & 8.919E-05 & $1.919 E-03$ \\
\hline HAB21-31 & $2.868 \mathrm{E}-04$ & $1.235 E-03$ & $1.061 E-03$ & $0.000 E+00$ & 2.332E-05 & $5.451 E-04$ & 9.199E-05 & $1.796 \mathrm{E}-03$ \\
\hline HRB21-32 & 2.871E-04 & $1.230 \mathrm{E}-03$ & $1.072 E-03$ & $0.000 \mathrm{E}+00$ & 2.397E-05 & 4.252E-04 & 9.254E-05 & $2.339 \mathrm{E}-03$ \\
\hline
\end{tabular}

Sample taken through hold-up volume 
Table 8-1. CONTINUED.

Sweep Gas Concentration (4Ci/ml)

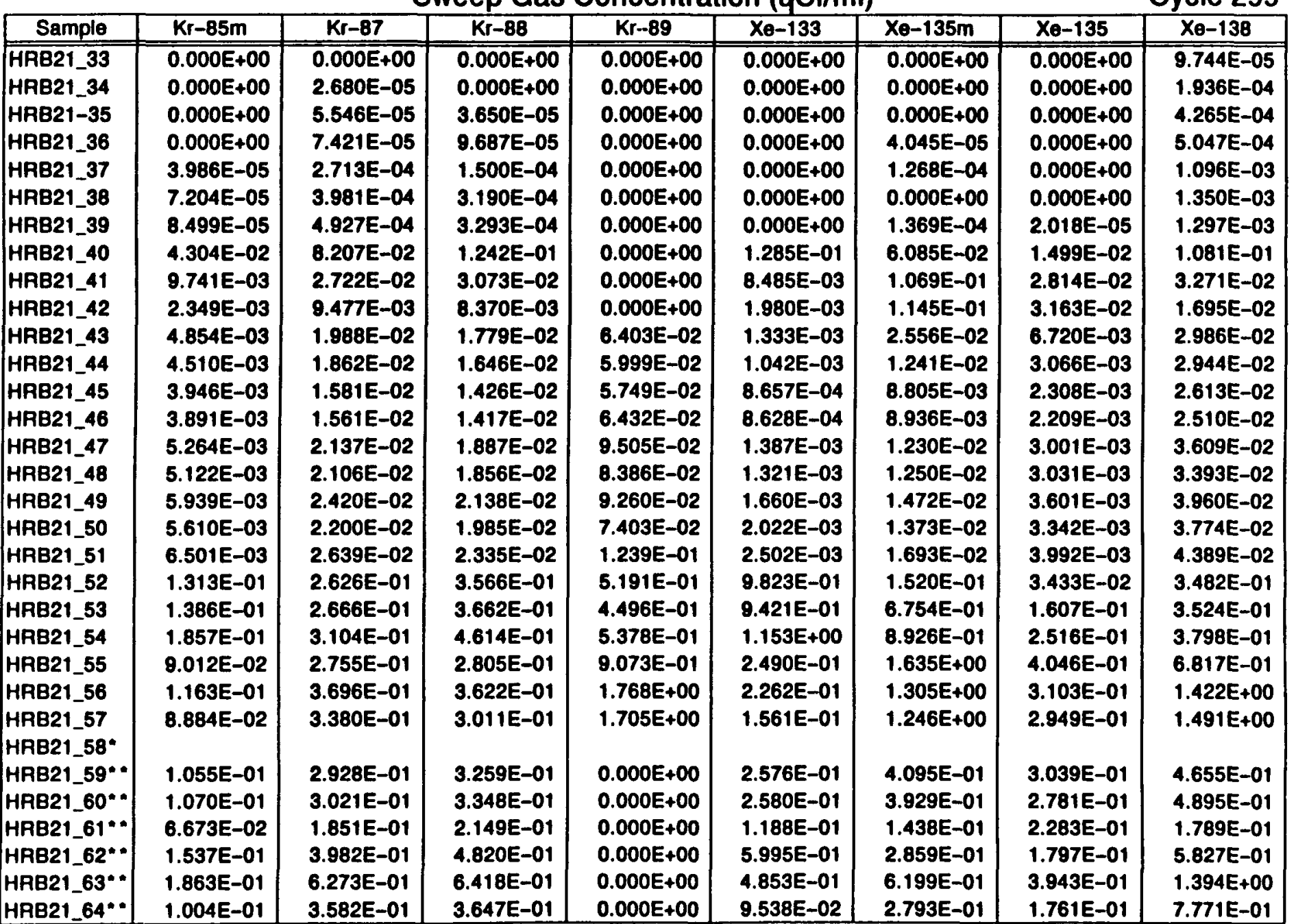

- Sample not analyzed

- Sample taken through "Hold-up" tank 
Table 8-1. CONTINUED.

Sweep Gas Concentration ( $\mathrm{uCi} / \mathrm{ml}$ )

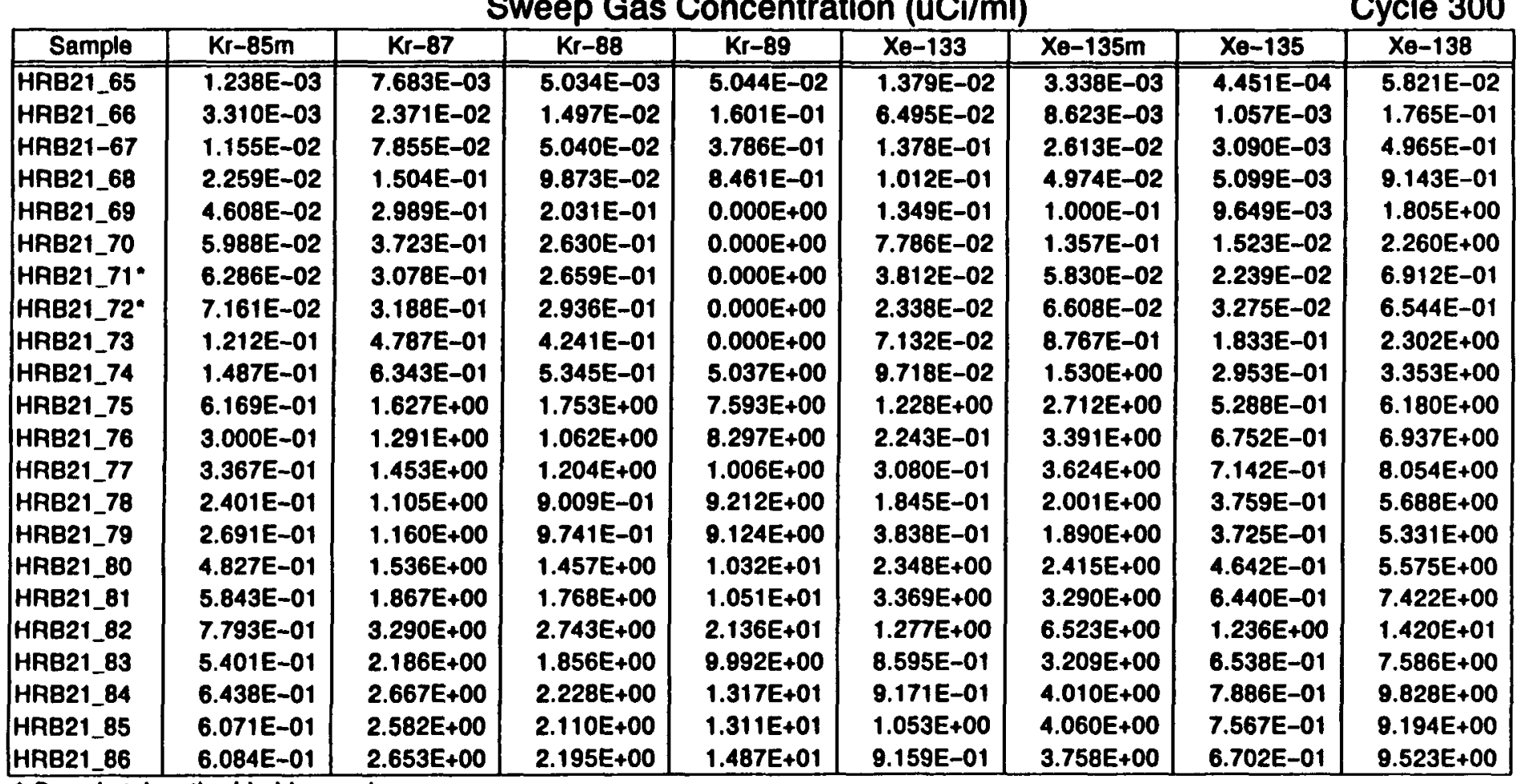

'Sample taken thru' hold-up volume 
Table 8-1. CONTINUED.

Sweep Gas Concentration ( $\mathrm{UCi} / \mathrm{ml})$

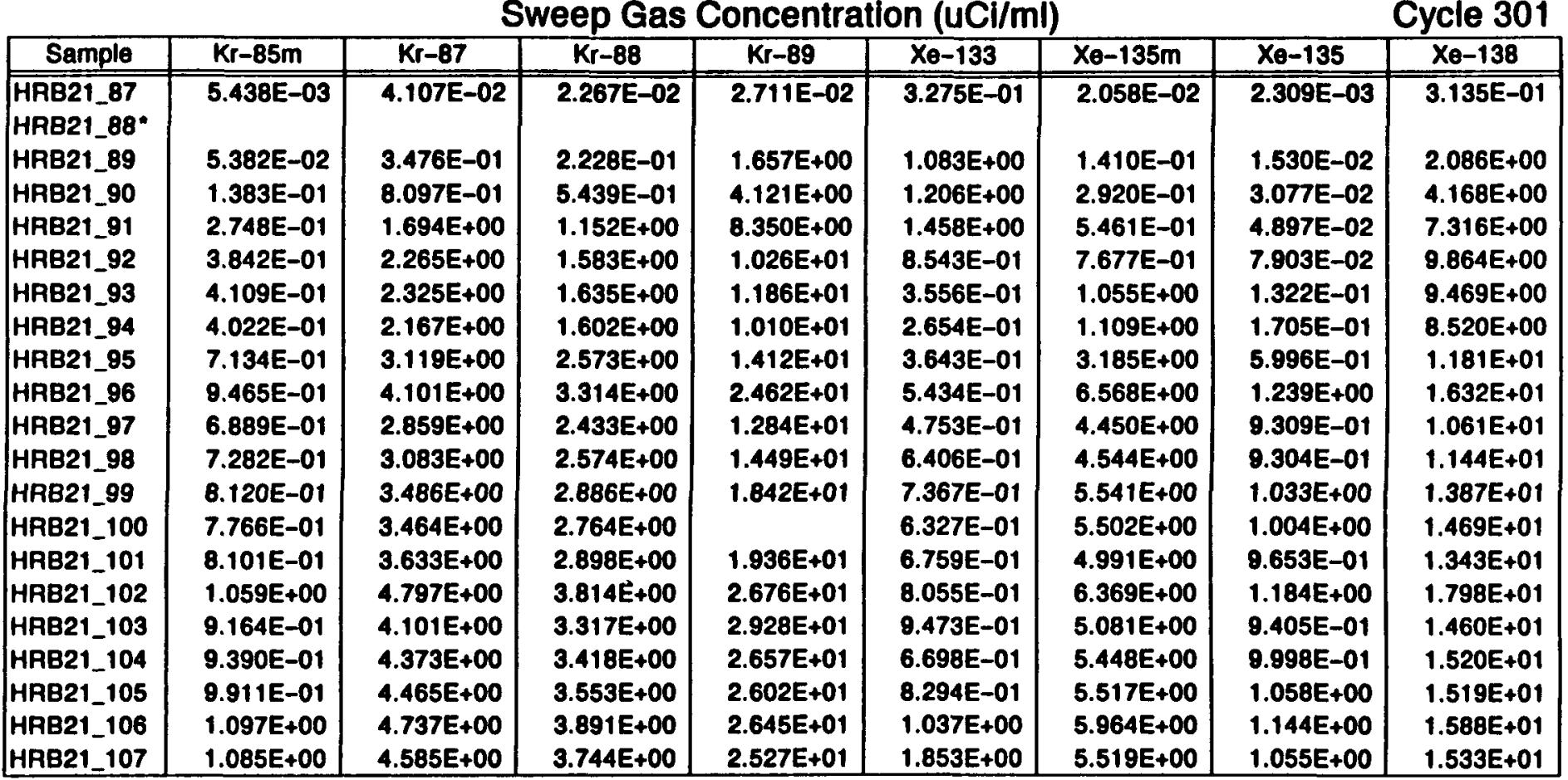

- Corrupted Data

- Counting delay - data lost 
Table 8-1. CONTINUED.

Sweep Gas Concentration (uCi/mI)

\begin{tabular}{|c|c|c|c|c|c|c|c|c|}
\hline Sample & & & & & & & & \\
\hline HRB21-108 & $\mathbf{9 . 5 7}$ & 6.606 & $3.81 t$ & 0.01 & 1.10 & 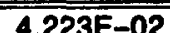 & 3 & \\
\hline HAB21-109 & $3.148 E-02$ & 409E-01 & I.487E-01 & $870 E+00$ & 264E+00 & $1.326 E-01$ & .347E-02 & $.021 E+00$ \\
\hline HRB21-110 & $1.039 E-01$ & 7.188E-01 & 4.467E-01 & $6.383 E+00$ & $1.446 E+00$ & $3.925 E-01$ & 2.648E-02 & $5.267 E+00$ \\
\hline HAB21-111 & 2.443E-01 & $1.593 E+00$ & $1.032 E+00$ & $1.033 E+01$ & $1.092 E+00$ & $7.160 E-01$ & 5.931E-02 & $9.131 E+00$ \\
\hline HRB21-112 & 6.124E-01 & $3.775 E+00$ & $2.528 E+00$ & $2.287 E+01$ & $2.041 E+00$ & $1.531 E+00$ & $1.289 E-01$ & $1.878 E+01$ \\
\hline HRB21-113 & $1.036 E+00$ & 6.147E+00 & $4.213 E+00$ & $3.698 E+01$ & $2.148 E+00$ & $2.534 E+00$ & 2.367E-01 & 2.791E+01 \\
\hline HRB21-116 & $1.239 E+00$ & $5.573 E+00$ & $4.470 E+00$ & - & $3.809 E-01$ & $6.297 E+00$ & $1.150 E+00$ & $2.007 E+01$ \\
\hline HAB21-117 & $1.160 E+00$ & $5.286 E+00$ & $4.153 E+00$ & 2.777E+01 & 4.472E-01 & $6.741 E+00$ & $1.267 E+00$ & $1.821 E+01$ \\
\hline HRB21-118 & $1.938 E+00$ & $8.715 E+00$ & $6.950 E+00$ & $4.552 E+01$ & $1.331 E+00$ & $1.278 E+01$ & $2.474 E+00$ & $2.760 E+01$ \\
\hline HRB21-119 & $2.167 E+00$ & $9.857 E+00$ & 7.677E+00 & $5.425 E+01$ & $1.533 E+00$ & $1.397 E+01$ & $2.683 E+00$ & $3.103 E+01$ \\
\hline HAB21-120 & $2.038 E+00$ & $9.496 E+00$ & $7.291 E+00$ & $5.030 E+01$ & $1.375 E+00$ & $1.377 E+01$ & $2.651 E+00$ & $3.085 E+01$ \\
\hline HAB21-121 & $1.886 E+00$ & 6.901E+00 & $6.778 E+00$ & $5.564 E+01$ & $1.184 E+00$ & $1.185 E+01$ & $2.155 E+00$ & $2.972 E+01$ \\
\hline HRE21-125 & 2.203E+00 & $1.032 E+01$ & $7.929 E+00$ & $6.014 E+01$ & $1.749 E+00$ & $1.177 E+01$ & $2.190 E+00$ & $3.372 E+01$ \\
\hline HAB21-126 & $2.581 E+00$ & $1.171 E+01$ & $9.114 E+00$ & $5.861 E+01$ & 2.507E+00 & $1.458 E+01$ & $2.750 E+00$ & $3.958 E+01$ \\
\hline HRB21-127 & $2.395 E+00$ & $1.089 E+01$ & 8.491E+00 & $6.272 E+01$ & $2.181 E+00$ & $1.352 E+01$ & $2.598 E+00$ & $3.707 E+01$ \\
\hline HAB21-128 & $2.340 E+00$ & $1.082 E+01$ & 8.320E+00 & $6.383 E+01$ & $1.690 \mathrm{E}+00$ & $1.410 E+01$ & $2.549 E+00$ & $3.827 E+01$ \\
\hline
\end{tabular}

finis

- Data lost due to counting delay 
Table 8-2.

R/B VALUES FOR SELECTED ISOTOPES FOR THE HRB-21 CAPSULE.

Cycle 298

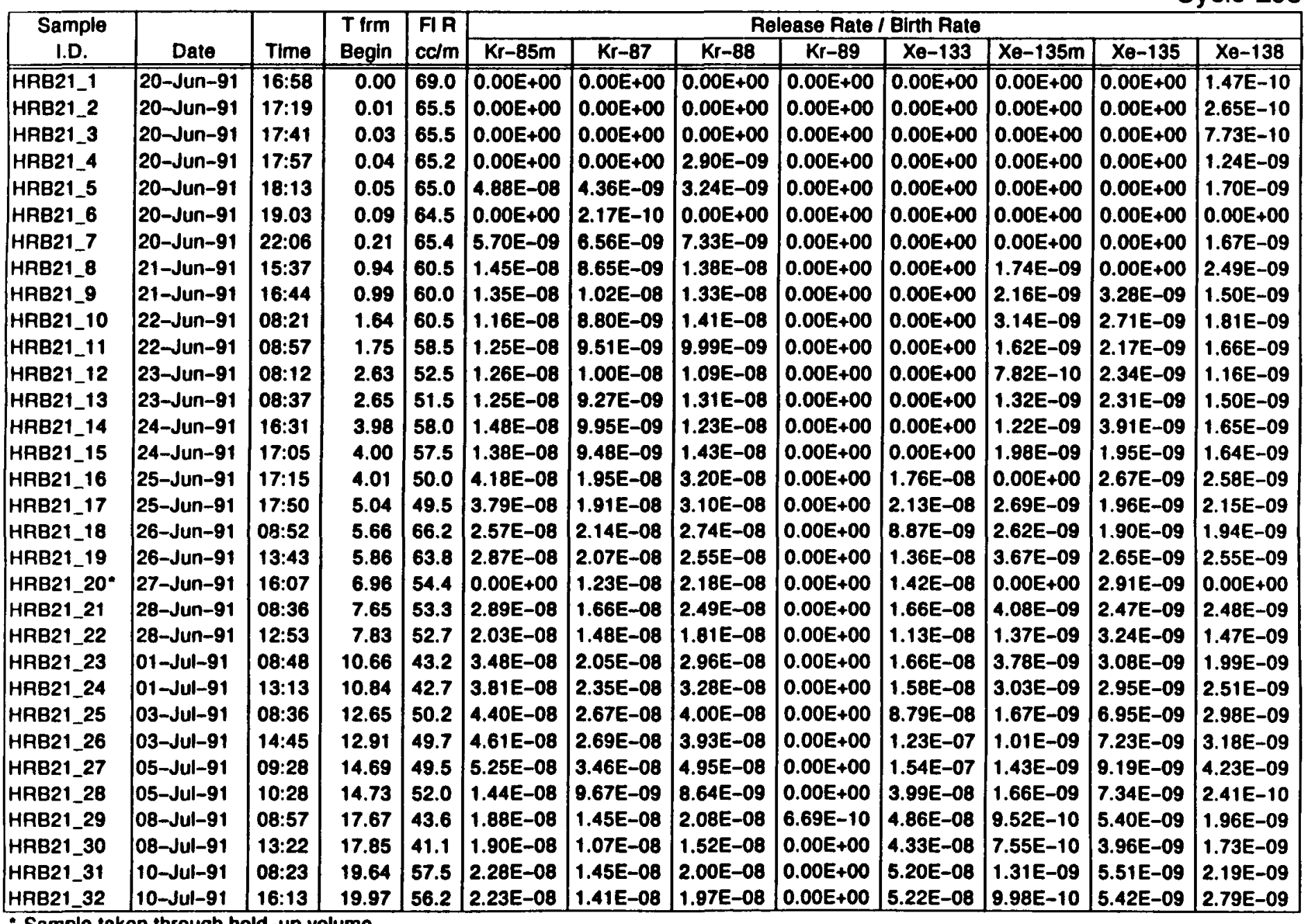

- Sample taken through hold-up volume 
Cycle 299

\begin{tabular}{|c|c|c|c|c|c|c|c|c|c|c|c|c|}
\hline \multirow{2}{*}{$\begin{array}{c}\text { Sample } \\
\text { I.D. }\end{array}$} & \multirow[b]{2}{*}{ Date } & \multirow[b]{2}{*}{ Time } & \multirow{2}{*}{$\begin{array}{l}\text { T irm } \\
\text { Begin } \\
\end{array}$} & \multirow{2}{*}{\begin{tabular}{|l|}
$\mathrm{FIR}$ \\
$\mathrm{cc} / \mathrm{m}$
\end{tabular}} & \multicolumn{8}{|c|}{ Release Rate / Birth Rate } \\
\hline & & & & & $\mathrm{m}$ & 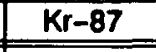 & 88 & $\mathrm{Kr}-89$ & $X_{\theta-133}$ & $x$ & & $=$ \\
\hline 33 & Jul-91 & $20: 57$ & 34.16 & 54.0 & 10 & $\overline{10}$ & & & & & & 11 \\
\hline & & 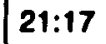 & & 2.0 & & & & & & & & \\
\hline & & 1:36 & & 2.2 & & 6.3 & & & & & 00 & 10 \\
\hline & & & & 52.6 & & & & & & & & \\
\hline & & & & & & & & & & & & \\
\hline & & $: 41$ & & 2.1 & & & & & & & & \\
\hline & & :20 & & 2.2 & & 99 & & & & & & \\
\hline & & 0 & & 0.1 & 3. & & & & & & & \\
\hline & & $: 53$ & & 0.1 & & & & & & & & \\
\hline & & & & .9 & & & & & & & & \\
\hline & & & & & & & & & & & & \\
\hline & & ::19 & & .8 & & & & & & & & \\
\hline & & $: 42$ & 30 & 5.2 & 7 & & & & & & & \\
\hline & & & & .3. & & & & & & & & \\
\hline & & & & & & & & & & & & \\
\hline & & & & & & & & & & & & \\
\hline & & :35 & & .0 & & & & & & & & \\
\hline & & :38 & & .4 & 17 & & & & & & & \\
\hline & & c & & .4 & & & & & & & & \\
\hline & & & & & & & & & & & & \\
\hline & & & & & & & & & & & & \\
\hline & & & & & & & & & & & & \\
\hline & & & & .7 & & & & & & & & \\
\hline & & & & & & & & & & & & \\
\hline & & & & & & & & & & & & \\
\hline & & & & & & & & & & & & \\
\hline 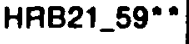 & & & & 5.7 & & & & & & & & -07 \\
\hline גרו & & & & 55.6 & & & & & & & & \\
\hline & & & & & & & & & & & & \\
\hline & & & & & & & & & & & & \\
\hline & & & & 57.8 & & & & & & & & \\
\hline & & & & & & & & & & & & 0.0 \\
\hline
\end{tabular}

- Sample not analyzed

". Sample taken through "Hold-up" tank 
Table 8-2. CONTINUED.

Cycle 300

\begin{tabular}{|c|c|c|c|c|c|c|c|c|c|c|c|c|}
\hline \multirow{2}{*}{$\begin{array}{c}\text { Sample } \\
\text { I.D. }\end{array}$} & \multirow[b]{2}{*}{ Date } & \multirow[b]{2}{*}{ Time } & \multirow{2}{*}{$\begin{array}{l}\text { frm } \\
\text { Begin }\end{array}$} & \multirow{2}{*}{\begin{tabular}{|l|} 
FIR \\
$\mathrm{cc} / \mathrm{m}$
\end{tabular}} & \multicolumn{8}{|c|}{ Release Rate / Birth Rate } \\
\hline & & & & & $\mathrm{Kr}-85 \mathrm{~m}$ & $\mathrm{Kr}-87$ & $\mathrm{Kr}-88$ & $\mathrm{Kr}-89$ & $\mathrm{X}_{\theta-133}$ & $X_{\theta-135 m}$ & $X_{\theta-135}$ & $x_{\theta-138}$ \\
\hline HAB21_65 & 28-Aug-91 & $10: 21$ & 68.72 & 72.4 & $1.24 E-07$ & $1.16 E-07$ & $1.23 E-07$ & 2.03E-08 & $9.02 E-06$ & $2.19 E-08$ & $2.09 E-08$ & $8.28 E-08$ \\
\hline & -91 & $10: 43$ & 68.74 & 79.9 & 3.65E-07 & 3.94E-07 & 4.03E-07 & 7.12E-08 & 4.69E-05 & $6.26 \mathrm{E}-08$ & 5.48E-08 & 2.77E-07 \\
\hline & & 11:03 & 68.75 & 80.9 & 1.29E-06 & 1.32E-06 & 1.37E-06 & 1.71E-07 & 1.01E-04 & 1.92E-07 & 1.62E-07 & 7.89E-07 \\
\hline HRE & & 11:23 & 68.77 & 80.5 & 2.51E-06 & 2.52E-06 & 2.68E-06 & 3.79E-07 & 7.36E-05 & 3.64E-07 & 2.67E-07 & -06 \\
\hline HAB21_69 & ug-91 & $11: 40$ & 68.78 & 80.5 & |5.12E-06 & 5.01E-06 & 5.51E-06 & $0.00 E+00$ & |9.81E-05 & 7.31E-07 & 5.04E-07 & 2.85E-06 \\
\hline HAB21_70 & ug-91 & 12:10 & 68.80 & 80.9 & |6.68E-06 & 6.27E-06 & 7.17E-06 & $0.00 E+00$ & 5.69E-05 & 9.97E-07 & 8.00E-07 & 3.59E-06 \\
\hline HRB21_71* & 28-Aug-91 & 13:38 & 68.86 & 79.9 & |6.93E-06 & 5.12E-06 & 7.16E-06 & $0.00 E+00$ & 2.75E-05 & 4.23E-07 & 1.16E-06 & 1.08E-06 \\
\hline HRB21_72* & 28-Aug-91 & 14:58 & 68.92 & 79.8 & 7.88E-06 & 5.29E-06 & 7.90E-06 & $0.00 E+00$ & 1.69E-05 & 4.79E-07 & 1.70E-06 & 1.03E-06 \\
\hline HRB21_73 & 29-Aug-91 & 09:18 & 69.68 & 83.1 & 1.40E-05 & 8.36E-06 & $1.20 \mathrm{E}-05$ & $0.00 E+00$ & 5.45 & -06 & -05 & 3.82E-06 \\
\hline HRB21_74 & 30-Aug-91 & $10: 23$ & 70.95 & 83.7 & 1.75E-05 & 1.13E-05 & $1.54 E-05$ & 2.41E-06 & 7.5 & -05 & 1.6 & 5.69E-06 \\
\hline HAB21_75 & 30-Aug-91 & $14: 36$ & 71.13 & 72.4 & $6.34 E-05$ & 2.53E-06 & $4.41 E-05$ & 3.18E-06 & 8.3 & -05 & 2.59 & 9.20E-06 \\
\hline HRB21_76 & -Aug-91 & $07: 18$ & 71.83 & 75.1 & 3.20E-05 & 2.08E-06 & 2.77E-05 & $3.60 E-06$ & 1.59 & -05 & -05 & 1.07E-05 \\
\hline HAB21_77 & -Sep-91 & $08: 55$ & 72.89 & 73.7 & 3.56E-05 & 2.32E-05 & 3.12E-05 & 4.33E-07 & 2.17E-04 & 2.54E-05 & 3.59E-05 & 1.23E-05 \\
\hline AB21_78 & -Sep-91 & 09:10 & 74.67 & 74.9 & 2.61E-05 & 1.82E-05 & 2.40E-05 & $4.08 E-06$ & 1.34E-04 & $1.45 E-05$ & 1.95E-05 & 9.00E-06 \\
\hline & Sep-91 & 13:20 & 5.85 & 74.5 & 2.92E-05 & 1.92E-05 & 2.60E-05 & $4.05 E-06$ & 2.79E-04 & $1.36 E-05$ & 1.94E-05 & 8.46E-06 \\
\hline & .91 & $08: 38$ & 77.65 & 75.6 & 5.35E-05 & 2.59E-05 & 3.97E-05 & 4.70E-06 & -03 & 1.78 & 2.47 & -06 \\
\hline & & $08: 51$ & 80.66 & 76.6 & 6.47E-05 & 3.14E-05 & 4.82E-05 & $4.80 \mathrm{E}-06$ & 2.5 & 2.41 & 3.43 & 1.21E-05 \\
\hline _82 & -91 & $08: 27$ & 82.64 & 6.3 & 8.36E-05 & 5.36E-05 & 7.25E-05 & 9.45E-06 & 9.22E-04 & 4.62 & 6.38E-05 & 2.25E-05 \\
\hline 21_83 & -91 & $09: 55$ & 84.70 & 3.7 & 5.39E-05 & 3.30E-05 & 4.56E-05 & 4.11E-06 & 5.76 & 2.1 & 3.13E-05 & 1.12E-05 \\
\hline 21_84 & Sep-91 & 12:33 & 84.81 & 72.8 & $34 E-05$ & 3.98E-05 & -05 & 5.35E-06 & 6.07E-04 & 2.60E-05 & 3.73E-05 & $1.43 E-05$ \\
\hline HRB21_85 & 16-Sep-91 & $08: 49$ & 87.66 & 4.1 & 5.71E-05 & 3.68E-05 & 4.89E-05 & $5.10 E-06$ & 6.65E-04 & 2.51E-05 & 3.41E-05 & $1.28 E-05$ \\
\hline HRB21_86 & 17-Sep-91 & 08:37 & 88.65 & 73.4 & 5.62E-05 & 3.73E-05 & 5.02E-05 & $5.70 \mathrm{E}-06$ & $5.69 \mathrm{E}-04$ & 2.28E-05 & 2.97E-05 & 1.30E-05 \\
\hline
\end{tabular}

- Sample taken thru' hold-up volume 
Table 8-2. CONTINUED.

Cycle 301

\begin{tabular}{|c|c|c|c|c|c|c|c|c|c|c|c|c|}
\hline \multirow{2}{*}{$\begin{array}{c}\text { Sample } \\
\text { I.D. }\end{array}$} & \multirow[b]{2}{*}{ Date } & \multirow[b]{2}{*}{ Time } & \multirow{2}{*}{$\begin{array}{l}\text { T frm } \\
\text { Begin } \\
\end{array}$} & \multirow{2}{*}{\begin{tabular}{|l|}
$\mathrm{FIR}$ \\
$\mathrm{cc} / \mathrm{m}$
\end{tabular}} & \multicolumn{8}{|c|}{ Release Rate / Birth Rate } \\
\hline & & & & & $\mathrm{Kr}-85 \mathrm{~m}$ & $\mathrm{Kr}-87$ & $\mathrm{Kr}-88$ & $\mathrm{Kr}-89$ & $\mathrm{Xe-133}$ & $\mathrm{Xe-135m}$ & $x_{e-135}$ & $X e-138$ \\
\hline AB21_87 & ep-91 & $19: 10$ & 99.09 & 77.4 & 5.54E-07 & $6.41 E-07$ & $5.87 E-07$ & $1.19 E-08$ & $2.36 \mathrm{E}-04$ & $1.40 \mathrm{E}-07$ & $1.18 E-07$ & $\overline{5.07 E-07}$ \\
\hline 38* & & 19:34 & 9.11 & 78.1 & & & & & & & & \\
\hline RB21_89 & 27-Sep-91 & $20: 30$ & 99.15 & 77.4 & 5.48E-06 & 66 & 66 & 07 & 18 & -07 & 77 & 06 \\
\hline 1 _90 & 27-Sep-91 & $0: 54$ & 99.16 & 77.6 & 1.41E-05 & 1.27E-05 & 1.41E-05 & 1.81E-06 & 8.73E-04 & $1.99 E-06$ & 1.58E-06 & -06 \\
\hline & & $1: 15$ & 9.18 & 77.5 & $2.80 E-05$ & 2.65E-05 & 2.98E-05 & 3.66E-06 & $1.05 E-03$ & 3.72E-06 & -06 & -05 \\
\hline RE & & 2 & & 77.4 & -05 & -05 & 4.10E-05 & 4.49E-06 & & -06 & -06 & \\
\hline $\mathrm{GB}$ & & $: 51$ & 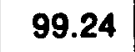 & 77.8 & 05 & & & & & -06 & -06 & \\
\hline 4 & & 0:06 & 30 & 77.4 & & & & 42E-06 & & -06 & -06 & \\
\hline 15 & & 56 & 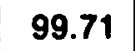 & 70.6 & 05 & & & & & -05 & -05 & \\
\hline & & 08:28 & .64 & 71.9 & & & & & & -05 & & \\
\hline & & 08:48 & & 72.5 & & & & & & & & \\
\hline & & 08:03 & & 71.5 & 7.0 & & & & & -05 & -05 & -05 \\
\hline & & 08:31 & & 72.9 & 8.0 & & & 91E-06 & & .05 & -05 & -05 \\
\hline 100 & & $08: 23$ & & 72.9 & 7.8 & & & $* *$ & & -05 & -05 & -05 \\
\hline HRB2 & -91 & $09: 36$ & 88.69 & 75.8 & 8.55 & 5.8 & 7.80E-05 & $6 E-06$ & .04 & -05 & -05 & -05 \\
\hline RB21_102 & $c t-91$ & $08: 29$ & .65 & 73.9 & 1.08 & 7.52 & 9.93E-05 & -05 & -04 & 4.37E-06 & -05 & $.98 E-05$ \\
\hline RB21_103 & $c t-91$ & $08: 33$ & 112.65 & 70.5 & 8.74E-05 & 6.01E-05 & 8.08E-05 & 1.22E-05 & 6.52 & 3.26E-05 & -05 & $.26 E-05$ \\
\hline AB21_104 & $c t-91$ & $10: 41$ & 112.74 & 69.9 & $8.88 E-05$ & 6.35E-05 & 8.26E-05 & 1.09E-05 & 4.57 & -05 & 4.83E-05 & $.34 E-05$ \\
\hline 105 & $t-91$ & $10: 40$ & 115.74 & 69.5 & 8.82E-05 & $6.11 E-05$ & 8.08E-05 & 1.01E-05 & 5.32 & -05 & -05 & $.19 E-05$ \\
\hline $\mathrm{AB} 2$ & & 08:29 & & 71.5 & $9.70 \mathrm{E}-05$ & 6.42 & 8.76 & 1.02 & & 3.5 & -05 & 2.25E-05 \\
\hline HAB21_107 & $18-$ Oct-91 & 08:28 & 19.64 & 69.9 & $.99 E-05$ & $5.83 E-05$ & 7.91E-05 & 9.09E-06 & 1.05 & -05 & 4.42E-05 & 2.04E-05 \\
\hline
\end{tabular}

- Corrupted Data

- Counting delay - data lost 
Table 8-2. CONTINUED.

Cycle 302

\begin{tabular}{|c|c|c|c|c|c|c|c|c|c|c|c|c|}
\hline \multirow{2}{*}{$\begin{array}{c}\text { Sample } \\
\text { I.D. }\end{array}$} & \multirow[b]{2}{*}{ Date } & \multirow[b]{2}{*}{ Time } & \multirow{2}{*}{$\begin{array}{l}T \text { frm } \\
\text { Begin }\end{array}$} & \multirow{2}{*}{$\begin{array}{l}\text { FIR } \\
\mathrm{cc} / \mathrm{m}\end{array}$} & \multicolumn{8}{|c|}{ Release Rate / Birth Rate } \\
\hline & & & & & $\mathrm{Kr}-85 \mathrm{~m}$ & $\mathrm{Kr}-87$ & $\mathrm{Kr}-88$ & $\mathrm{Kr}-89$ & $\mathrm{Xe}_{e-133}$ & $\mathrm{X}_{\theta-135 m}$ & $X_{e-135}$ & $X_{e-138}$ \\
\hline HRB21-108 & $0-0 c t-91$ & $10: 25$ & 131.73 & 72.2 & $8.55 E-07$ & $9.04 E-07$ & $8.58 E-07$ & $0.00 E+00$ & $7.45 E-05$ & $2.56 \mathrm{E}-07$ & $1.78 \mathrm{E}-07$ & $8.38 E-07$ \\
\hline HRB21-109 & $30-$ Oct-91 & $10: 41$ & 131.74 & 71.5 & 2.78E-06 & 3.27E-06 & 3.31E-06 & 7.35E-07 & 8.41E-04 & 7.97E-07 & 6.32E-07 & 3.09E-06 \\
\hline HRB21-110 & $30-$ Oct-91 & $11: 07$ & 131.75 & 72.1 & 9.27E-06 & 9.83E-06 & $1.00 \mathrm{E}-05$ & 2.53E-06 & $9.70 E-04$ & 2.38E-06 & $1.25 E-06$ & 8.11E-06 \\
\hline HRB21-111 & $30-O c t-91$ & 11:29 & 131.77 & 71.8 & 2.17E-05 & 2.17E-05 & $2.31 E-05$ & 4.08E-06 & 7.30E-04 & 4.32E-06 & 2.80E-06 & $1.40 E-05$ \\
\hline HAB21-112 & $30-O c t-91$ & 11:54 & 131.79 & 71.8 & 5.44E-05 & $5.14 E-05$ & 5.65E-05 & 9.02E-06 & $1.36 E-03$ & 9.24E-06 & 6.08E-06 & 2.88E-05 \\
\hline RB21-113 & $30-O c t-91$ & $12: 20$ & 131.81 & 71.9 & 9.21E-05 & 8.38E-05 & 9.43E-05 & $1.46 E-05$ & 1.44 & 1.53 & 1.12 & 4.29E-05 \\
\hline HRB21-114 & $30-O c t-91$ & 13:55 & 131.87 & 71.4 & 1.01E-04 & 8.50E-05 & 1.01E-04 & 1.49 & & 1.94 & -05 & 3.80 \\
\hline-115 & -Oct-91 & $15: 37$ & 131.94 & 71.2 & 1.07E-04 & 8.53E-05 & 1.03E-04 & 1E-05 & 4.69E-04 & 2.26E-05 & 2.60E-05 & 3.56E-05 \\
\hline 116 & $-O c t-91$ & $08: 42$ & 132.65 & 72.5 & $1.12 E-04$ & 7.77E-05 & 1.02E-04 & & 2.61E-04 & 3.89E-05 & 5.55E-05 & 3.14E-05 \\
\hline 17 & ov-91 & 09:08 & 67 & 3.1 & 1.07E-04 & 7.50E-05 & 9.65 & .05 & -04 & 4.24E-05 & $=-05$ & 2.92E-05 \\
\hline 18 & ov-91 & $08: 13$ & 134.63 & 4.6 & 1.84E-04 & 1.27E-04 & $1.66 \mathrm{E}-04$ & 1.92E-05 & -04 & 8.30E-05 & $1.26 E-04$ & 4.55E-05 \\
\hline 19 & 3-Nov-91 & 09:07 & 135.67 & 75.9 & 2.11E-04 & 1.47E-04 & 1.88E-04 & 2.35E-05 & -03 & 9.30E-05 & 1.40E-04 & 5.25E-05 \\
\hline & 4-Nov & 09:20 & & 73.6 & 1.94 & 1.38 & 1.74 & .05 & -04 & -05 & -04 & -05 \\
\hline 21 & 6-Nov-91 & 09:22 & 138.68 & 73.4 & .04 & -04 & $1.63 E$ & 05 & .04 & 7.7 & -04 & -05 \\
\hline HRB21-122 & 8-Nov-91 & $11: 32$ & 140.77 & 71.6 & 8.55E-05 & 5.98E-05 & 7.67E-05 & 8.90E-06 & $4.26 \mathrm{E}-04$ & 3.19 & -05 & -05 \\
\hline HRB21-123 & 11-Nov-91 & $11: 42$ & 143.78 & 71.4 & 1.82E-04 & $1.33 E-04$ & $1.66 \mathrm{E}-04$ & $2.28 \mathrm{E}-05$ & $9.53 E-04$ & $7.23 E-05$ & 1.02E-04 & 5.17E-05 \\
\hline HRB21-124 & -Nov-91 & $11: 35$ & 145.77 & 71.4 & $1.99 E-04$ & $1.44 E-04$ & 1.79E-04 & 2.49E-05 & $1.04 E-03$ & 7.82E-05 & 1.09E-04 & 5.62E-05 \\
\hline HRB21-125 & 15-Nov-91 & $10: 13$ & 147.72 & 71.8 & 1.94E-04 & 1.39E-04 & 1.75E-04 & 2.35E-05 & $1.15 E-03$ & 6.99E-05 & 1.02E-04 & $5.10 E-05$ \\
\hline HRB21-126 & $18-N o v-91$ & 10:14 & 150.72 & 70.2 & 2.10E-04 & 1.46E-04 & 1.86E-04 & 2.11E-05 & 1.52E-03 & 7.99E-05 & $1.18 E-04$ & $5.50 E-05$ \\
\hline HRB21-127 & 20-Nov-91 & $11: 00$ & 152.75 & 71.1 & $1.89 E-04$ & $1.31 E-04$ & $1.68 \mathrm{E}-04$ & $2.19 E-05$ & $1.28 E-03$ & 7.17E-05 & $1.07 E-04$ & $4.96 E-05$ \\
\hline HRB21-128 & 20-Nov-91 & $15: 40$ & 152.94 & 71.4 & $1.86 \mathrm{E}-04$ & 1.31E-04 & 1.65E-04 & 2.24E-05 & 9.93E-04 & 7.51E-05 & 1.06E-04 & 5.14E-05 \\
\hline
\end{tabular}

- Data lost due to counting delay 
ORNL-DWG $92-16007$
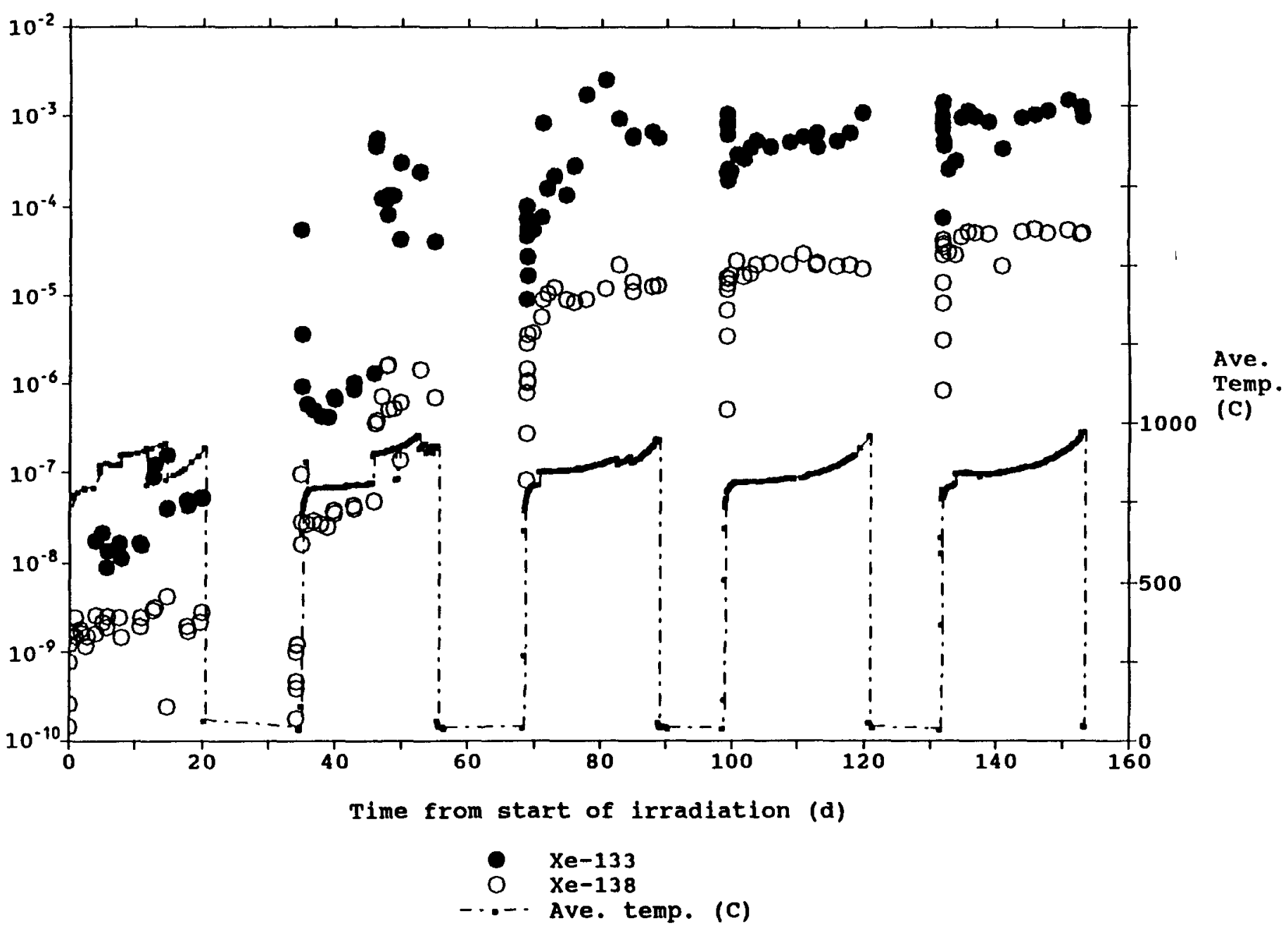

Figure $8-5$.

R/B VALUES FOR Xe-133 AND Xe-138 AND THE CAPSULE AVERAGE FUEL TEMPERATURE AS A FUNCTION OF TIME FROM THE START OF THE IRRADIATION. 
ORNL-DWG 92-16008

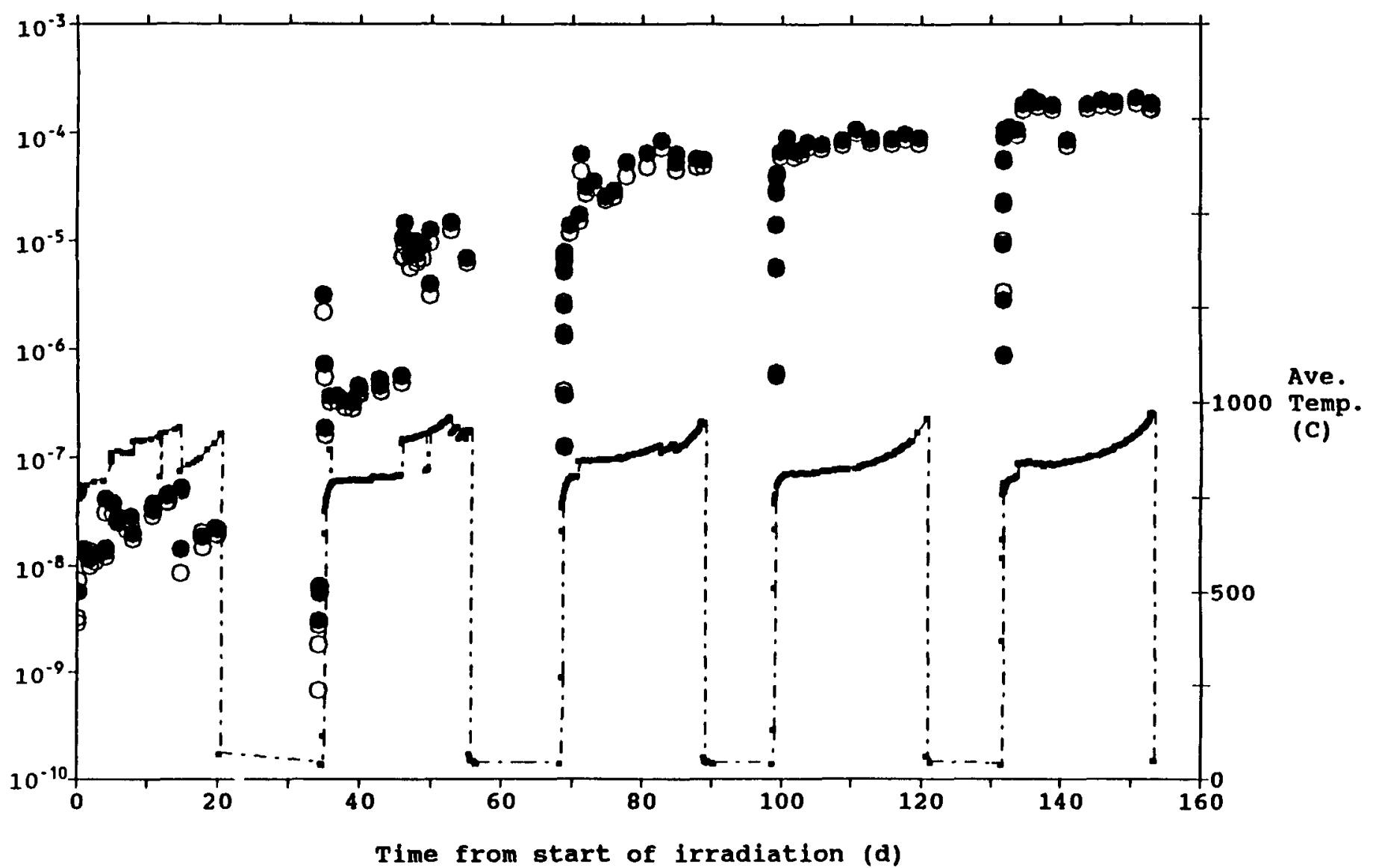

\begin{tabular}{ll}
0 & $\mathrm{Kr}-85 \mathrm{~m}$ \\
$\mathrm{O}$ & $\mathrm{Kr}-88$ \\
\hline & Ave.
\end{tabular}

Figure 8-6.

R/B VALUES FOR ${ }^{85} \mathrm{mr}$ AND ${ }^{88} \mathrm{Kr}$ AND THE CAPSULE AVERAGE FUEL TEMPERATURE AS A FUNCTION OF TIME FROM THE START OF THE IRRADIATION. 
The $R / B$ ratios remained low during the first cycle but rose rapidly at the beginning of cycle 299 and then increased steadily during the remaining irradiation consistent with the indications of particle failures as shown in Fig. $8-4$. 
SECTION 9

CONCLUSIONS

The HRB-2l experiment operated successfully in the HFIR reactor for five cycles. The mean average volumetric temperature for the fuel appears to have been very close to the desired $975^{\circ} \mathrm{C}$. The calculated maximum fuel compact temperature exceeded the specified $1250^{\circ} \mathrm{C}$ limit in compacts in zones 3 and 4 during the fifth cycle (cycle 302). It was anticipated that greater maximum temperatures could be reached during the planned sixth cycle; therefore, the capsule was removed after the fifth cycle. Even so, fluence and burnup levels of 70 and 878 of the desired peaks were achieved. The temperature, sweep gas radiation level, and R/B sampling systems functioned properly throughout the test. 
A large number of people have contributed to the HRB-21 irradiation test. In particular, the authors acknowledge those responsible for the design, assembly, and operation of the test: Ken Thoms, Luther Pugh, Earl Clemmer, Dennis Heatherly, John Wolfe, Joe Wright, J M Robbins, Bruce Patton, Ilana Simon-Tov, and Mike Kania. Randy Hobbs provided invaluable interfacing with the Research Reactors Division. The authors also thank Donna Balltrip for final report preparation, Kathy Spence for editing, and Glenda Carter for quality assurance review. This research was supported in part by an appointment to the U.S. Department of Energy Cooperative Postgraduate Training Program administered by Oak Ridge Associated Universities. 
SECTION 11

LIST OF REFERENCES

1. I. M. Tang, HRB-21 Test Specification, DOE-HTGR-88331, Rev. D, December 1991.

2. G. L. Copeland, Operating Guideline for In-Reactor Operation of HTGR Capsule HRB-21, M\&C Quality Assurance Document MET-FMT-0G-001, Martin Marietta Energy Systems, Inc., Oak Ridge Natl. Lab., June 1991.

3. Gas-Cooled Reactor Programs: High-Temperature Gas-Cooled Reactor Technology Development Program. Annual Progress Report for Period Ending December 31, 1981, ORNL-5871, Union Carbide Corp. Nuclear Div., Oak Ridge Nat1. Lab., December 1981.

4. E. J. Allen, CACA-2: Revised Version of CACA-A Heavy Isotope and Fission Product Concentration Calculational Code for Experimental Irradiation Capsules, ORNL/TM-5266, Union Carbide Corp. Nuclear Div., Oak Ridge Natl. Lab., February 1976.

5. K. W. Childs, HEATING 7.0 User's Manual, K/CSD/INF/90-32, Martin Marietta Energy Systems, Inc., Oak Ridge Gaseous Diffusion Plant, July 1990.

6. Graphite Design Handbook, DOE-HTGR-88111, Rev.0, General Atomics, San Diego, September 1988.

7. Fuel Design Data Manual (Issue F 1987) supplied by General Atomics, San Diego.

8. G. L. Be11, Calculation of the Maximum Fuel Compact Temperature and an Uncertainty Analysis Technique for the New Production Reactor Test Capsules, ORNL/M-1974, Martin Marietta Energy Systems, Inc., Oak Ridge Nat1. Lab., to be published.

9. J. W. Ketterer and B. F. Myers, Capsules HRB 17/18 Final PIE Report, DOE-HTGR-86-083, Rev. 1, May 1987.

10. N. H. Packan, et al., Operating Plan for Capsule HRB-21 Irradiation, DOE-HTGR-88370, ORNL/TM-11403, Martin Marietta Energy Systems, Inc., Oak Ridge Natl. Lab., December 1989.

11. E. D. Clemmer, Sweep Gas Sampling, ORNL Engineering Technology Division Procedure ETD-IE-SOP-005, Martin Marietta Energy Systems, Inc., Oak Ridge Nat1. Lab., December 1988.

12. L. C. Emerson, HFIR Sweep Gas Counting and Analysis, M\&C Quality Assurance Document MET-FMT-OG-002, Martin Marietta Energy Systems, Inc., Oak Ridge Nat1. Lab., June 1991. 
13. Capsule HRB-21 Pre-Irradiation Report, DOE-HTGR-88357, Rev. C, General Atomics, San Diego, April 1991.

14. Unpublished data of F. E. Hooks and M. B. Richards, General Atomics, transmitted in letter from G. C. Bramblett (Georgia) to M. J. Kania (Oak Ridge Natl. Lab.), "Pre-test Prediction for HRB-21 Capsule," GA/ORNL-014-91, July 10, 1991. 
APPENDIX A

MAPPING THERMOCOUPLE DATA TO FUEL COMPACT TEMPERATURE

\begin{abstract}
[Note: This program estimates the volumetric average fuel temperature based on the thermocouple readings (in the graphite) and the accumulated fast fluence effects in the graphite and the fuel compacts.]
\end{abstract}



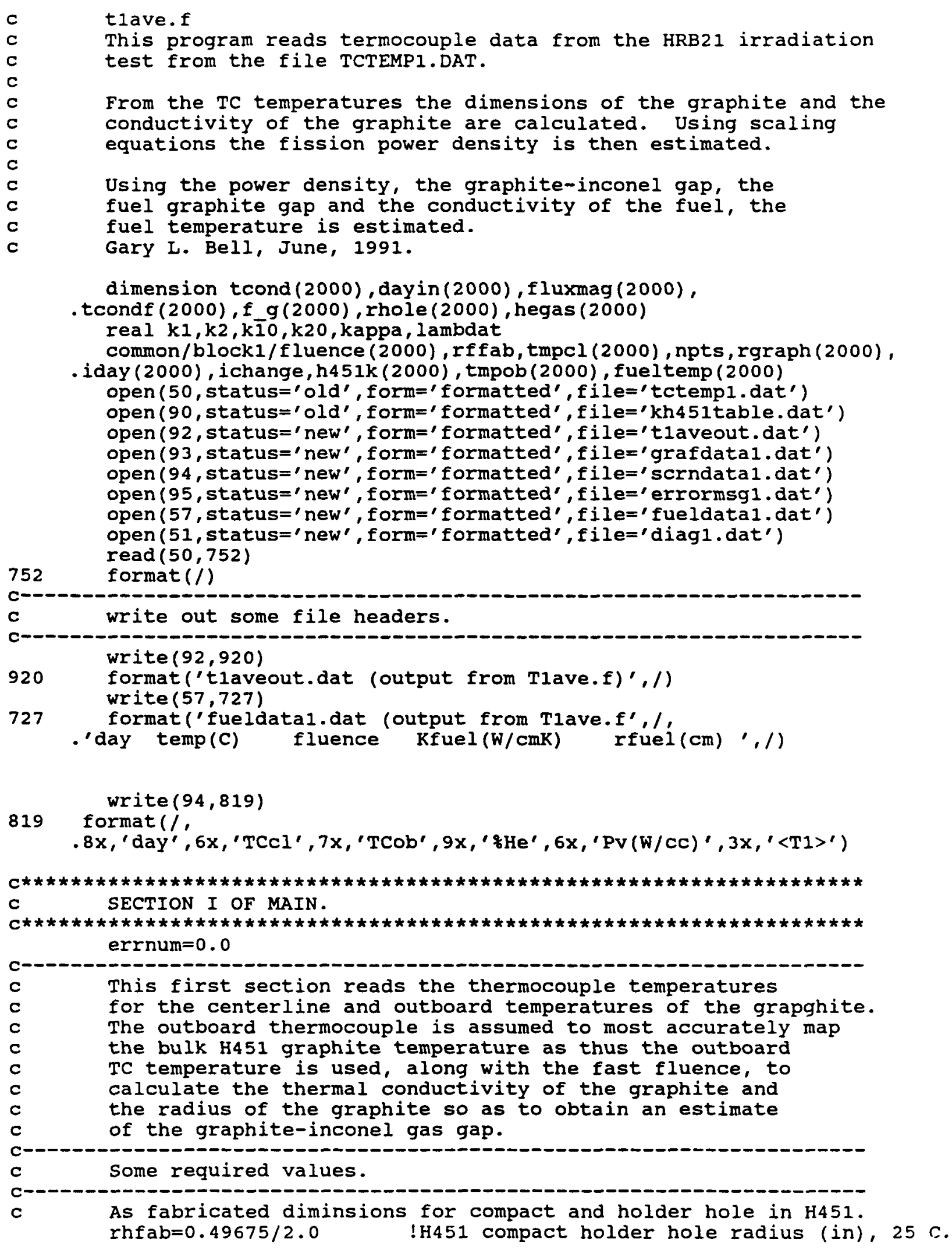


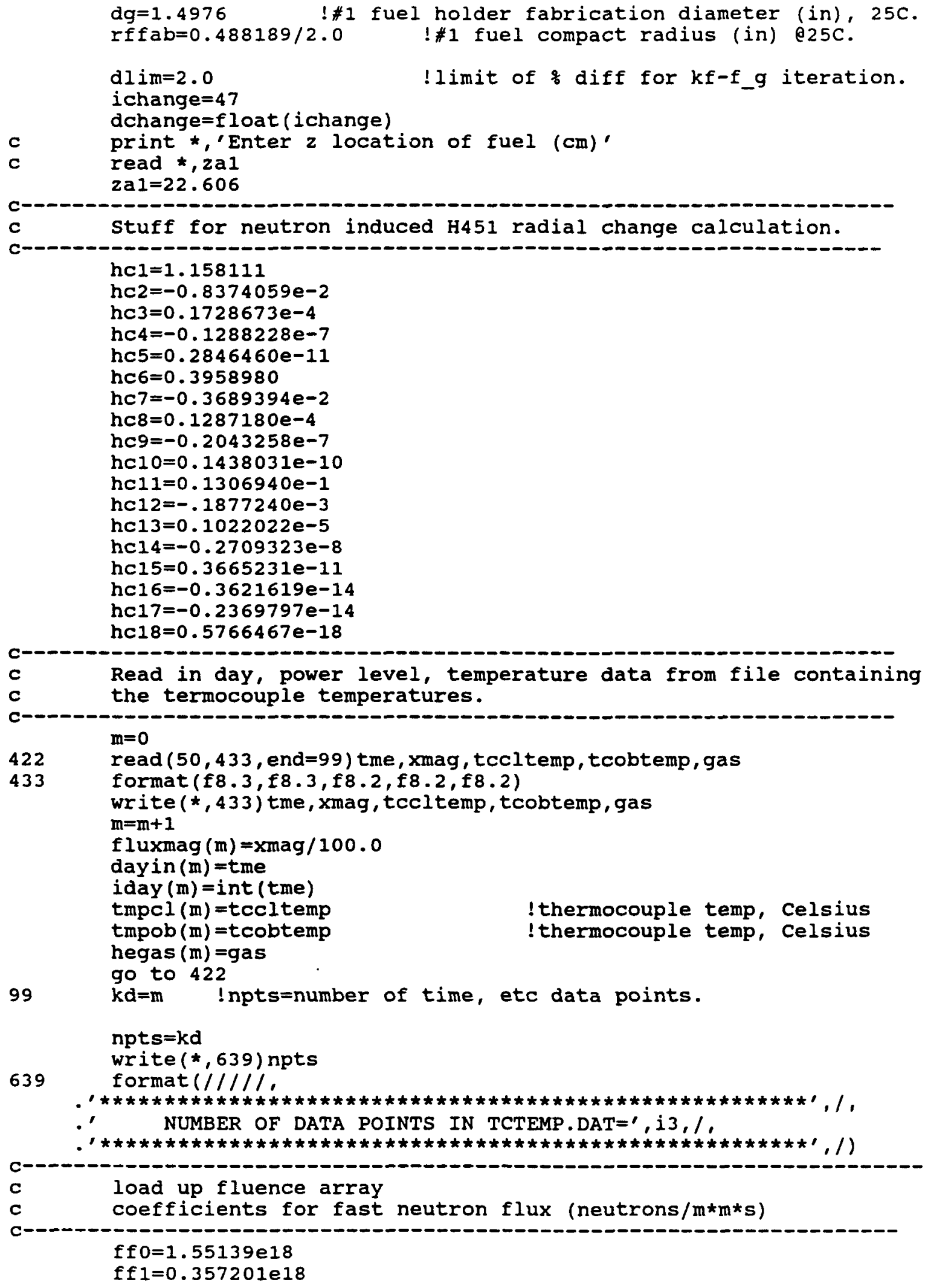




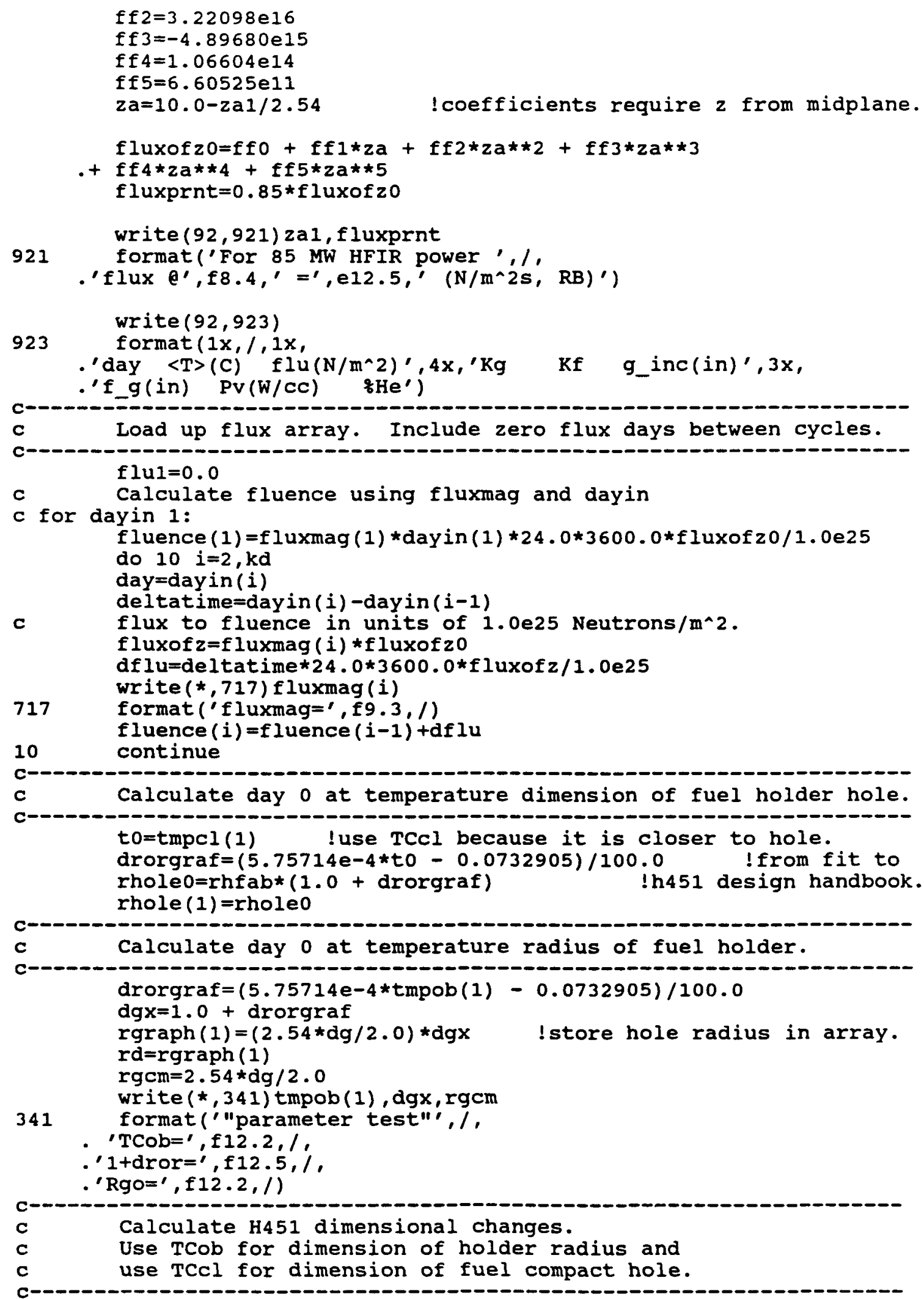




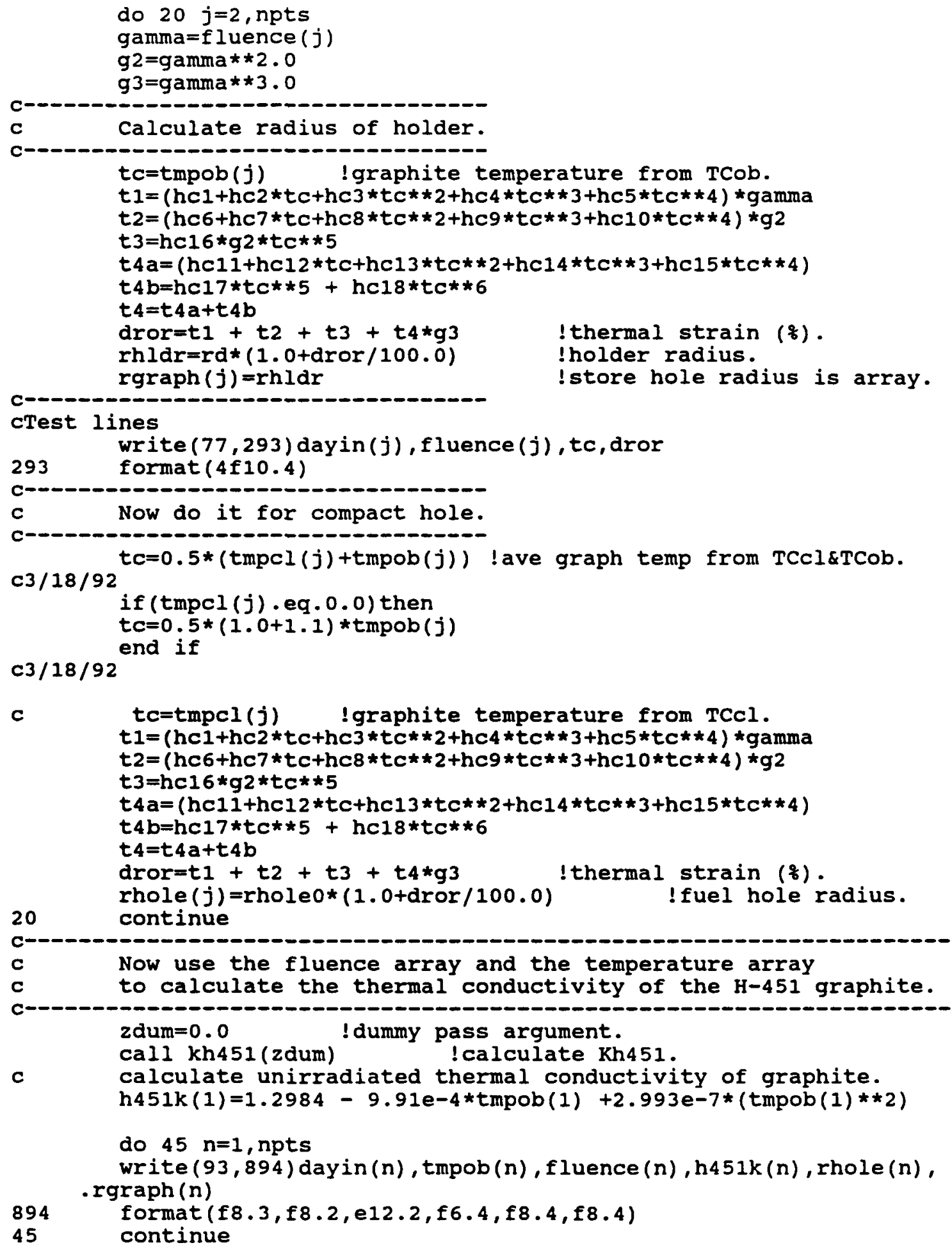




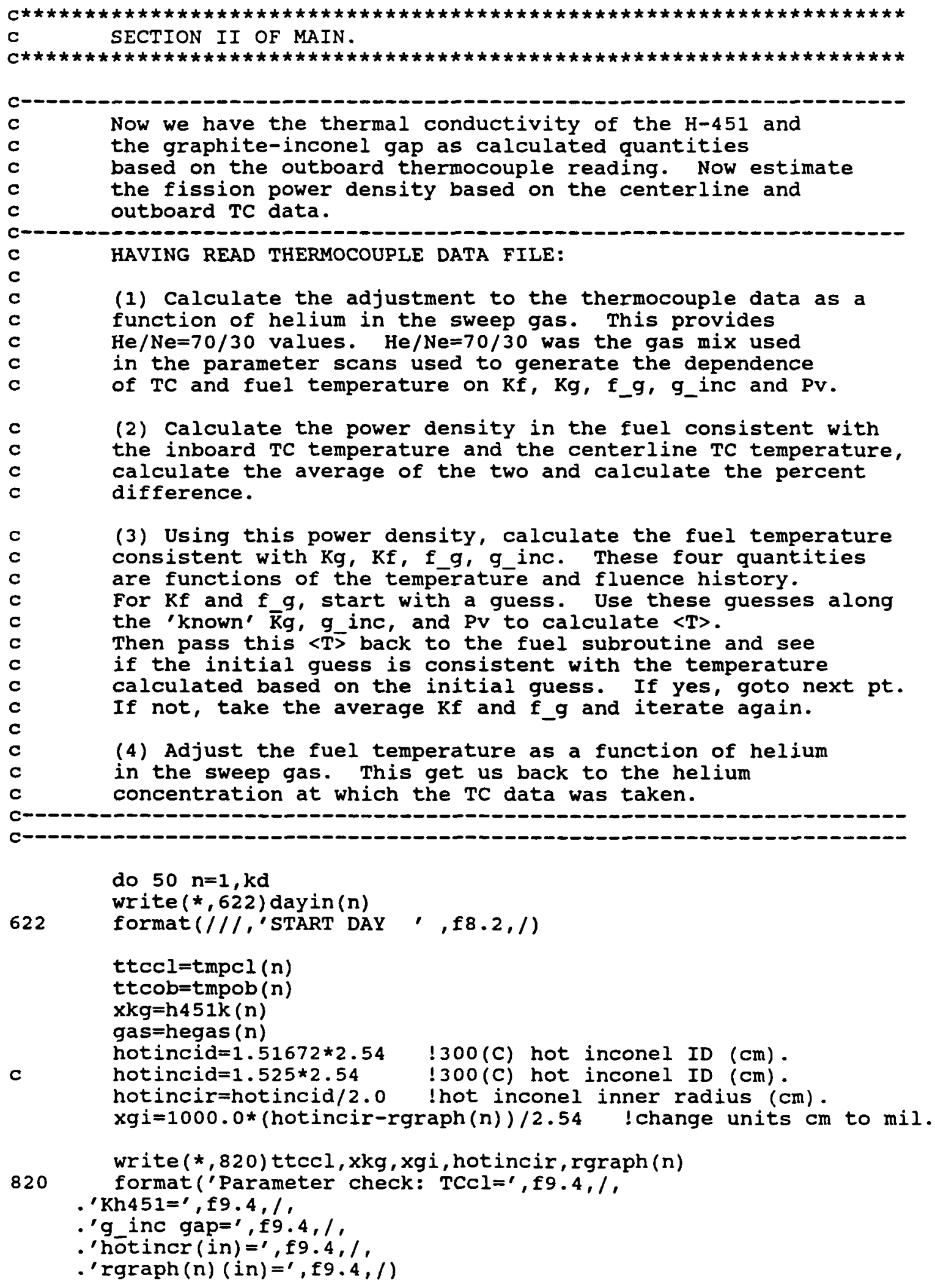

DOE-HTGR-90322, Rev. 0 


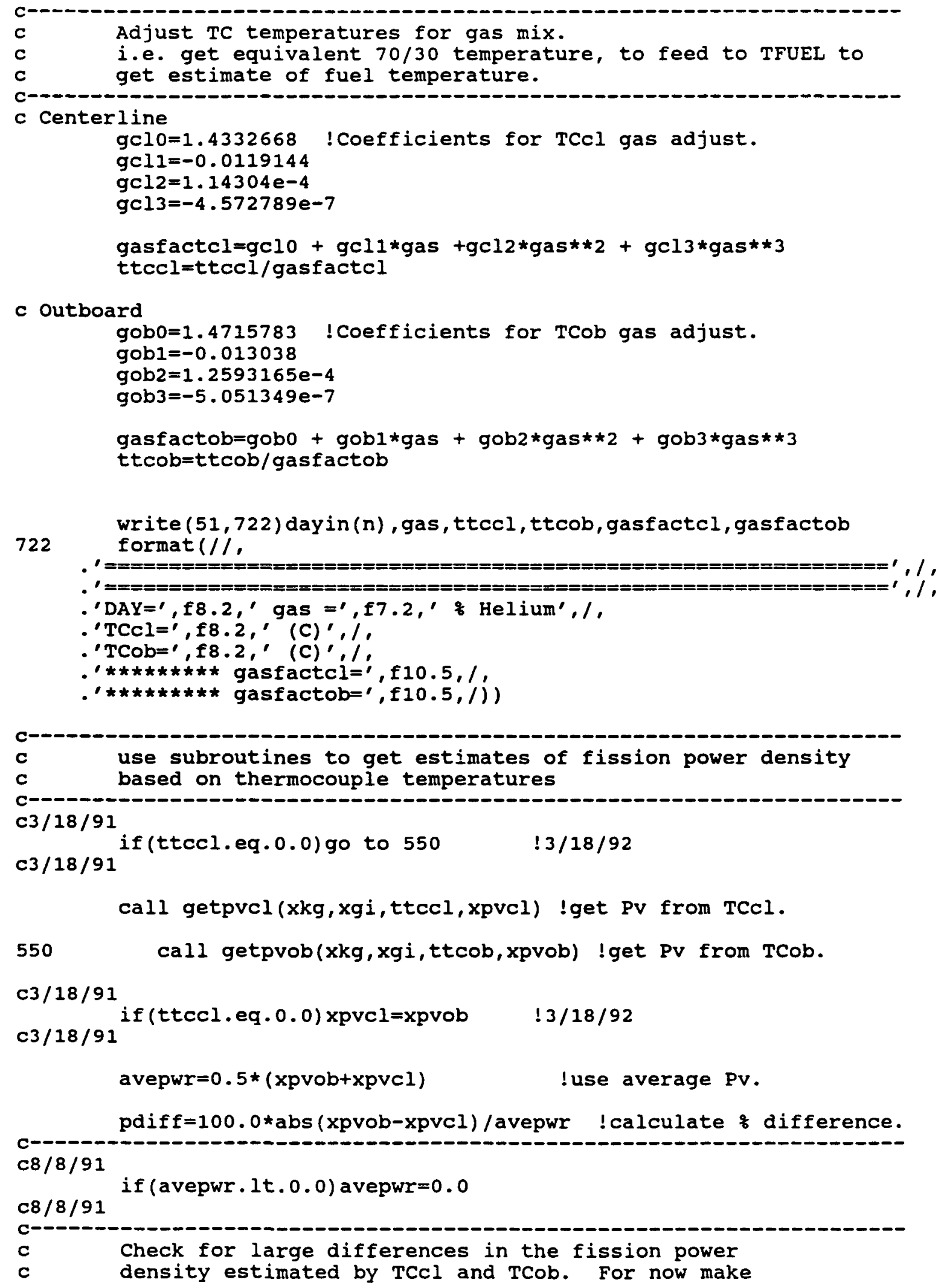



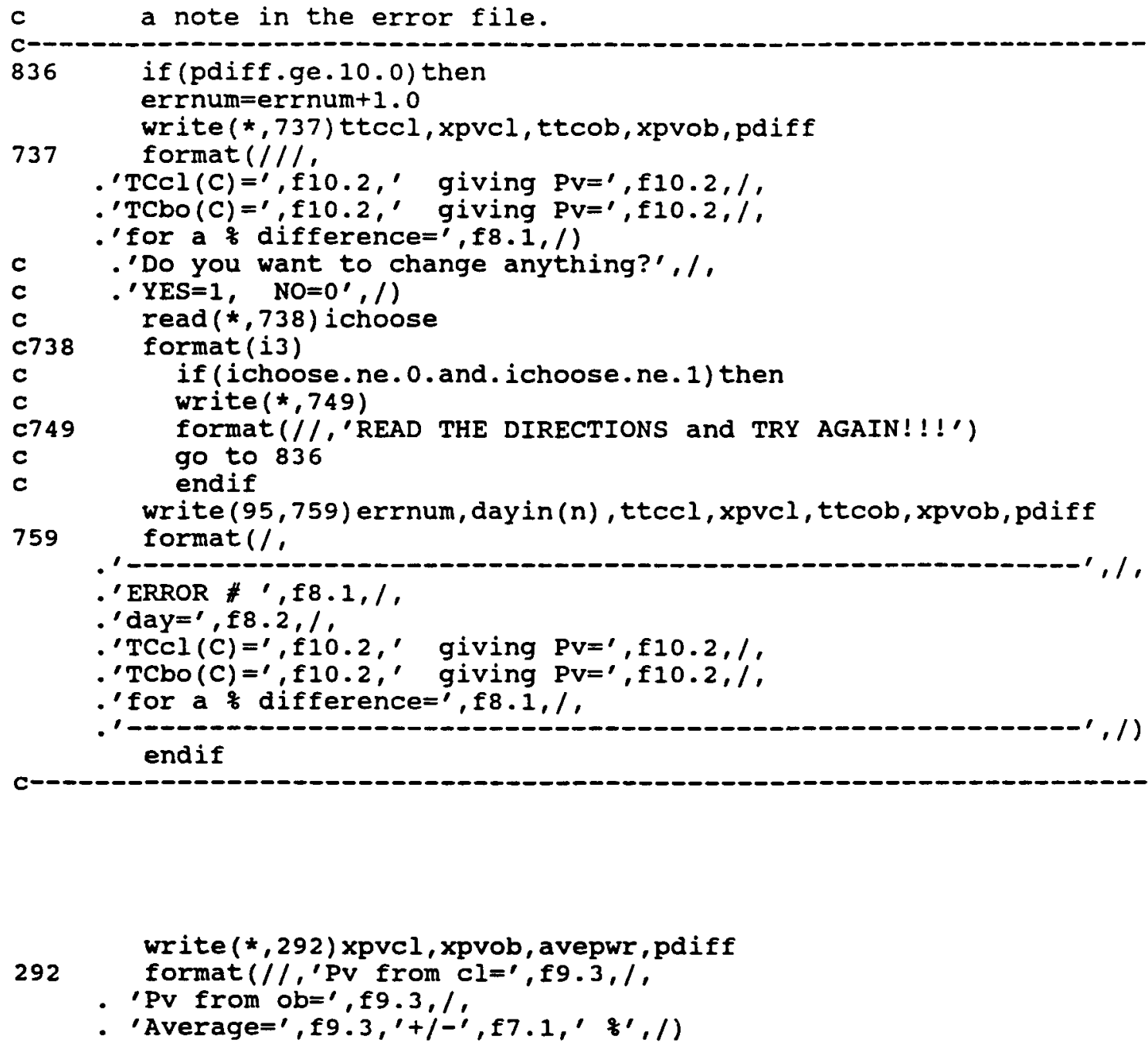
write $(51,510) \times \mathrm{kg}, \mathrm{xgi}, \mathrm{ttccl}, \mathrm{xpvcl}, \mathrm{ttcob}, \mathrm{xpvob}$, avepwr, pdiff format (//,'TEST OUTPUT FROM tlave.f',/,
' 'from getpvcl\&getpvob subroutines', /,
.' $\mathrm{Kg}=\prime, \mathrm{f} 9.4, /, ' g$ inc=', $f 7.2, /$,
'ttccl=', f8.2,' Pvcl=', f8.2, /,
'ttcob=', f8.2,' Pvob=', $f 8.2,1$,
' 'Average=', f9.3,'+/-',f7.1,' $\left.,^{\prime},, /\right)$

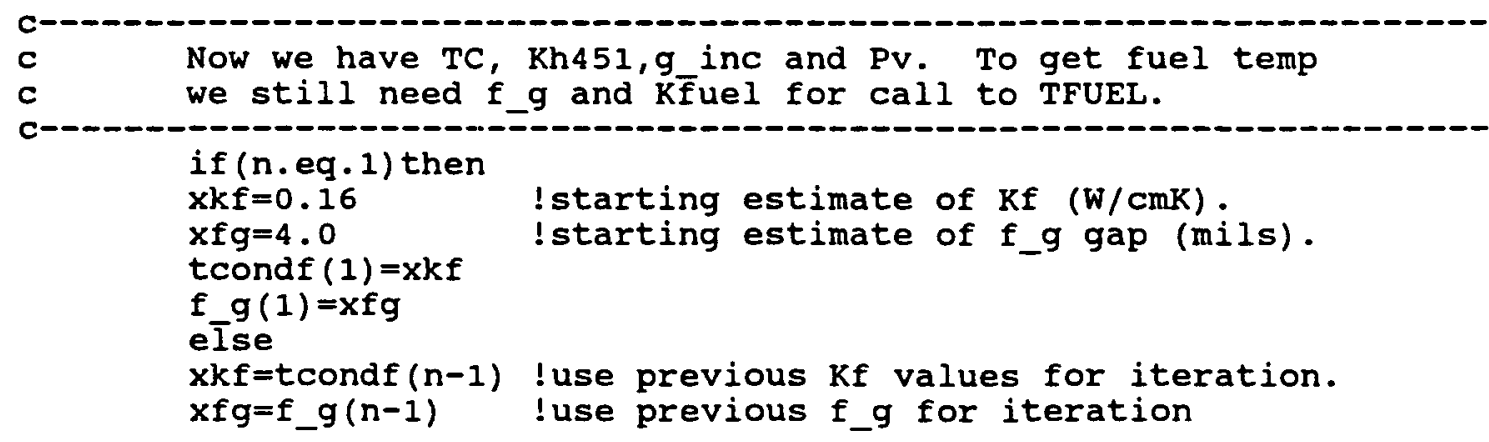


endif

$\mathrm{Get}$ first estimate of $70 / 30$ fuel temperature.
$\mathrm{c}$

call tfuel (avepwr, $x g i, x f g, x k f, x k g, t 4 e s t$ )

c Adjust $<\mathrm{T}>$ to present gas mix.

gf $0=1.4850385$

gf $1=-0.013004$

gf $2=1.202567 e^{-4}$

gf $3=-4.712046 e-7$

gasfactf $=g f 0+g f 1 * g a s+g f 2 * g a s * * 2+g f 3 * g a s * \star 3$

write $(51,723)$ gasfactf, t4est

723 format $\left(/,,^{\prime} * \star \star \star \star \star \star *\right.$ gasfact $f=1, f 10.5, /,^{\prime}$ pret $\left.4=\prime, f 8.2, /\right)$

t4est $=t 4$ est $t$ gasfact $f$

t4 est $0=t 4$ est

c Now we have 1st estimate of the fuel temperature at the present gas mix.

Pass this fuel temperature along to the subroutine $k f$ to calculate a thermal conductivity of the fuel as well as a radius of the fuel compact. Then compare the new xkf and $x f g$ to see if they are consistent (within 10\%) of the values used to

c calculate the fuel temperature in the first iteration.

c-n-_nday $=\mathrm{n} ! \mathrm{n}$ is the loop counter and specifies array elements.

760 call kf (xkf1, rfuel, nday, t4est)

c calculate $f g$ consistent with 1st estimate of $\langle T\rangle$ and TCob. $x f g 1=($ rhole $(n)-r f u e l) * 1000.0 \quad$ if_g gap in mils.

c-------

c Compare the values used with the subroutine values.

c--

$x k f$ ave $=0.5 *(x k f+x k f 1)$

$x f g a v e=0.5 *(x f g+x f g 1)$

akfdiff $=100.0 * a b s(x k f-x k f 1) / x k f a v e \quad ! z d i f f e r e n c e$.

afgdiff $=100.0 *$ abs $(x f g-x f g 1) / x f g a v e \quad ! z d i f f e r e n c e$.

write $(*, 331)$ nday, t4 est, xkf, xkf 1 , akfdiff, xfg, xfg1, afgdiff

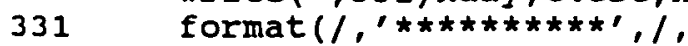

-'Day of iteration=', i4, /,

' Fuel temp (C)=',f9.2,l,

.' fuel cond: $O L D=\prime, f 9.4, ' N E W=\prime, f 9.4, '$ zdiff $=$ ', f8.2,

.'fuel-graphite gap:OLD=', f9.4,' $N E W=\prime$, f $9.4, '$ ofdiff=',f8.2,/,

. 'Now go to TFUEL with average $\mathrm{kf}$ and $f \mathrm{~g}$ to improve estimate',/,

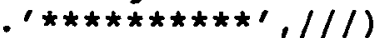

c make another call to TFUEL using latest values

c of $f_{-g}$ and $\mathrm{Kf}$. 


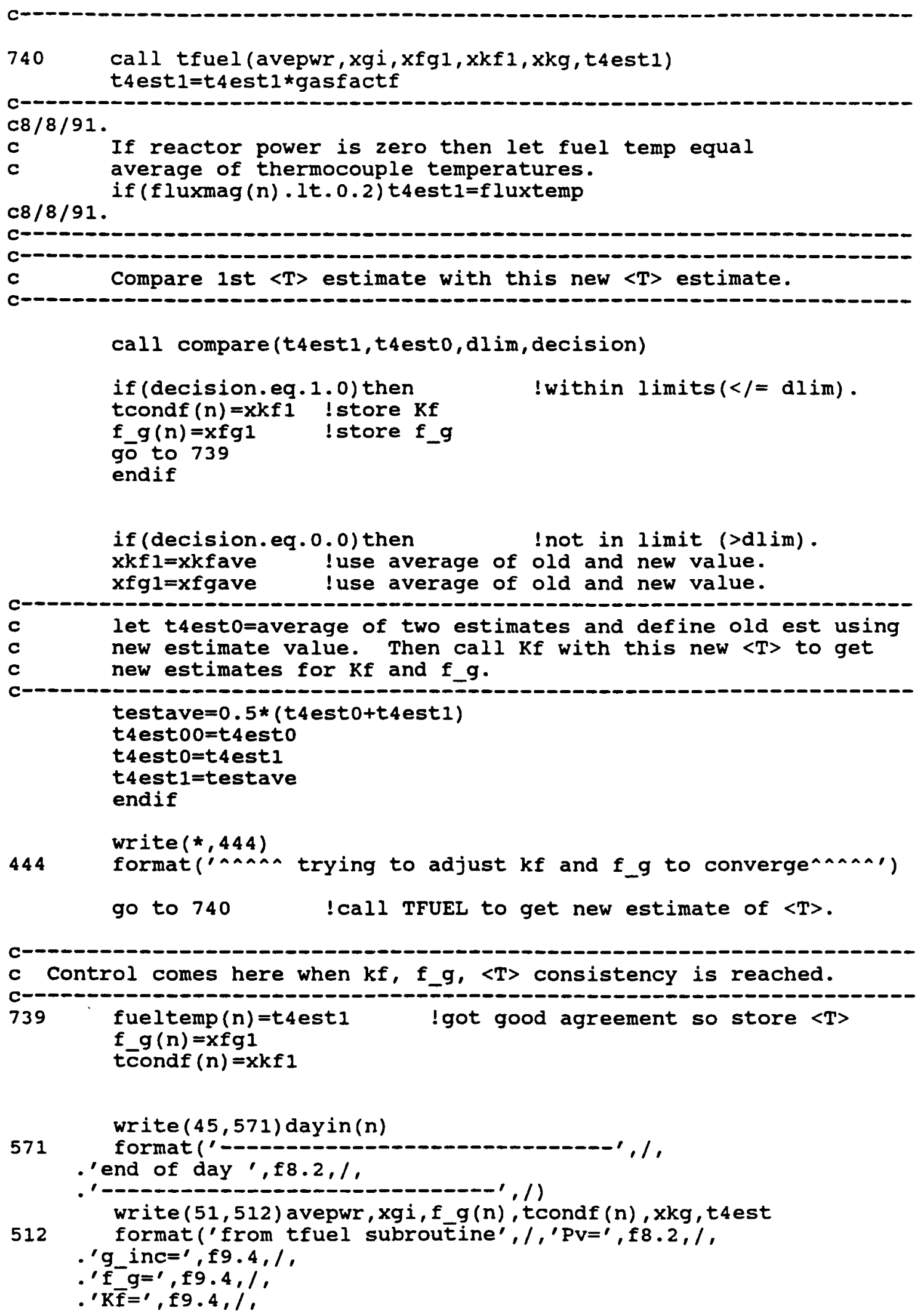




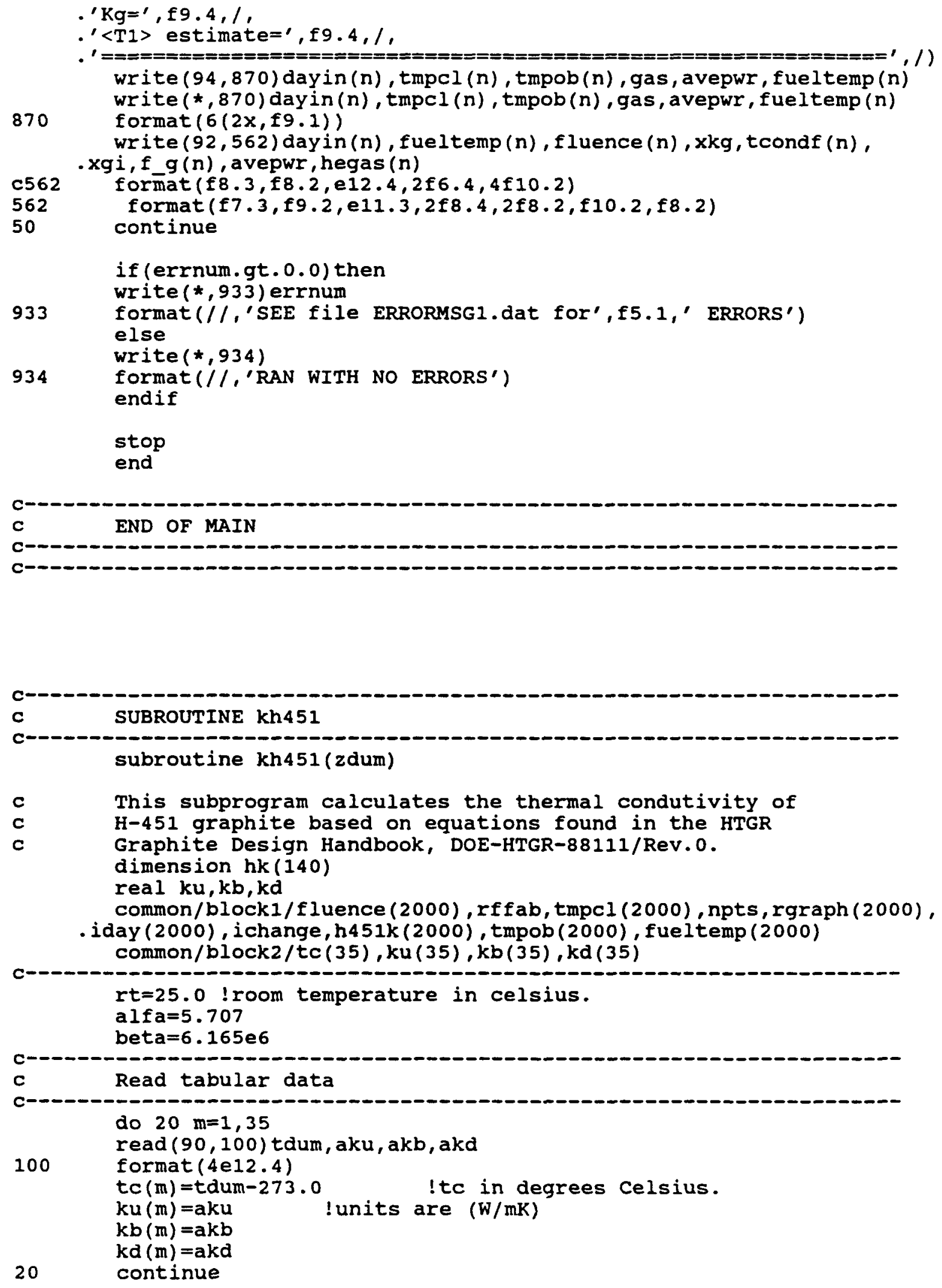


$\mathrm{uk}=0.0$

$\mathrm{bk}=0.0$

$\mathrm{dk}=0.0$

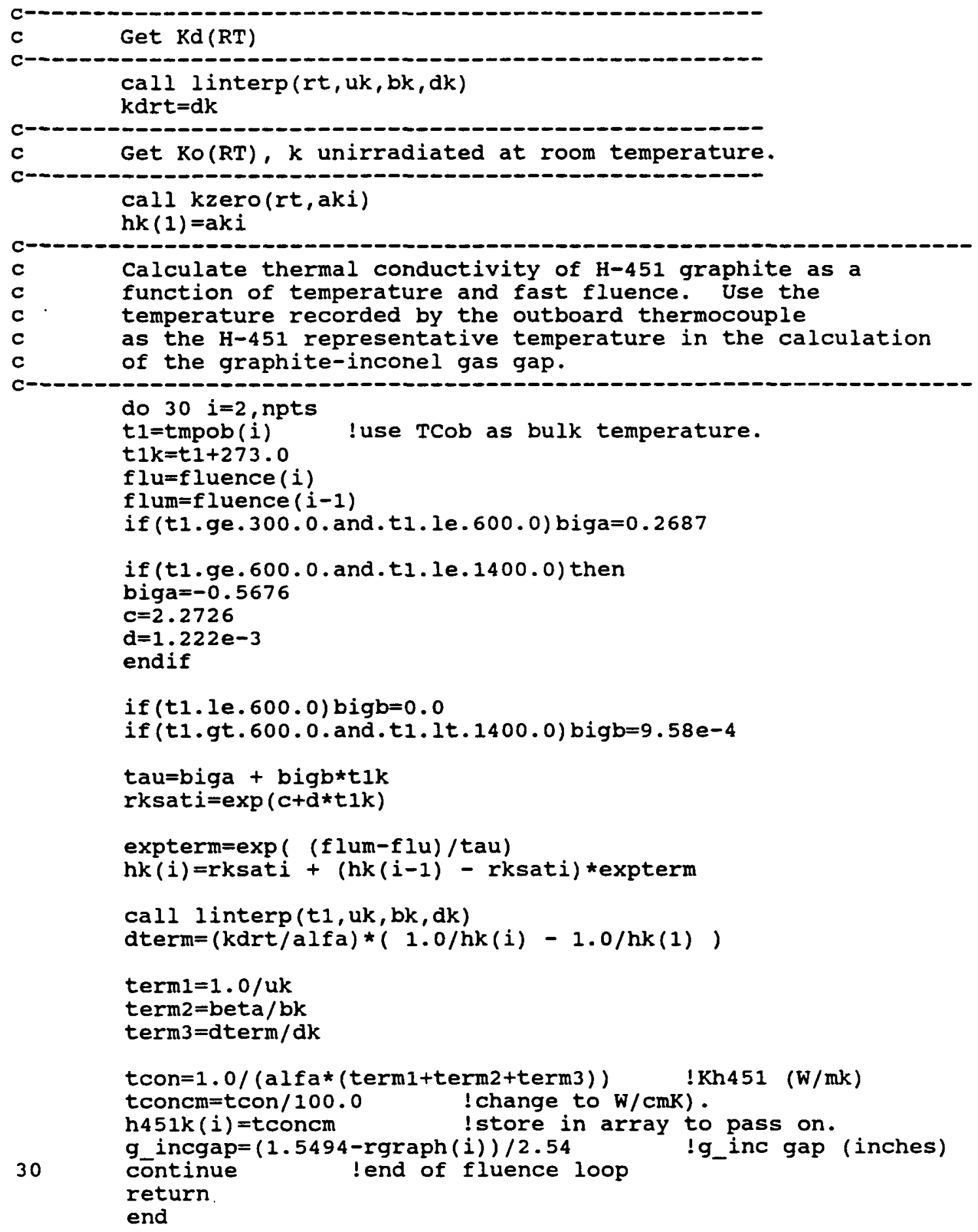




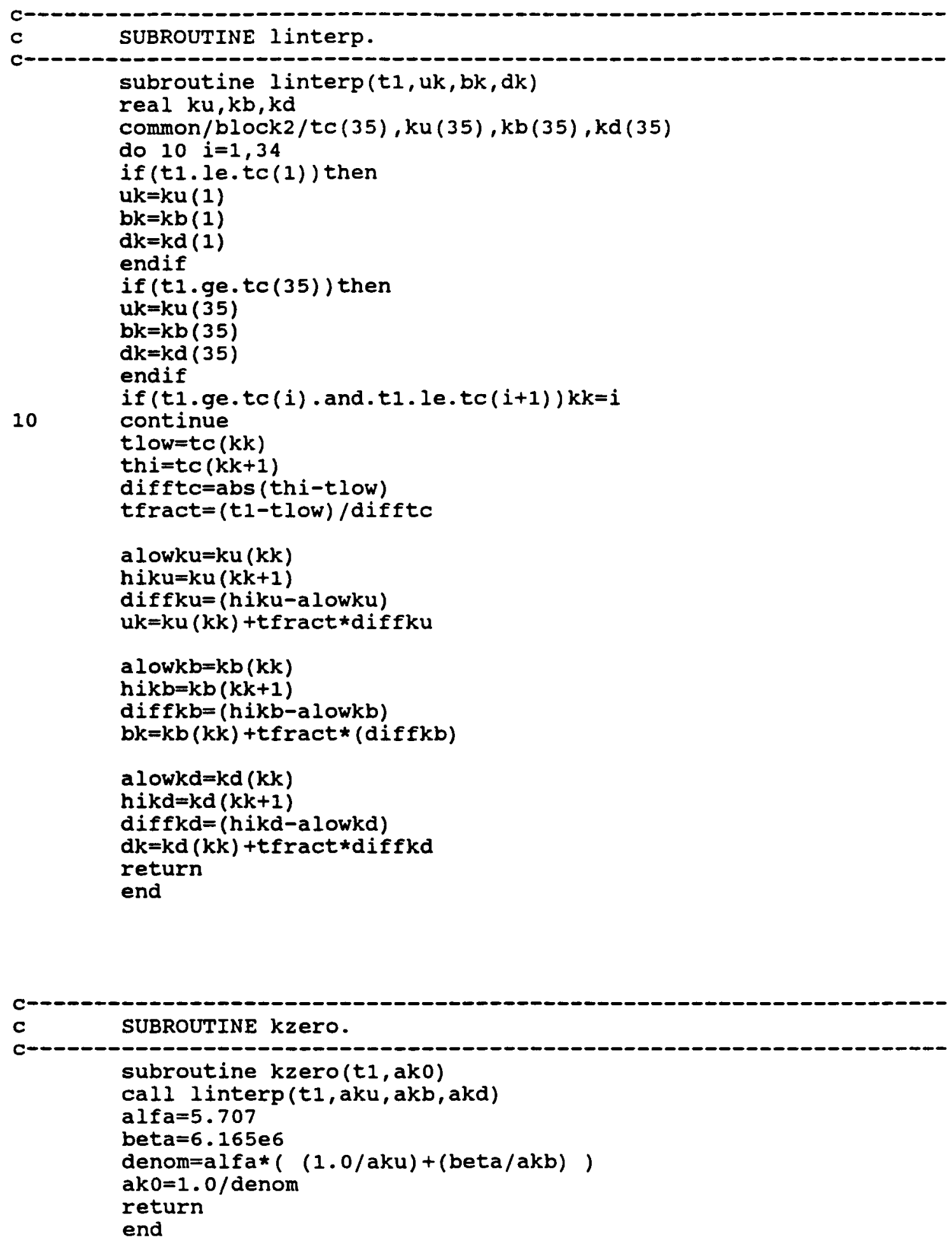




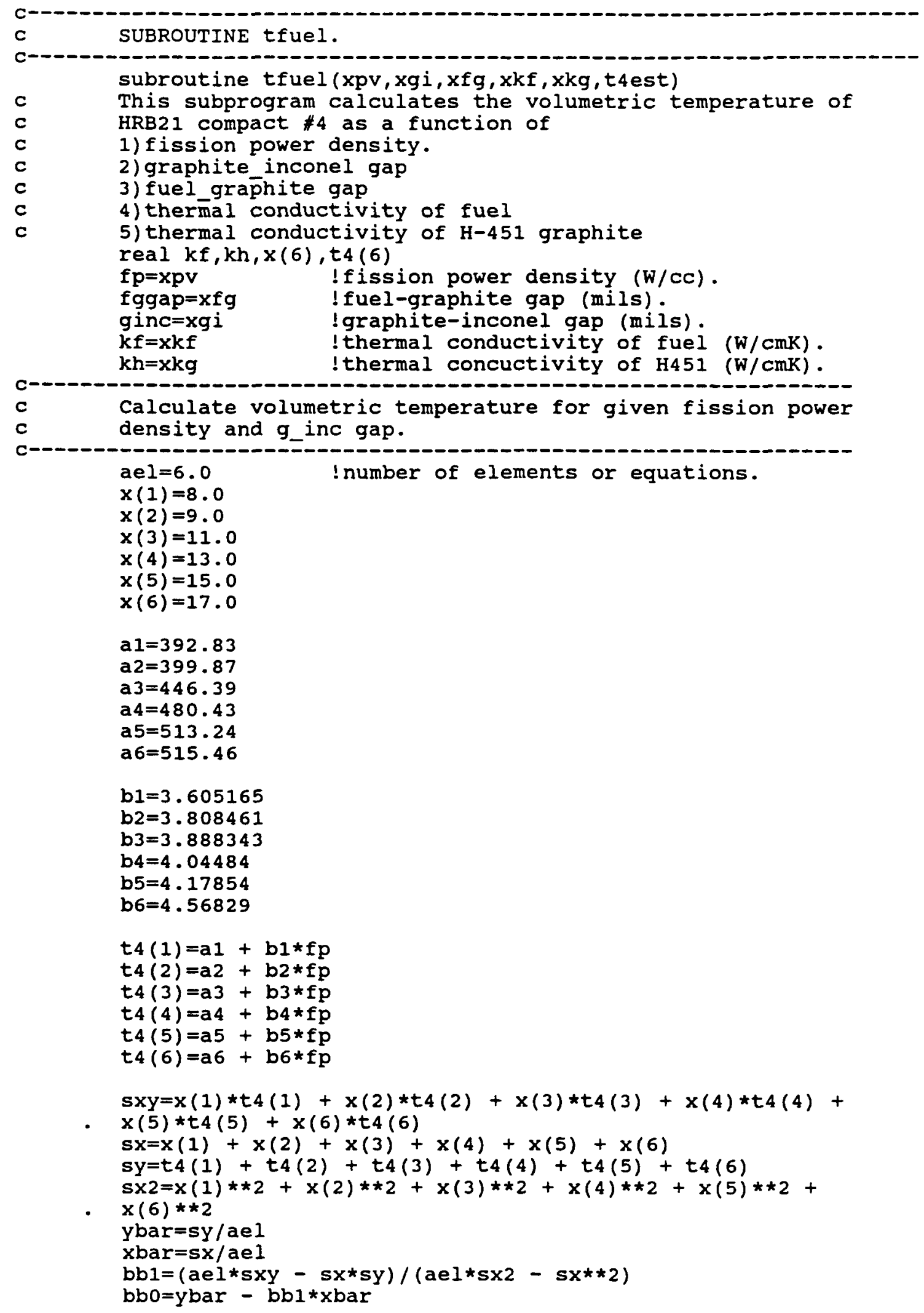




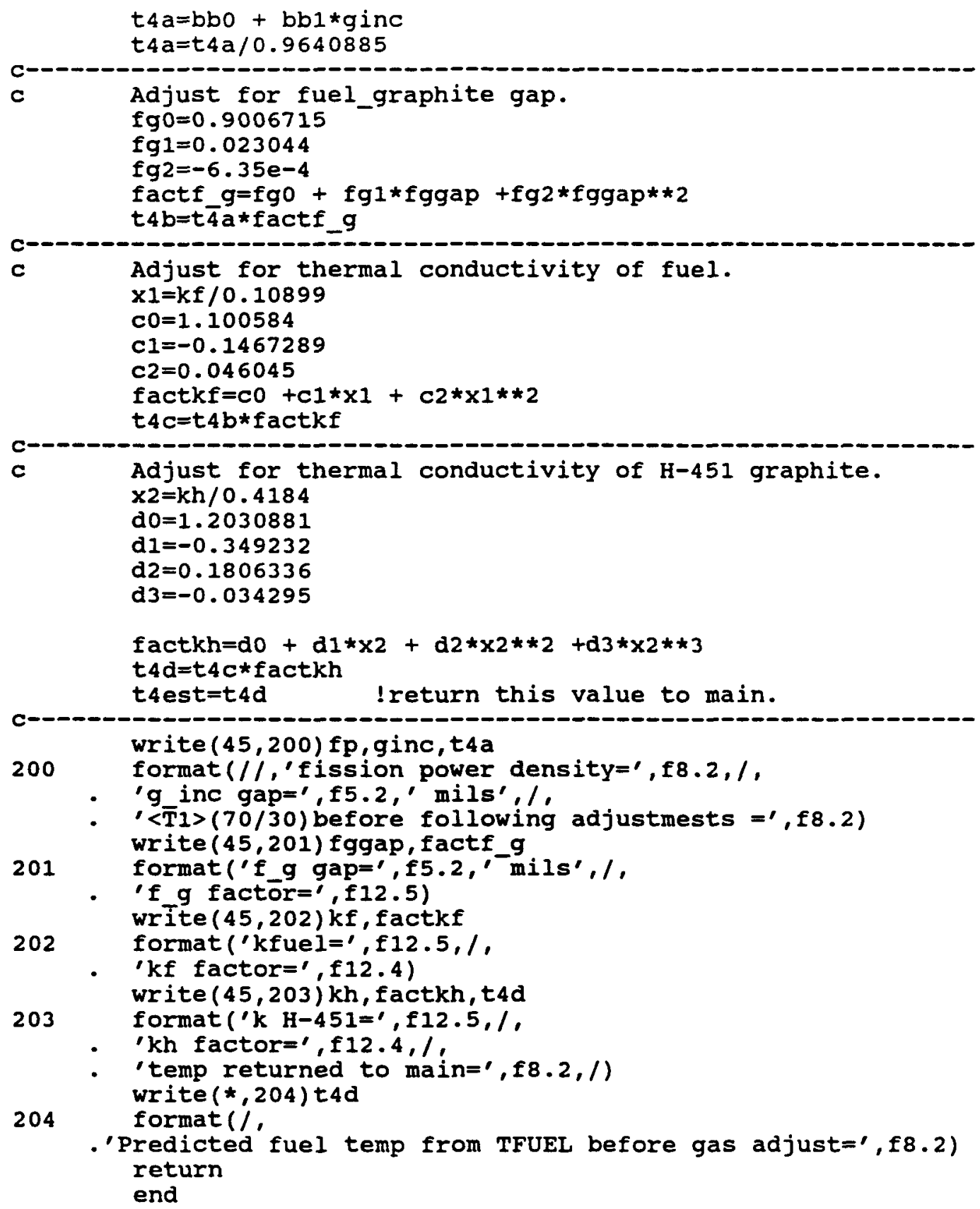


$x \mathrm{~kg}=\mathrm{h} 451$ thermal conductivity (W/cmK)

$x g i=g r a p h i t e-i n c o n e l$ gap (mils)

ttccl=temperature from centerline thermocouple.

xpvcl=fission power density (W/CC) based on TCcl

ekg=0.4184

dimension $x(6), y(6)$

$z=x \mathrm{~kg} / 0.4184$

clkgo $=1.386585$

clkg1 $=-0.652703$

clkg2 $=0.32763$

clkg3 $=-0.0612314$

factor $=\operatorname{clkg} 0+\operatorname{clkg} 1 * 2+\operatorname{clkg} 2 * 2 * \star 2+\operatorname{clkg} 3 * z * \star 3$

ae $1=6.0$
a1 $=-108.249$
a2 $=-105.231$
a3 $=-113.582$
a4 $=-117.229$
a5 $=-121.044$
a $6=-112.699$

! number of elements or equations.

$1=0.27975$

b2 $=0.265548$

b3 $=0.257761$

$\mathrm{b} 4=0.246985$

$b 5=0.238525$

$b 6=0.219463$

$x(1)=8.0$

$x(2)=9.0$

$x(3)=11.0$

$x(4)=13.0$

$x(5)=15.0$

$x(6)=17.0$

$y(1)=a 1+b 1 * t t c c l / f a c t o r$

$y(2)=a 2+b 2 * t t c c l /$ factor

$y(3)=a 3+b 3 * t t c c l /$ factor

$y(4)=a 4+b 4 * t t c c l /$ factor

$y(5)=a 5+b 5 * t t c c l / f a c t o r$

$y(6)=a 6+b 6 * t t c c l /$ factor

Least squares fit to $(x, y)$ pairs to get $P v=f(g$ inc)

$5 x y=x(1) * y(1)+x(2) * y(2)+x(3) * y(3)+x(4) * y(4)+x(5) * y(5)+$ . $x(6) * y(6)$

$\mathrm{sx}=\mathrm{x}(1)+\mathrm{x}(2)+\mathrm{x}(3)+\mathrm{x}(4)+\mathrm{x}(5)+\mathrm{x}(6)$

sy $=y(1)+y(2)+y(3)+y(4)+y(5)+y(6)$

$\mathrm{s} \times 2=x(1) * * 2+x(2) * \star 2+x(3) * * 2+x(4) * \star 2+x(5) * \star 2+$ .$x(6) * \star 2$

ybar=sy/ael

xbar $=s x /$ ael

bb $1=($ ael*sxy $-s x * s y) /(a e l * s x 2-s x * * 2)$

bbo $=y$ bar - bb $1 * x b a r$

xpvcl $=b b 0+b b 1 * x g i$

write $(51,525)(k, x(k), y(k), k=1,5)$

format ('from getpvcl--k=', i3,' $x=$ ', f7.2,' $y=$ ', f9.4) write $(51,511) \mathrm{z}$, factor, bb1, bbo, xbar, ybar

511 format $(/, ' z=\prime, f 9.4, /, ' \mathrm{Kf}$ factor=',f9.5,/,

$\cdot \mathrm{bb}^{\prime}=\prime, \mathrm{f} 12.4, \mathrm{\prime}^{\prime} \mathrm{bbO}=\prime, \mathrm{f} 12.4, /$, 


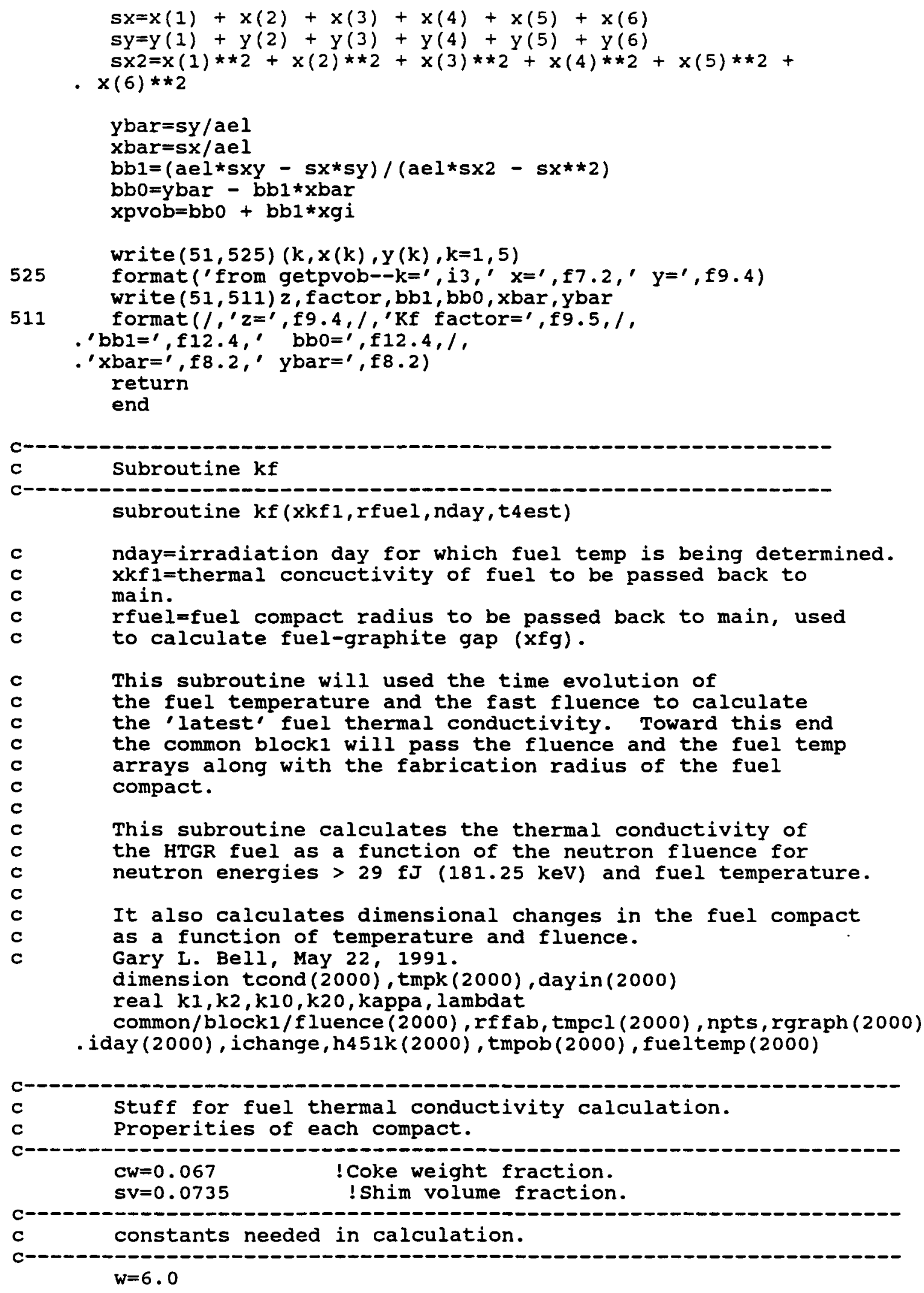




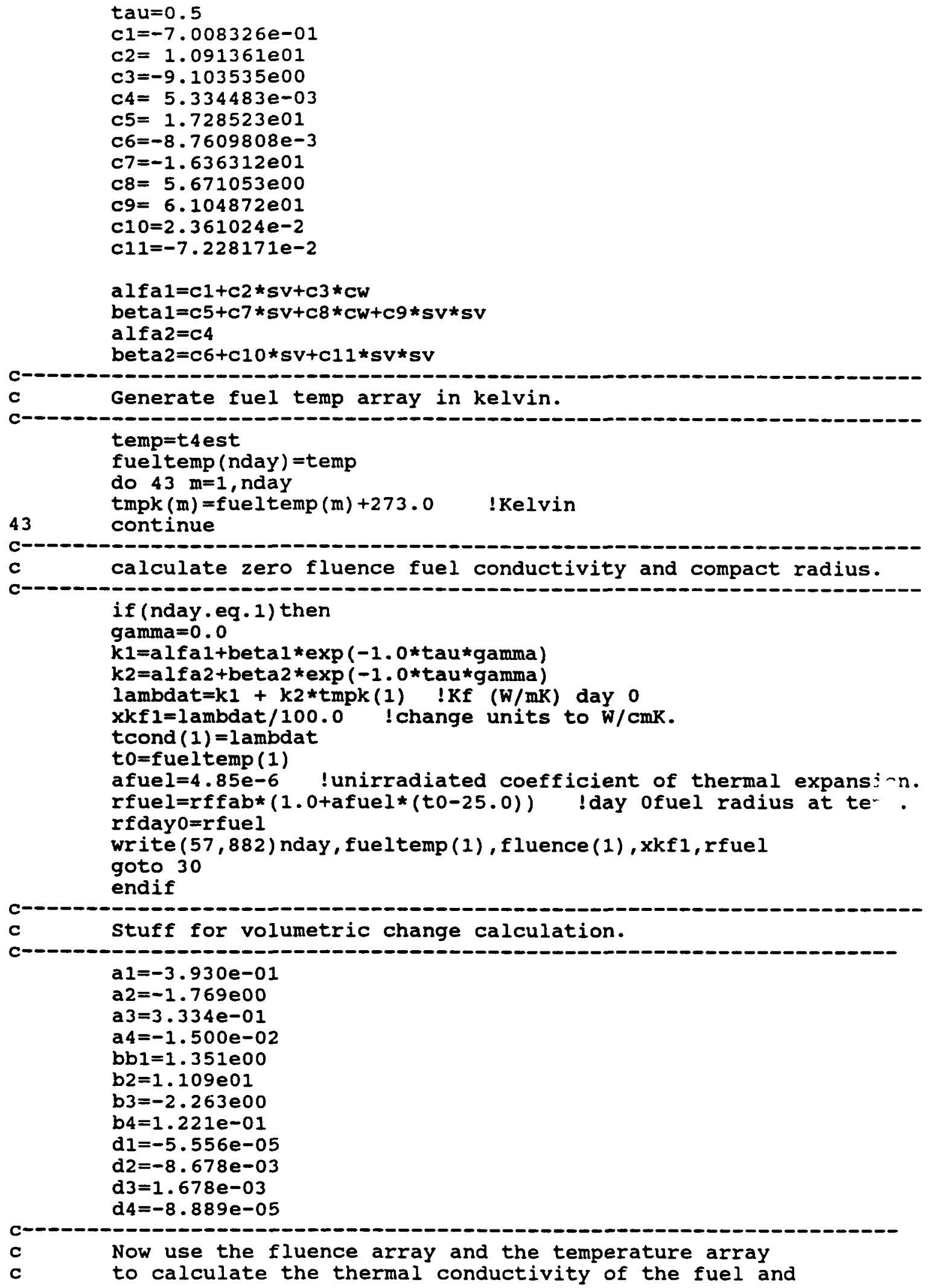

alfa $1=c 1+c 2 * s v+c 3 * c w$ beta $1=c 5+c 7 * s v+c 8 * c w+c 9 * s v * s v$ 
DOE-HTGR-90322, Rev. 0

INTERNAL DISTRIBUTION

1-2. Central Research Library

3. Document Reference Section

4-5. Laboratory Records Department

6. Laboratory Records, ORNL RC

7. ORNL Patent Section

8-10. M\&C Records Office

11. B. R. Appleton

12. C. A. Baldwin

13-17. G. L. Bel1

18. T. D. Burchell

19-23. G. L. Copeland

24. D. F. Craig

25. C. E. DeVore

26-30. L. C. Emerson

31. W. A. Gabbard

32. H. A. Glovier

33. D. W. Heatherly

34. F. J. Homan

35. H. Jones
36. M. J. Kania

37. O. F. Kimball

38. R. C. Martin

39. R. N. Morris

40. D. L. Moses

41. B. F. Myers

42. M. F. Osborne

43. N. H. Packan

44-48. J. T. Parks

49. P. L. Rittenhouse

50. P. S. Sklad

51. 0. M. Stansfield

52. R. D. Taylor

53. K. R. Thoms

54. D. B. Trauger

55. A. W. Trivelpiece

56. M. W. Vance

57. J. C. Whitson

EXTERNAL DISTRIBUTION

58-60. General Atomics, P.0. Box 85608, San Diego, CA 92138-5608

G. C. Bramblett

F. Silady

R. F. Turner

61. MODULAR HTGR PLANT DESIGN CONTROL OFFICE, P.0. Box 85608, San Diego, CA 92138-5608

J . Kendall

62. PDCO-East, Merek, Inc., 3206 Power Oaks Blvd., Suite 300, Rockville, MD 20852

R. R. Mills

63-64. DOE, DIVISION OF HTGRs, NE-451, Washington, DC 20545

J. E. Fox

P. M. Williams 
65. DOE, OFFICE OF ADVANCED REACTOR PROGRAMS, NE-45, Washington, DC 20545

Director

66. DOE, SAN FRANCISCO FIELD OFFICE, 1333 Broadway, Oakland, CA 94612

S. El-Safwany

67. DOE, OAK RIDGE FIELD OFFICE, Office of Energy Research and Development, P.O. Box 2001, Oak Ridge, TN 37831-8600

L. Blankner

68-77. DOE, OFFICE OF SCIENTIFIC AND TECHNICAL INFORMATION, Office of Information Services, P.O. Box 62, Oak Ridge, TN 37831

For distribution as shown in TIC-4500, Distribution Category UC-522T (Gas-Cooled Reactor Technology) 